Prepared for the

U.S. Nuclear Regulatory Commission under a Related Services Agreement

with the U.S. Department of Energy

Contract DE-AC05-76RL01830

\title{
Assessment of Weld Overlays for Mitigating Primary Water Stress Corrosion Cracking at Nickel Alloy Butt Welds in Piping Systems Approved for Leak-Before-Break
}

\author{
EJ Sullivan \\ MT Anderson
}

August 2012

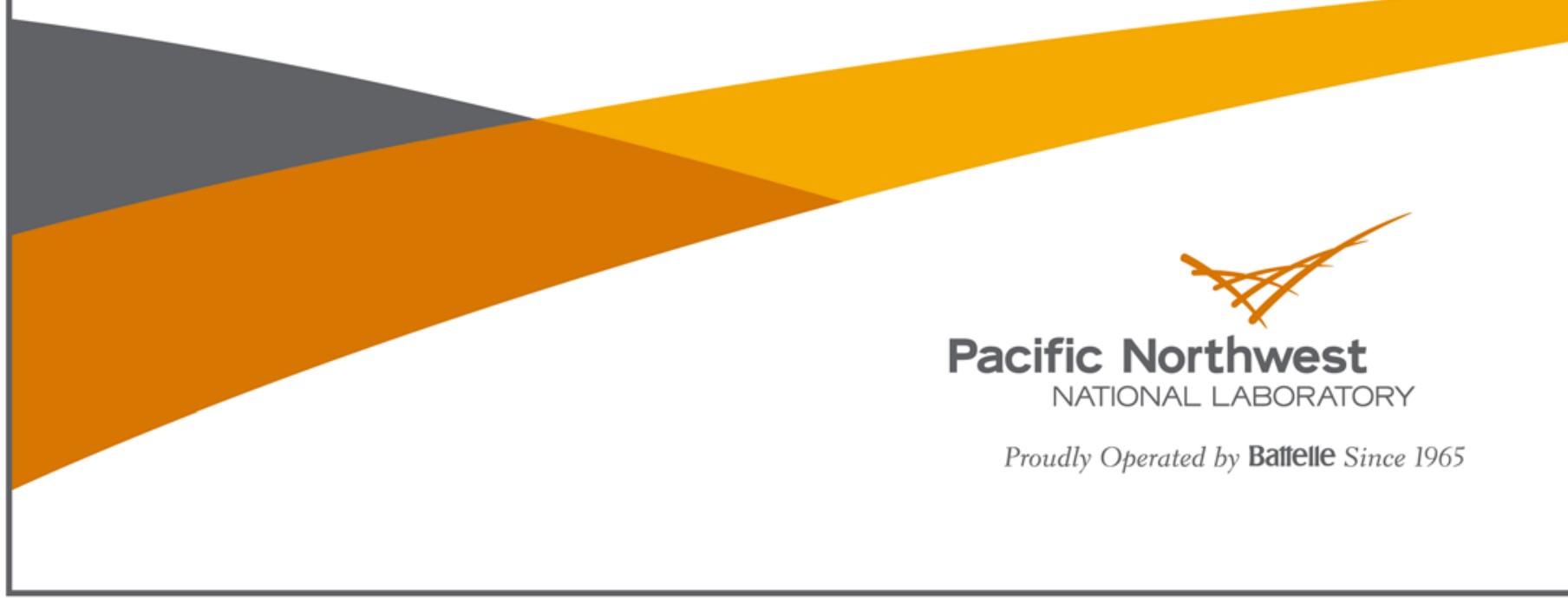




\title{
DISCLAIMER
}

This report was prepared as an account of work sponsored by an agency of the United States Government. Neither the United States Government nor any agency thereof, nor Battelle Memorial Institute, nor any of their employees, makes any warranty, express or implied, or assumes any legal liability or responsibility for the accuracy, completeness, or usefulness of any information, apparatus, product, or process disclosed, or represents that its use would not infringe privately owned rights. Reference herein to any specific commercial product, process, or service by trade name, trademark, manufacturer, or otherwise does not necessarily constitute or imply its endorsement, recommendation, or favoring by the United States Government or any agency thereof, or Battelle Memorial Institute. The views and opinions of authors expressed herein do not necessarily state or reflect those of the United States Government or any agency thereof.

\author{
PACIFIC NORTHWEST NATIONAL LABORATORY \\ operated by \\ BATTELLE \\ for the \\ UNITED STATES DEPARTMENT OF ENERGY \\ under Contract DE-AC05-76RL01830 \\ Printed in the United States of America \\ Available to DOE and DOE contractors from the \\ Office of Scientific and Technical Information, \\ P.O. Box 62, Oak Ridge, TN 37831-0062; \\ ph: (865) 576-8401 \\ fax: (865) 576-5728 \\ email: reports@adonis.osti.gov \\ Available to the public from the National Technical Information Service, \\ U.S. Department of Commerce, 5285 Port Royal Rd., Springfield, VA 22161 \\ ph: (800) 553-6847 \\ fax: (703) 605-6900 \\ email: orders@ntis.fedworld.gov \\ online ordering: http://www.ntis.gov/ordering.htm
}

This document was printed on recycled paper.

(9/2003) 


\title{
Assessment of Weld Overlays for Mitigating Primary Water Stress Corrosion Cracking at Nickel Alloy Butt Welds in Piping Systems Approved for Leak-Before-Break
}

\author{
EJ Sullivan \\ MT Anderson
}

August 2012

Prepared for

U.S. Nuclear Regulatory Commission under a Related Services Agreement with the U.S. Department of Energy Contract DE-AC05-76RL01830

Pacific Northwest National Laboratory Richland, Washington 99352 



\section{Summary}

In recent years, operating experience (OE) has shown that Alloy 82/182/600 materials used in reactor coolant system (RCS) pressure boundaries of pressurized water reactors (PWRs) are susceptible to primary water stress corrosion cracking (PWSCC). Cracking can initiate at the inside surface of these materials, in part, because of tensile residual stresses introduced by welding. These materials are present in piping systems that were approved by the NRC for leak-before-break (LBB) analyses before PWSCC was found in RCS dissimilar metal butt welds. The identification of PWSCC led to concerns regarding the potential effect of this degradation on existing LBB analyses.

In response to these concerns, RES initiated a program entitled, "PWSCC in Leak-Before-Break Systems," and a follow-on program entitled, "Degradation in Extremely Low Probability of Rupture (xLPR) Systems." Under these programs, Pacific Northwest National Laboratory (PNNL) is assessing the various strategies being used by industry to manage potential or existing PWSCC in susceptible welds in piping systems approved for LBB.

The commercial nuclear power industry has implemented strategies to manage PWSCC at Alloy 82/182 dissimilar metal welds (DMW) in PWRs. One general strategy consists of management by a combination of mitigation plus inspection, where several mitigation techniques have been used by industry. The other general strategy is to manage potential PWSCC by inspection alone.

At the request of the NRC, ASME developed Code Case N-770-1, which provides inspection requirements to address PWSCC in Class 1 butt welds containing Alloy 82/182. Code Case N-770-1 has requirements for inspection of unmitigated as well as mitigated Alloy 82/182 RCS butt welds. As such, specific inspection requirements for welds mitigated by weld overlays (WOLs), the subject of this TLR, are contained in the Code Case. The NRC incorporated ASME Code Case N-770-1 by reference into $\S 50.55 \mathrm{a}$ (76 FR 36232, p. 36278) in June 2011.

This TLR provides an assessment of weld overlays as a mitigation strategy, and includes an assessment of the WOL-related inspection requirements of Code Case N-770-1, as conditioned in $\S 50.55 \mathrm{a}$.

There are two types of weld overlays - full structural weld overlays (FSWOLs), which have a minimum thickness of one-third the pipe wall thickness, and optimized weld overlays (OWOLs), which have different design requirements and result in less applied weld overlay metal. Depending upon the weld geometry, fabrication practices, and the presence of a nearby safe end-to- pipe weld, Alloy 82/182 piping butt welds may have tensile residual axial and hoop stresses within a zone near the inside surface of the weld. This tensile zone contributes to the susceptibility of Alloy 82/182 to PWSCC. Weld overlays convert tensile residual stresses in inner diameter regions of these welds, to zones of compressive residual stresses, or substantially reduced tensile residual stresses.

In performing this assessment, PNNL considered operating experience with weld overlays and a number of factors that affect the ability of weld overlays to perform effectively. Weld residual stress (WRS) and crack growth analyses were evaluated. The reliability of pre- and post- WOL nondestructive examination (NDE) to detect and characterize PWSCC was evaluated. The requirements of ASME Code Case N-770-1, as conditioned in $\$ 50.55 \mathrm{a}(\mathrm{g})(6)(\mathrm{ii})(\mathrm{F})$, were assessed with respect to relying on weld 
overlays as a strategy to manage potential and existing PWSCC. Finally, considering all these factors, an evaluation was performed of the effectiveness of WOLs as a mitigation technique capable of precluding PWSCC from being a potential source of pipe rupture in LBB piping systems.

The results of the WRS analyses showed that the full structural weld overlay technique is effective in producing compressive or low tensile values of axial and circumferential weld residual stresses in the inner region of welds, thereby minimizing the likelihood of initiation of PWSCC in Alloy 82/182 DMWs. The results of the WRS analyses for the geometries considered also indicate that the OWOL design is an effective technique for mitigating PWSCC in PWRs.

Results of NDE performed prior to WOL are of interest for determining the service life of the weld overlay. Post-WOL NDE is also important for determining if fabrication flaws in the overlay have been introduced, whether any new flaws have initiated or existing flaws have propagated, and for assessing the potential effect any of these flaws may have on the service life of the weld. As such, highly effective and reliable NDE for both pre- and post-WOL should be performed; this can be affected by a number of factors, such as geometry or access limitations and the presence of cast austenitic stainless steel (CASS) materials adjacent to the weld mitigated. In the case of these adjacent CASS materials, studies have shown that, although ASME performance demonstration requirements for inspecting CASS piping welds have yet to be developed, low-frequency phased-array techniques are capable of detecting and adequately characterizing flaws.

The ability to reliably detect and characterize PWSCC can be distinctly and significantly improved by performing UT modeling analyses when designing inspection parameters, using encoded techniques that have been qualified by performance demonstration, and having analysts experienced in distinguishing service induced flaw signals from other UT signals that may be present. An assessment of the ASME Code Case N-770-1 requirements, with NRC conditions that are applicable to WOLs, was performed. Overall, it was concluded that these requirements are comprehensive and will provide an appropriate defense-in-depth function for monitoring the condition of WOL welds.

Using the criteria in ASME Code Case N-770-1, Appendix I, to evaluate the effectiveness of WOLs as a mitigation technique, it is concluded that WOLs provide effective mitigation against the initiation of PWSCC and against the growth of existing PWSCC allowed by the design to remain in service. It is also shown that the WOL design combined with ASME Code monitoring requirements using effective and reliable NDE would be expected to satisfy the qualitative leak-before-break screening criteria regarding corrosion found in Standard Review Plan (SRP) 3.6.3. Per NRC guidance in Regulatory Information Summary 2010-07, Regulatory Requirements for Application of Weld Overlays and Other Mitigation Techniques in Piping Systems Approved for Leak-Before-Break, licensees are expected to ensure that the quantitative criteria of SRP 3.6.3 are satisfied by WOLs. Therefore, WOLs would be expected to preclude PWSCC from being a potential source of pipe rupture. 


\section{Acknowledgments}

The authors would like to acknowledge PNNL staff members Susan Crawford, Tony Cinson, and Tracy Moran; and Jeff Devers and Todd Blechinger from LMT, Inc., for their contributions to the NDE workshop held in May 2012. The authors would also like to thank Ms. Kay Hass for assistance in preparing this manuscript. 



\section{Acronyms and Abbreviations}

\begin{tabular}{|c|c|}
\hline ASME Code & American Society of Mechanical Engineers Boiler and Pressure Vessel Code \\
\hline $\mathrm{B} \& \mathrm{~W}$ & Babcock \& Wilcox \\
\hline BCL & Battelle Columbus Laboratory \\
\hline BWR & boiling water reactor \\
\hline BWROG & BWR Owners' Group \\
\hline BWRVIP & Boiling Water Reactor Owners Group's Vessel and Internals Project \\
\hline CASS & cast austenitic stainless steel \\
\hline $\mathrm{CE}$ & Combustion Engineering \\
\hline DHD/iDHD & deep hole drilling/incremental deep hole drilling \\
\hline DMW & dissimilar metal welds \\
\hline EPRI & Electric Power Research Institute \\
\hline ET & eddy current testing \\
\hline FE & finite element \\
\hline FSWOL & full structural weld overlay \\
\hline GDC & General Design Criterion \\
\hline ID & inner diameter \\
\hline IGSCC & intergranular stress corrosion cracking \\
\hline IHD & incremental hole drilling \\
\hline ISI & in-service inspection \\
\hline LBB & leak-before-break \\
\hline LOS & loss of signal \\
\hline $\mathrm{MHz}$ & megahertz \\
\hline MRP & Materials Reliability Program \\
\hline MSIP & mechanical stress improvement process \\
\hline NDE & nondestructive examination \\
\hline NEI & Nuclear Energy Institute \\
\hline $\mathrm{NRC}$ & U.S. Nuclear Regulatory Commission \\
\hline NRR & Office of Nuclear Reactor Regulation \\
\hline $\mathrm{OE}$ & operating experience \\
\hline OWOL & optimized weld overlay \\
\hline PA & phased array \\
\hline PNNL & Pacific Northwest National Laboratory \\
\hline PVP & Pressure Vessel and Piping (Conference) \\
\hline PWR & pressurized water reactor \\
\hline PWSCC & primary water stress corrosion cracking \\
\hline PZR & pressurizer \\
\hline
\end{tabular}




$\begin{array}{ll}\text { RCP } & \text { reactor coolant pump } \\ \text { RCS } & \text { reactor coolant system } \\ \text { RES } & \text { Office of Nuclear Regulatory Research } \\ \text { RMSE } & \text { root mean square error } \\ \text { RPV } & \text { reactor pressure vessel } \\ \text { SCC } & \text { stress corrosion cracking } \\ \text { SG } & \text { steam generator } \\ \text { SNR } & \text { signal-to-noise ratio } \\ \text { SRP } & \text { Standard Review Plan } \\ \text { SS } & \text { stainless steel } \\ \text { TFC } & \text { thermal fatigue crack } \\ \text { TRL } & \text { transmit-receive longitudinal } \\ \text { UT } & \text { ultrasonic testing } \\ \text { WOL } & \text { weld overlay } \\ \text { WRS } & \text { weld residual stress } \\ \text { xLPR } & \text { Extremely Low Probability of Rupture } \\ \text { XRD } & \text { X-ray diffraction }\end{array}$




\section{Contents}

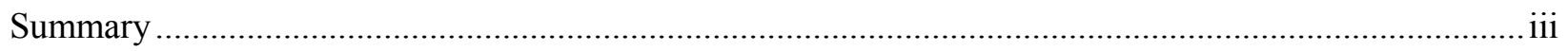

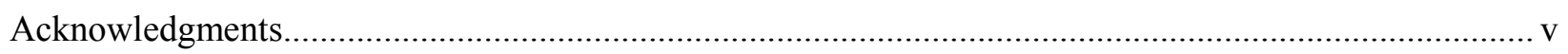

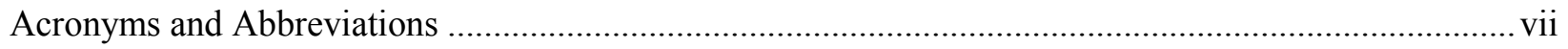

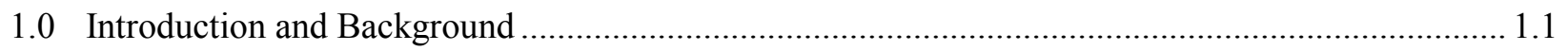

2.0 Assessment of Weld Residual Stress and Crack Growth Analyses ............................................. 2.1

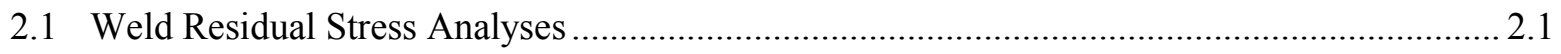

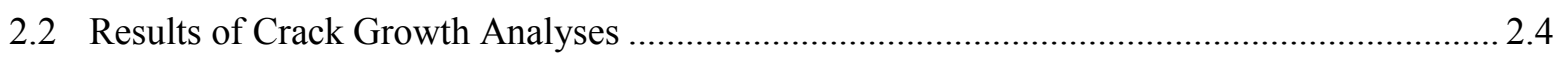

2.3 Welding Residual Stress Finite Element Analysis Validation Studies .................................. 2.8

2.4 Residual Stress and Crack Growth Conclusions ............................................................ 2.11

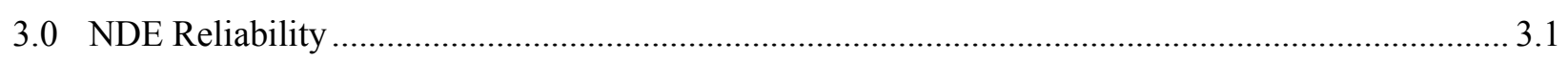

3.1 Assessment of Pre-WOL UT Examination Results .............................................................. 3.1

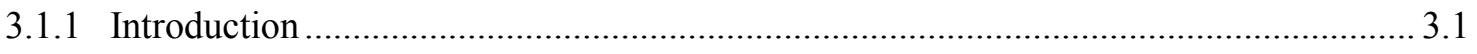

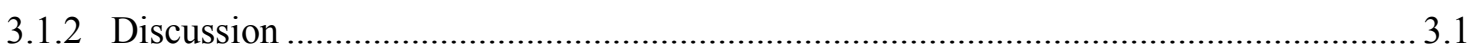

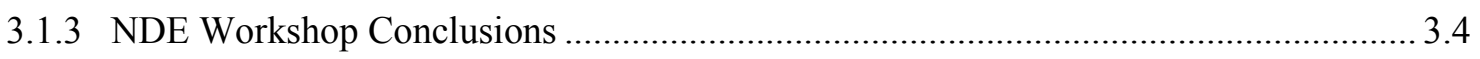

3.2 Inspection of Dissimilar Metal Weld Overlay Specimens ...................................................... 3.4

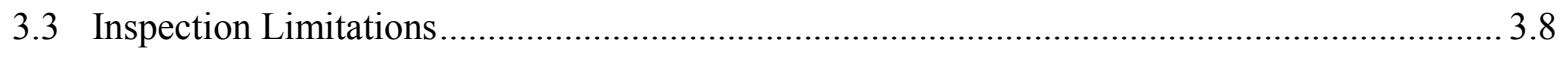

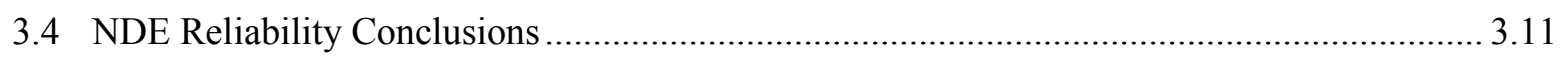

4.0 ASME Code Case N-770-1 Requirements .............................................................................. 4.1

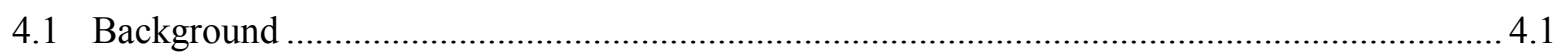

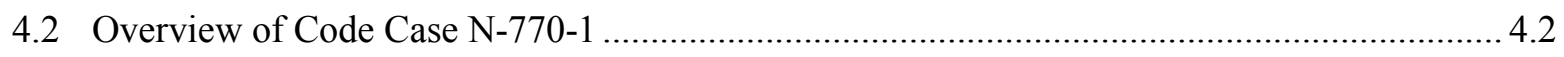

5.0 Evaluation of the Effectiveness of WOLs as a Mitigation Technique........................................... 5.1

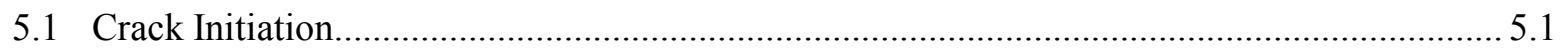

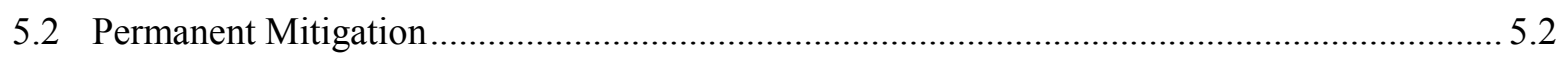

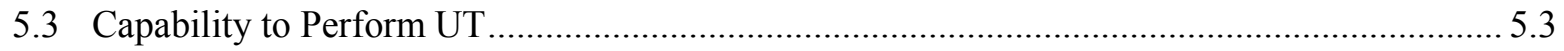

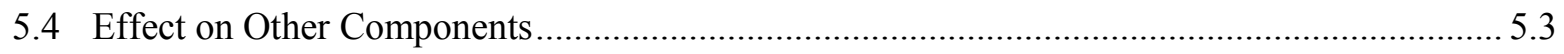

5.5 Inspectable by a Qualified Process................................................................................... 5.4

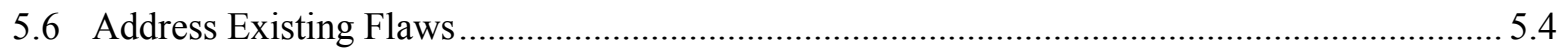

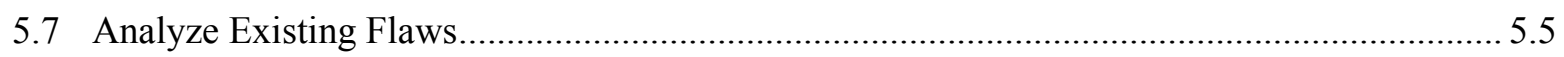

5.8 Conclusions for WOL as a Mitigation Technique.............................................................. 5.5

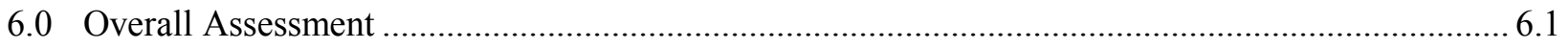

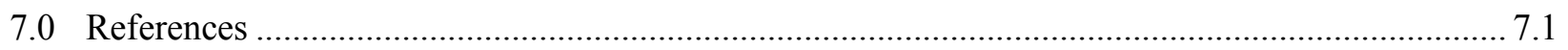


Appendix A - Background on Leak-Before-Break Per the Requirements of 10 CFR 50, Appendix A, General Design Criterion-4 ....

Appendix B - Assessment of ASME Code Case N-770-1 as Implemented in 10 CFR

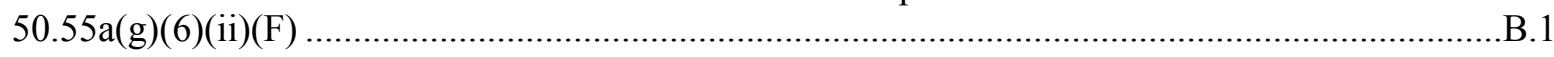

Appendix C - Dissimilar Metal Weld Inspection Limitations of a Typical Westinghouse Plant...............1 Appendix D - Dissimilar Metal Weld Inspection Limitations of a Typical Combustion

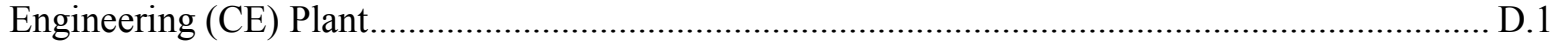




\section{Figures}

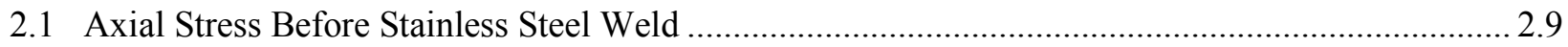

2.2 Axial Stress After Stainless Steel Weld............................................................................... 2.10

\section{Tables}

2.1 Structural Factors per ASME Code, Section XI, and Industry Proposed Structural Factors for Special Flaw Assumption

2.2 Structural Factors for Three Sample OWOL Designs Assuming a 100\% Through-Wall Flaw

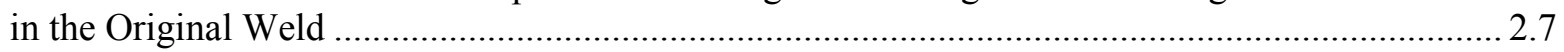

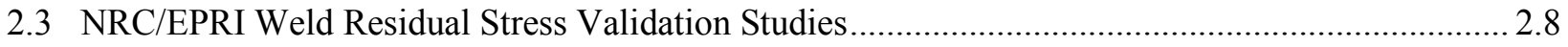

3.1 Flaw Detection Table for Specimen 9C-034 Post-WOL ............................................................... 3.6

3.2 Depth Sizing RMSE for Deep Flaws ........................................................................................... 3.7

3.3 RCS Alloy 82/182 Butt Weld Code Required Volume Coverage Obtained for a Typical Westinghouse Plant.

3.4 RCS Alloy 82/182 Butt Weld Code Required Volume Coverage Obtained for a Typical Combustion Engineering Plant 



\subsection{Introduction and Background}

The U.S. Nuclear Regulatory Commission (NRC) started approving leak-before-break (LBB) analyses in 1984 by granting exemptions from General Design Criterion (GDC)-4, "Environmental and Dynamics Effects Design Bases," in Title 10 of the Code of Federal Regulations, as written at the time. In 1987, GDC-4 was revised to allow "dynamic effects associated with postulated pipe ruptures to be excluded from the design basis when analyses reviewed and approved by the Commission demonstrate that the probability of fluid system piping rupture is extremely low." This is generally regarded to mean that the probability is less than $10^{-6} /$ reactor year. The statement of considerations for the proposed revision to GDC-4 indicated that the LBB approach should not be considered applicable to fluid system piping that operating experience (OE) has shown is particularly susceptible to failure from the effects of corrosion. Draft Standard Review Plan (SRP) 3.6.3, Leak-Before-Break Evaluation Procedures, states that, "evaluations must demonstrate that these [degradation] mechanisms are not potential sources of pipe rupture" (NRC 1987). In practice, review criteria were implemented that exclude systems with potential corrosion degradation mechanisms. Satisfying draft SRP review criteria was considered a demonstration that the probability of fluid system piping rupture is extremely low. Appendix A to this report contains background on leak-before-break per the requirements of 10 CFR 50, Appendix A, General Design Criterion-4.

In recent years, OE has shown that Alloy 82/182/600 materials used in reactor coolant system (RCS) pressure boundaries of pressurized water reactors (PWRs) are susceptible to primary water stress corrosion cracking (PWSCC). Cracking can initiate at the inside surface of these materials, in part, because of tensile residual stresses introduced by welding. These materials are present in piping systems that were approved by the NRC for LBB before PWSCC was found in RCS dissimilar metal butt welds. The identification of PWSCC led to concerns regarding the potential effect of this degradation on existing LBB analyses.

To begin to address this issue, the Office of Nuclear Reactor Regulation (NRR) issued NRR-2005011, "User Need Request on Primary Water Stress Corrosion Cracking in Leak-Before-Break Systems." NRR requested that the Office of Nuclear Regulatory Research (RES) develop a technical basis to support NRC's establishment of a regulatory policy concerning LBB systems, which are subject to conditions that may cause PWSCC. The research results would also be used to recommend licensing criteria and longterm inspection guidance for maintaining safety margin against pipe ruptures that the staff assumed when it approved LBB analyses.

In response to this request, RES initiated a program entitled, "PWSCC in Leak-Before-Break Systems," and a follow-on program entitled, "Degradation in Extremely Low Probability of Rupture (xLPR) Systems." Under these programs, Pacific Northwest National Laboratory (PNNL) is assessing the various strategies being used by industry to manage potential or existing PWSCC in susceptible welds in piping systems approved for LBB. The commercial nuclear power industry has implemented strategies to manage potential or existing PWSCC at Alloy 82/182 dissimilar metal welds (DMW) in PWRs. One general strategy consists of management by a combination of mitigation plus inspection, where three or four mitigation techniques have been used by industry. The other general strategy is to manage potential PWSCC by inspection alone. The Electric Power Research Institute (EPRI) issued a report in 2005 (Materials Reliability Program (MRP)-139) that provided industry guidance for the volumetric and visual inspections of unmitigated and mitigated butt welds in PWR primary systems (EPRI 2005c, 2008a). The 
MRP-139 inspections augmented examinations of these locations already required by Section XI of the American Society of Mechanical Engineers Boiler and Pressure Vessel Code (ASME Code). The ASME Code is incorporated into the NRC regulations in Title 10, Section 50.55a, Codes and Standards, of the Code of Federal Regulations ( $\$ 50.55 a)$ (10 CFR 50.55a 2011).

In December 2005, the NRC sent a letter to ASME (Dyer 2005) requesting it to address the inspection requirements for Class 1 PWR piping butt welds fabricated with Alloy 82/182 weld materials. ASME approved the development of an ASME Code Case on appropriate inspection requirements to address PWSCC in Class 1 butt welds containing Alloy 82/182. This case was later numbered Code Case N-770 (ASME 2009b). Code Case N-770 was revised in 2009 to address NRC concerns and Code Case N-7701 was issued later that year (ASME 2009a). The NRC incorporated ASME Code Case N-770-1 by reference into $\$ 50.55 \mathrm{a}$ (76 FR 36232, p. 36278) in June 2011. Code Case N-770-1 contains requirements for inspection of unmitigated as well as mitigated Alloy 82/182 RCS butt welds. Code Case N-770-1 contains specific inspection requirements for welds mitigated by weld overlays (WOLs). This report includes an assessment of the WOL-related inspection requirements of Code Case N-770-1, as conditioned in $\S 50.55 \mathrm{a}$.

Decisions to mitigate welds against PWSCC have been driven by several factors. Because the majority of PWR butt weld mitigations implemented to date have been in pressurizer (PZR) welds, and because those welds tend to be partially un-inspectable due to tapers, contours, and materials issues, weld overlays have been applied. Weld overlays create a new surface from which to inspect and result in a new examination volume that, with the possible exception of cast stainless steel locations, is fully inspectable. Mitigation by the mechanical stress improvement process (MSIP) was typically not a viable option for these welds due to limitations to performing qualified examinations and access limitations to performing MSIP. However, MSIP was used to mitigate PZR surge nozzle welds at Calvert Cliffs 1 and 2 and at Palisades (EPRI 2006). Consequently, weld overlay was the preferred mitigation choice for PZR locations. The initial or baseline examinations of the MRP-139 program have all been performed. Since most of the PZR weld locations have been mitigated, the generally favorable examination results to date for the hot-leg and cold-leg temperature locations have decreased the urgency to mitigate these welds in the short term.

The examination results to date for the hot-leg and cold-leg temperature locations, as opposed to PZR temperature locations, have decreased the urgency to mitigate welds in the near term.

Weld overlay repairs were first applied to stainless steel piping in BWRs in 1982 (EPRI 1991). These repairs were initially applied as interim repairs to welds affected by intergranular stress corrosion cracking (IGSCC) to allow the plants to return to power.

The RCS branch line Alloy 82/182 nozzle welds that are approximately the size of surge nozzle welds (about $32.4 \mathrm{~cm}$ [12.75 in.] in diameter) are the smallest diameter Alloy 82/182 piping welds in LBB systems (EPRI 2005b).

The larger diameter Alloy 82/182 welds in LBB systems are in the primary loop of the RCS; these are the reactor vessel nozzle-to-pipe welds in Westinghouse plants and reactor coolant pump (RCP) nozzleto-pipe welds in Combustion Engineering and Babcock and Wilcox plants. For these welds, factors such as access to welds, the volume of weld that has to be deposited for weld overlays, the outage time required to apply weld overlays, the welding difficulties that have occurred with applying some weld 
overlays, and the costs of performing a new LBB analysis are all being considered in decisions on shortterm and long-term strategies for managing PWSCC.

The owner for Davis-Besse elected to apply optimized weld overlays (OWOLs) to the RCP discharge nozzles and full structural weld overlays to the RCP inlet nozzles (White 2010). This licensee also submitted a license amendment request with an updated leak-before-break analysis. By letter dated March 24, 2010, the NRC issued the license amendment with its safety evaluation for the updated LBB analysis (Mahoney 2010). In February 2011, the owner of Calvert Cliffs, Units 1 and 2, received NRC approval to apply full structural weld overlays (FSWOLs) on a contingency basis in case any unacceptable indications of cracking are found during the fourth interval in the reactor coolant pump inlet and outlet nozzles, PZR surge hot-leg nozzles, safety injection cold-leg nozzles, PZR spray cold-leg nozzles, PZR relief nozzles, cold-leg letdown drain nozzles, cold-leg charging inlet nozzles, and cold-leg loop drain nozzles. As of early 2012, no indications of unacceptable cracking have been found in these locations at Calvert Cliffs 1 or 2 and, accordingly, no FSWOLs have been applied at these units since the NRC authorized application of these FSWOLs in February 2011 (Salgado 2011). The owner of North Anna Unit 1 requested NRC authorization in March 2011 to mitigate the primary water stress corrosion cracking susceptibility of the North Anna Unit 1 steam generator (SG) hot-leg nozzle DMWs by installing a FSWOL on each of the DMWs during the North Anna Unit 1 spring 2012 refueling outage (Price 2011). The NRC authorization to install weld overlays on the North Anna, Unit 1 SG nozzles was issued on January 27, 2012 (Salgado 2012). These mitigation approaches provide an alternative to relying on inspection alone as a means to manage potential PWSCC at these locations.

Austenitic stainless steel FSWOLs have been successfully used in the past as a mitigation strategy for IGSCC in the boiling water reactor (BWR) fleet. Prior to wide use in BWRs, it was evaluated extensively by the industry through the Electric Power Research Institute (EPRI 1991) and the Battelle Columbus Laboratory under NRC contract (Scott 1987). ASME Code Case N-504 was developed to address design and preservice examination aspects of full structural weld overlays for BWRs. Regulatory Guide 1.147, Revision 16, issued in October 2010, conditionally accepted Code Case N-504-4 (ASME 2006).

In PWRs, the weld overlay process consists of applying an annulus of Alloy 52-type weld material on the outside of a pipe over the susceptible Alloy 82/182 DMW and the materials on either side of the DMW. Weld overlays are expected to continue to be relied upon in the mitigation of Alloy 82/182 welds in PWRs.

There are two types of weld overlays - full structural weld overlays, which have a minimum thickness of one-third the pipe wall thickness, and optimized weld overlays, which have different design requirements and result in less applied weld overlay material. Weld overlays extend in both axial directions some distance beyond the weld. Weld overlays extend $360^{\circ}$ circumferentially around the pipe. For FSWOLs, no structural credit is taken for the original pipe thickness. The ASME has developed Code Cases N-740-2 (ASME 2008) and N-754 (ASME 2011) for application of full structural weld overlays and optimized weld overlays, respectively, for PWRs and BWRs. The NRC has not yet approved either of these Code Cases in Regulatory Guide 1.147.

Depending upon the weld geometry, fabrication practices, and the presence of a nearby safe end-topipe weld, Alloy 82/182 piping butt welds may have tensile residual axial and hoop stresses within a zone near the inside surface of the weld. This tensile zone contributes to the susceptibility of Alloy 82/182 to PWSCC. Weld overlays convert tensile residual stresses along the inside surface of piping in the weld to 
a zone of compressive residual stresses or substantially reduced tensile residual stresses. Weld overlays are beneficial from the standpoint of providing additional structural reinforcement. In addition, there is additional potential benefit in that the WOLs may provide OD surface geometry more favorable for inspection.

The weld overlay thickness is designed based on the presence of a postulated flaw (the design-basis flaw) in the original pipe, DMW, or nozzle. The ASME Code, Section XI, establishes an allowable flaw size for the end-of-evaluation period (the time period during which the flaw is calculated to be acceptable) based on the maximum flaw size that can be sustained in the component without exceeding the structural (safety) factors specified in the ASME Code. The maximum allowable flaw size in accordance with the ASME Code, Section XI, IWB-3640, "Evaluation Procedures and Acceptance Criteria for Flaws in Austenitic and Ferritic Piping," is $75 \%$ of the component nominal wall thickness. The weld overlay sizing requirements are described in MRP-169, Revision 1 (EPRI 2008b) and are also contained in ASME Code Cases N-740-2 for FSWOLs (ASME 2008), Code Case N-754 for OWOLs (ASME 2011), and N-504-4 (ASME 2006) for WOLs on austenitic stainless steel piping.

In this discussion, pipe wall thickness and DMW wall thickness are the same thickness. In addition, the pipe wall thickness refers to the original pipe/weld thickness, not the thickness of the pipe wall plus the weld overlay thickness.

The FSWOL thickness is designed based on ASME Code, Section XI, IWB-3640 and Appendix C, "Evaluation of Flaws in Piping." The design-basis flaw is a circumferential flaw $100 \%$ through-wall and $360^{\circ}$ around the weld circumference that is postulated to be present in the DMW. Once the FSWOL is applied, the design-basis flaw becomes the allowable flaw size for the end-of-evaluation period. The weld is not required to be inspected prior to application of the weld overlay. The required inspection volume for a FSWOL includes the weld overlay thickness and the outer $25 \%$ of the original pipe wall. If a pre-FSWOL inspection is not performed, an initial flaw $75 \%$ through the original weld thickness is postulated. Any actual observed or postulated flaws in the DMW must be demonstrated, by a crack growth calculation, not to grow beyond the allowable size before the next scheduled in-service inspection (ISI). Weld overlay sizing for FSWOLs is governed, in many cases, by the general requirements in the ASME Code, Section XI that no flaws of depth greater than $75 \%$ through-wall are acceptable. This maximum flaw depth dictates that the minimum FSWOL thickness, regardless of the applied loading, is one-third the thickness of the original pipe thickness, regardless of the applied loads. Thicknesses greater than this may be required depending upon the magnitude of the applied loadings and other factors, such as the resulting axial length of the overlay.

Code Cases N-504-2, N-754, and N-740-4 also provide guidance for weld overlay length sizing, and these are the same for both FSWOLs and OWOLs. The underlying requirement is that sufficient weld overlay length be provided on either side of the observed crack to allow for adequate transfer of axial loads between the pipe and the weld overlay. For axi-symmetric loading of a cylinder, local loading effects can be shown to attenuate to a small fraction of their peak value at an axial distance of $0.75 \sqrt{ } \mathrm{Rt}$ from the point of loading (where $\mathrm{R}$ is the outer radius and $\mathrm{t}$ is the nominal wall thickness of the cylinder). Thus, if the weld overlay length is set equal to $0.75 \sqrt{ } \mathrm{Rt}$ on either side of the crack, resulting in a total weld overlay length of $1.5 \sqrt{ } \mathrm{Rt}$, the overlay will extend beyond any locally elevated stresses due to the crack. In application of weld overlays preemptively, however, no crack will have been detected, so the above criterion is conservatively applied such that the minimum weld overlay length must be $0.75 \sqrt{ }$ Rt beyond either side of the susceptible material. This will result in a total weld overlay length equal to $1.5 \sqrt{ } \mathrm{Rt}$ plus 
the length of susceptible material (Alloy 82 or 182 weld metal and buttering) on the OD surface of the original DMW. The $0.75 \sqrt{ }$ Rt recommendation is only a rule of thumb, and shorter lengths may be used, if justified by stress analysis of the specific pre-emptive WOL configuration to demonstrate that adequate load transfer and stress attenuation are achieved. The length of the weld overlay can also be affected by the requirements to obtain full coverage of the required inspection volume.

The NRC staff notes that the structural integrity of the FSWOL does not take credit for the underlying DMW because the design-basis flaw is $100 \%$ through the original pipe wall and $360^{\circ}$ around the circumference. Design requirements for FSWOLs applied over cast material, for which ASME Section XI, Appendix VIII, qualification requirements have not been written, are provided in Code Case N-740-2.

An OWOL may be used preemptively or for DMWs with flaws of limited depth. The design-basis flaw for an OWOL is a circumferential flaw 75\% through the original pipe wall and $360^{\circ}$ around the DMW circumference. The OWOL design takes credit for the structural support of the outer $25 \%$ wall thickness of the DMW. The design-basis flaw depth assumption of $75 \%$ of original wall thickness already meets the general Section XI, IWB-3643 maximum through-wall flaw depth requirement of 75\% without an overlay. Thus, the minimum OWOL thickness is not controlled by this limit, as with FSWOLs, but instead is based on the actual internal pressure and pipe loads at the location of the DMW being overlaid and the ASME Code, Section XI, IWB-3641-allowable flaw size requirements. In addition, Code Case N-754 requires that the minimum thickness of the OWOL be sufficient to reduce residual stresses to less than $69 \mathrm{MPa}(10 \mathrm{ksi})$ tensile at operating temperature and pressure on the internal wetted surface of all stress corrosion cracking (SCC)-susceptible materials.

The OWOL design requires that the pipe weld be inspected immediately prior to the overlay application, using an inspection technique qualified in accordance with ASME Section XI, Appendix VIII and found to exhibit no evidence of cracking greater than $50 \%$ of the wall thickness in the original weld. If a detected flaw has a depth greater than 50\% through-wall, the OWOL design will not be applicable for the repair. The required inspection volume for OWOLs includes the OWOL thickness and the outer 50\% of the original pipe wall. Specific design and inspection requirements for OWOLs applied over cast material, for which ASME Section XI, Appendix VIII, qualification requirements have not been written, are provided in Code Case N-754. Post-overlay baseline ultrasonic testing (UT) and ISI examinations are required to verify the integrity of the applied OWOLs. Because OWOLs take credit for the underlying $25 \%$ wall thickness of the DMW material, the design may be required to account for the potentially lower toughness of the DMW material (particularly at the fusion line with the low-alloy or carbon steel nozzle) (EPRI 2008b).

Additional details on design and evaluation of WOLs are provided in MRP-169, Rev. 1 (EPRI 2008b) and the NRC staff's evaluation of MRP-169, Rev. 1 (Blount 2010).

PNNL reviewed the following documents in an effort to locate information about operating experience with weld overlays: Scott (1987), EPRI (1991), EPRI (1999), Fredette and Scott (2010), EPRI (2008b), and Blount (2010). EPRI (1991) and EPRI (1999) contain summaries of the results of BWR weld overlay inspections performed prior to the preparation of the reports. The inspections summarized in EPRI (1999) after about 1985 were performed using procedures qualified in accordance with the NDE Coordination Plan agreed upon by NRC, EPRI, and the BWR Owners' Group (BWROG), generally referred to as the Tri-Party Agreement. The conclusions of this report state that, "Volumetric 
examination of each weld overlay volume and a portion of the underlying piping material has been performed using ultrasonic techniques that have been qualified for detection of IGSCC. Each weld overlay has been examined multiple times, on an inspection frequency consistent with the requirements of NUREG-0313, Revision 2 for Category E welds. None of the examinations have revealed any indication of flaw propagation into the weld overlay repair or within the outer $25 \%$ of the component base metal. Some of the repairs [weld overlays] have been in service in excess of fifteen years, with no indication of weld overlay degradation."

No other similar reports were located summarizing collective operating experience. PNNL corresponded with an industry representative who participates in ASME Code development and who has been active in the area of examinations performed for SCC and mitigation of SCC in both BWR and PWR piping welds. This representative indicated that once every 6 months, the Boiling Water Reactor Owners Group's Vessel and Internals Project (BWRVIP) submits a summary of outage results and that as of the last outage season there have been no instances of flaws propagating into overlays. Since this is the general understanding of various engineers contacted by PNNL and the understanding of the authors of this report based on their involvement with PWSCC and mitigation of DMWs, PNNL has not expended further resources to locate and review the semi-annual BWRVIP reports. Likewise, PNNL contacted staff at NRC and Battelle Columbus Operations in an effort to acquire information on operating experience with weld overlays. No service-related operating experience involving WOLs indicating crack growth or any other issues of concern was found.

The following provides background on field experience with the installation of weld overlays in PWRs. By letter to the NRC dated April 28, 2006 (Hoots 2006a), as supplemented by letters dated August 18, 2006 (Hoots 2006b) and September 14, 2006 (Jury 2006), Exelon submitted a request for relief from the ASME Code, Section XI, for Byron, Unit 1, for the third 10-year interval, which began June 30, 2006. The licensee requested relief from the repair/replacement requirements for structural weld overlays on PZR spray, relief, safety, and surge nozzle safe ends. This relief request was motivated in part by the industry MRP-139 guidelines for PWR licensees to complete the inspections of PZR temperature Alloy 82/182 butt welds by December 31, 2007. This relief request was one of the early requests for NRC approval to apply FSWOLs to PWR butt welds. During a teleconference call between the NRC staff and the licensee on September 14, 2006, verbal relief was authorized for Byron, Unit No. 1, to install the weld. NRC's written authorization for the installation of these weld overlays was provided to the licensee in a letter dated January 29, 2007 (Marshall 2007). During the installation of many of the FSWOLs to the PZR butt welds at Byron, Unit 1, the licensee's examinations detected fabrication flaws in the weld overlays. These flaws exceeded the acceptance criteria proposed by the licensee in its relief request. These fabrication flaws were removed and the weld overlays were subsequently successfully installed. This experience resulted in the NRC requesting that licensees requesting relief from ASME Code requirements to install weld overlays include a commitment to provide the results of the ultrasonic examination of the structural weld overlays within 14 days after the completion of the last weld overlay preservice ultrasonic examination.

In 2009, a problem with welding fabrication flaws occurred during the installation of FSWOLs on the reactor vessel hot-leg nozzle welds at Catawba, Unit 2. The weld overlays were essentially removed by grinding prior to restart (Bartley 2009). As of the writing of this TLR, weld overlays have not been installed on the Catawba, Unit 2, reactor vessel hot-leg nozzles. 
In performing this assessment, PNNL considered several factors. Operating experience with respect to welds previously mitigated by weld overlays was discussed above (Section 1.0). Weld residual stress and crack growth analyses and the reliability of nondestructive examination (NDE) to detect and characterize PWSCC were evaluated (Section 2.0). The reliability of NDE in pre- and post-WOL examinations was assessed (Section 3.0). The requirements of ASME Code Case N-770-1, as conditioned in $\$ 50.55 \mathrm{a}(\mathrm{g})(6)(\mathrm{ii})(\mathrm{F})$, were assessed with respect to relying on weld overlays as a strategy to manage potential PWSCC (Section 4.0 and Appendix B). Finally, considering the information in the preceding sections, an evaluation was performed of the effectiveness of WOLs as a mitigation technique capable of precluding PWSCC from being a potential source of pipe rupture in LBB piping systems (Section 5.0). Based on the factors considered during this review, conclusions have been made regarding the effectiveness of WOLs to mitigate PWSCC, as intended.

The approach described by this report is deterministic in that it relies on empirical data assessments and engineering judgment to arrive at conclusions. A probabilistic modeling approach to assessing PWSCC management strategies is being undertaken in the joint NRC RES-EPRI xLPR project. 



\subsection{Assessment of Weld Residual Stress and Crack Growth Analyses}

RES initiated a program entitled, "PWSCC in Leak-Before-Break Systems." One of the studies performed under this research program involved the evaluation of weld overlays and was conducted by Battelle Columbus Laboratory (BCL) (Fredette and Scott 2009, 2010). An assessment of this BCL report by PNNL is contained in PNNL-20580, Technical Letter Report Assessment of Battelle Columbus Reports Evaluating Mechanical Stress Improvement and Weld Overlays as Mitigation Strategies for Primary Water Stress Corrosion Cracking in Pressurized Water Reactors (Sullivan and Anderson 2011).

BCL analyzed welds associated with a cold-leg reactor pressure vessel (RPV) nozzle, RCP outlet nozzle, PZR surge nozzle, and a PZR safety valve nozzle. The cold-leg RPV nozzle was only analyzed for weld overlay thicknesses up to the OWOL. These four nozzle welds cover the range of welds for which the industry has applied weld overlays or would consider applying weld overlays. BCL analyses of the cold-leg RPV nozzle weld, RCP outlet nozzle weld, and the surge line nozzle weld correspond fairly well to the pipe sizes approved for LBB and that would be considered candidates for applying WOLs. Based on MRP-140, "Leak-Before-Break Evaluation for PWR Alloy 82/182 Welds," (EPRI 2005a), Alloy $82 / 182$ welds are contained in the following piping systems that NRC approved for LBB: main coolant loop (Westinghouse, Combustion Engineering [CE], and Babcock \& Wilcox [B\&W]), surge line (Westinghouse and CE), core flood piping (B\&W), shutdown cooling (CE), and safety injection (CE). No piping systems smaller than 12-inch nominal pipe diameter, which contain Alloy 82/182, have been qualified for LBB.

Section 2.1 contains a summary of the results of BCL's weld overlay weld residual stress analysis. Section 2.2 contains a summary of BCL weld overlay crack growth analyses. Section 2.3 contains a summary of results from the weld residual stress validation program conducted jointly by NRC and EPRI. Section 2.4 contains conclusions based on the work described in this section.

\subsection{Weld Residual Stress Analyses}

The methods used by BCL to calculate weld residual stress (WRS) take into account detailed temperature-dependent material property data for the ferritic, Alloy 82/182/600, and stainless steel (SS) components. The methods use finely meshed models; simulate detailed thermal modeling of the fabrication process using layering of individual weld beads; model all the major steps in weld fabrication such as preheat, weld buildup, root pass grind out and re-weld, in some cases the installation of a heat shield, and, as applicable, the installation of a secondary SS safe-end weld; and use appropriate boundary conditions and accepted constitutive laws and stress intensity formulations. In each case, WRS, before and after WOL application, were estimated by finite element (FE) analysis techniques.

For the cold-leg RPV nozzle weld, the pre-WOL hoop stresses are tensile through the entire wall thickness, even when the stresses are reduced by the effect of the secondary SS safe-end weld. As a result, the hoop stresses for the cold-leg RPV nozzle case indicate that one might expect for a similar hotleg nozzle weld geometry that an axial crack may grow completely through the wall thickness. This finding is supported by field experience; for example, the axial through-wall crack growth on the hot-leg RPV nozzle DMW at V.C. Summer. The hot-leg RPV nozzle DMW at V.C. Summer has similar 
geometry and construction as the cold-leg RPV nozzle weld analyzed, except that it did not have the beneficial effect of the secondary SS safe-end weld.

The OWOL significantly reduced the cold-leg RPV nozzle weld hoop stresses by introducing a compressive residual stress field in the hoop direction for the inner $50 \%$ of the wall thickness. This OWOL-induced compressive stress field would be expected to minimize the possibility of axial throughwall crack initiation and prevent the growth of pre-existing shallow flaws.

For the surge nozzle and safety nozzle cases, the models indicate that pre-overlay hoop stresses are generally lower throughout the wall thickness than the cold-leg RPV nozzle such that one would not expect significant axial crack growth, either before or after the application of the weld overlay. Notwithstanding, an indication of axial cracking in an Alloy 82/182 surge line nozzle-to safe end DMW was found in 2003 at Three Mile Island, Unit 1 (TMI-1, NRC 2002). The licensee characterized it as spanning the width of the weld on the inside surface, extending about 50\% through-wall at the deepest location of the flaw. Based on the location, acoustic response, and operating temperature, TMI-1 concluded that the indication was due to PWSCC. TMI-1 performed a full structural weld overlay repair to maintain weld integrity (NRC 2008).

There is a similarity in the results of the axial WRS analyses for the geometries considered. The analyses show high tensile stresses at the inside surface of the welds, which tend to be mitigated (reduced) by the presence of the secondary SS weld, except for the case of the reactor coolant pump outlet nozzle. For the RCP outlet nozzle, the secondary SS weld was approximately $400 \mathrm{~mm}$ (16 in.) from the DMW, which is too far removed from the DMW to produce a beneficial effect. The surge nozzle inside surface axial stresses near the butter/ferritic steel interface (before fabricating the SS safe-end weld) are calculated to be approximately $550 \mathrm{MPa}(80 \mathrm{ksi})$ tensile. After fabricating the secondary SS weld joining the safe end to the pipe, the model predicts that axial stresses at the inside surface at this location drop to $140 \mathrm{MPa}(20 \mathrm{ksi})$ tensile. Additionally, the inside surface of the entire safe end for the surge nozzle is in compression after fabricating the secondary SS weld. This would be important if there are cases where the safe end is fabricated from Alloy 600 material, which is susceptible to PWSCC.

The FSWOL further reduces the weld residual stresses. For the surge nozzle, the FSWOL reduces the inside surface axial stresses near the butter/ferritic steel interface from $140 \mathrm{MPa}(20 \mathrm{ksi})$ tension to about $35 \mathrm{MPa}$ (5 ksi) tension (a reduction of $105 \mathrm{MPa}$ [15 ksi]). For the cold-leg RPV nozzle weld, the effect of installing an OWOL was less pronounced. The OWOL only reduced the inside surface axial stresses at the butter/ferritic steel interface from $70 \mathrm{MPa}(10 \mathrm{ksi})$ tension to $35 \mathrm{MPa}(5 \mathrm{ksi})$. For the cold-leg RCP outlet nozzle weld, where there was no initial reduction in residual stress from installing the SS safe-end weld, the effect of the weld overlay was more pronounced. The FSWOL lowered the inside surface axial stresses at the butter/ferritic steel interface from nearly $480 \mathrm{MPa}$ (70 ksi) tension (post-secondary SS weld) to $200 \mathrm{MPa}$ (30 ksi) tension (post FSWOL) (a reduction of $280 \mathrm{MPa}$ [40 ksi]) while, contrary to what might be expected, an OWOL applied to the RCP outlet nozzle weld reduced the stresses at this location to approximately $70 \mathrm{MPa}(10 \mathrm{ksi})$ tension (a reduction of $410 \mathrm{MPa}$ [60 ksi]). These post-overlay inside surface axial stresses along the length of the DMW were further reduced into compression with the application of the operating temperature and pressure.

Based on the results of the WRS analyses, it is apparent that the weld overlay technique is effective in producing compressive or low tensile values of axial and circumferential weld residual stresses in the inner region of welds, thereby minimizing the likelihood of initiating PWSCC in Alloy 82/182 DMWs. 
A series of WRS sensitivity analyses were conducted. The following effects were considered by these analyses: FSWOL weld sequence (i.e., left to right versus right to left), FSWOL fabrication with dual welding heads vs. a single head, the secondary SS safe-end weld, overlay thickness, and ID repair depths. The major findings from these sensitivity analyses were as follows.

- Weld Sequencing - The effect of weld sequencing, that is, left-to-right versus right-to-left weld deposition, had a minimal effect on the resultant weld residual stresses. However, the resultant weld residual stresses for the case where two weld heads moving in the same direction were used were higher (less favorable) than when a single head was used. This sensitivity study showed that in designing a WOL, it is crucial that the design that is evaluated and approved is the design that is actually created in the field.

- Effect of Secondary Stainless Steel Weld - The secondary SS weld had a significant effect on the axial weld residual stresses at the DMW. The secondary SS weld tends to add an element of radial constraint to the adjacent DMW, which reduces the axial stresses on the inside surface of the DMW. However, there are cases where there is no secondary SS weld, such as the reactor vessel nozzle weld geometry at V.C. Summer and Sharon Harris. Also, cases where the secondary SS weld is not in close proximity to the DMW, such as the cold-leg/RCP outlet nozzle weld evaluated in Fredette and Scott (2010), showed that there is essentially no beneficial effect of the secondary weld. In those cases, the sensitivity analyses conducted as part of this effort indicated that a FSWOL would produce DMW residual stresses nearly as compressive as the post-FSWOL stresses for cases where a secondary SS weld is in close proximity to the DMW.

It would be instructive to understand the effect of having a safe-end weld installed much closer to the DMW than studied by BCL, because it is possible that the length of a safe end was reduced or shortened as a result of multiple repairs. This condition is one possibility to be aware of during weld overlay design. To avoid incorrect design assumptions about the length of safe ends, it may be necessary to perform field measurements and/or to review fabrication records.

- Number of Weld Passes - As a result of the BCL study, it was shown that the FSWOL is an effective method to reduce weld residual stresses at the pipe weld inside surface, which can contribute to PWSCC in DMWs in PWR piping systems where standard weld procedures were used. A study was conducted in which weld overlay thicknesses less than required for a full structural weld overlay were examined. The studies showed that the results from adding layers of weld overlay varied with the weld geometry being studied.

For the surge nozzle geometry considered, the number of weld overlay passes had a minimal effect on the through-thickness axial stresses near the weld centerline. There was some effect on the inner diameter (ID) axial stresses at the butter/ferritic steel interface (i.e., more layers of weld overlay resulted in a greater reduction in stress), but that effect tended to saturate after about three layers of overlay. However, the ID axial tension in the DMW area remained in tension in all cases and was only reduced to near zero with the application of the FSWOL thickness. For the hoop stress case, the effect was more pronounced with each successive layer further reducing the stresses.

The safety nozzle results showed oscillation in the through-thickness axial stress with the first layer of material increasing the tension stresses beyond those initially present. This stress behavior was unexpected. In this geometry, no improvement in the maximum ID axial stress in the Alloy 82/182 weld area, at room temperature, was found until all four layers of the FSWOL were applied. The hoop stress reduction for the safety nozzle was progressive with thickness. 
The results for the cold-leg nozzle through-wall axial stresses show a similar oscillation behavior as the analyses showed for the safety nozzle. The maximum axial tension stress on the inner diameter in this nozzle is found at the transition between the Inconel butter layer and the ferritic steel pressure vessel. The application of one, two, and three layers makes the ID stress progressively higher than the original stress with no weld overlay. The fourth layer brings the stresses back down, but not down to the level that they were with no weld overlay at all. The remaining layers do not change the stress much in this cross section; that is, there is a saturation effect. BCL emphasized that it is important to look at the stresses on the ID along the whole length of the PWSCC-susceptible area to examine the effect on the most highly stressed region. The stress improvement for the ID axial stress for layers four through OWOL reverses about half way through the width of the butter (axial length of the butter). At this point, the weld overlay increases the ID axial stress above the value with no weld overlay at all, although the ID axial stresses remain compressive. However, the application of operating pressure and temperature reduce these stresses to values below what would be obtained with no weld overlay. Regarding ID hoop stress, there is a progressive improvement with more layers of the weld overlay, but this effect is not proportional to weld overlay thickness. Application of layers one and two decrease the tension stress. The application of layer three makes a large change in the hoop stress thus reducing the maximum value, and placing the whole area encompassing the DMW into compression. Subsequent layers progressively improve on this by adding more compression.

For the RCP outlet nozzle, the axial stresses were also shown to oscillate. Application of layers one through three reduce the maximum stress, and layers five through eight raise the stress from the minimum achieved with layer three. OWOL actually produced better results than the FSWOL in the axial stresses, and the results were virtually the same for both OWOL and FSWOL in the hoop direction.

- Repair Welds - Peak stresses were comparable for each of the repair sizes considered; that is, $0 \%$, $25 \%$, and $50 \%$ of the wall thickness. However, the extent of the affected area was much more pronounced for the deeper repairs. For the deeper repairs, the axial extent of the tensile stresses along the ID surface and the through-thickness extent of those stresses remain tensile for more of the wall thickness. After application of a WOL, it is evident that a large reduction in tensile stresses was achieved and that more improvement was made to the cases with the weld repairs than to the one without.

These sensitivity studies considered the effect on WRS in the presence or absence of a nearby secondary SS weld (configuration) and the effect of repairs, weld sequencing, and number of WOL layers (fabrication). From the sensitivity analyses, it is evident that detailed evaluation of weld procedures, sequencing, and weld overlay thicknesses should be a standard part of designing full structural weld overlays for unique geometries. Discrepancies between design analyses and field installation procedures could render the WOL less effective than planned, or even ineffective as a mitigation technique.

\subsection{Results of Crack Growth Analyses}

This section summarizes (a) the results of crack growth analyses performed by BCL to explore the effect FSWOLs would have on existing cracks and (b) the results of a review performed by the NRC staff on potential beyond-design-basis flaw considerations. 
The FSWOL process is designed to provide enough structural material replacement to accommodate an existing through-wall crack. Cracks $75 \%$ of the thickness and $100 \%$ of the circumference were modeled to simulate the situation in which a very large crack was repaired with a FSWOL. Two crack locations were analyzed by BCL in the surge nozzle and safety nozzle geometries: cracks between the butter layer and the DMW, and cracks between the carbon steel nozzle material and the butter. For convenience, the time for a crack to propagate through the remaining thickness of material was calculated based on assuming that the crack growth rate at the initial flaw depth (e.g., 75\% through-wall) is a constant crack growth rate.

The results for the analyses where circumferential cracks were introduced were consistent for the two geometries considered and indicate that a circumferential crack in an untreated surge or safety nozzle would most likely not grow beyond one-third of the wall thickness before being stopped by the compressive weld residual stresses in the structure. In each case, the stress intensity factors $(\mathrm{K})$ after applying the FSWOL were less than what they would have been if no FSWOL had been applied. For example, for the surge nozzle cracks between the butter layer and the DMW, in the unlikely event that a crack grows beyond one-third of the wall thickness to $60 \%$ of the wall thickness, or greater, it would not be made worse by the FSWOL. The analyses show that the stress intensity factor for a crack at $75 \%$ through-wall would be reduced by approximately $50 \%$ by the FSWOL application.

Based on BCL's analyses, if a FSWOL were applied to a surge nozzle DMW, the K value of a 75\% deep crack at the interface between the butter and the DMW would decrease to approximately 3.5 $\mathrm{MPa} \sqrt{\mathrm{m}}(3.21 \mathrm{ksi} \sqrt{ }$ in.) and would be predicted to require greater than 80 years to grow through the remainder of the original wall. This calculation does not take credit for the reduced susceptibility to cracking of the WOL material but also assumes that the stress intensity is constant at the stress intensity value calculated at the initial flaw depth. BCL showed a similar, although less dramatic, reduction in stress intensity factor for the surge nozzle crack between the butter and the ferritic nozzle. For DMWs with similar pre-existing cracks, the authors of the BCL WOL report (Fredette and Scott 2010) indicated they would expect similar results for cracked welds mitigated by OWOLs as for welds mitigated by FSWOLs, assuming that the number of OWOL weld overlay layers installed is sufficient to achieve a weld residual stress saturation effect.

This result is in contrast to what was found in the MSIP study, where the results demonstrate that if a deep crack (i.e., greater than approximately $60 \%$ of the wall thickness) existed in the weld prior to the application of MSIP, this process increased the stress intensity factors. Because of this effect, the time required for these deep cracks to grow through the remaining wall thickness of the treated weld (postMSIP) was significantly shorter than the time required to grow similar deep cracks through the remaining wall thickness for an untreated case (no MSIP applied).

In addition to enhancing the residual stress field near the inside surface, a FSWOL also adds an element of structural reinforcement to the DMW. BCL demonstrated this assertion during full-scale pipe experiments conducted for the NRC in 1980s. The experiments involved bending through-wall cracked pipe sections that had been repaired with weld overlays. The addition of the Alloy 52M material over the top of DMWs adds several layers of material to the pressure boundary that are more resistant to PWSCC than the underlying Alloy 82/182 weld metal. Furthermore, the overlay may enhance the quality of subsequent ultrasonic inspections by providing a smoother, and possibly longer, axial surface area, for these examinations. 
At industry's request the NRC staff performed a review of MRP-169, "Materials Reliability Program (MRP): Technical Basis for Preemptive Weld Overlays for Alloy 82/182 Butt Welds in PWRs." NRC's safety evaluation of MRP-169 (Blount 2010) notes that the OWOL has less thickness than the FSWOL and is unable, by itself, to satisfy the structural integrity requirements of the ASME Code, Section XI. The OWOL design relies on a portion of the underlying DMW to remain intact and carry a portion of the piping loads because the design-basis crack is $75 \%$ through the original pipe wall. To understand potential limitations of OWOLs, the NRC staff considered the possibility that the OWOL design, installation process, or the associated NDE may not perform as expected such that either (1) a large preexisting crack may be missed by the pre-OWOL UT or (2) a crack grows in the original DMW after the OWOL is applied. A possible reason for a WOL not performing as expected is weld sequencing in the field being significantly different from that modeled in the design, resulting in unfavorable weld residual stresses. During initial phases of crack growth, bending and residual stress variations and metallurgical inhomogeneity could lead to uneven growth. However, once a portion of a surface crack grows deep enough to encounter the weld overlay, it would stop growing or grow slowly in the depth direction at that azimuthal location. Other segments of the crack could continue to grow deeper until they also reach the overlay interface. NRC's concern with OWOLs was that the crack growth could continue until the remaining uncracked ligament of the original DMW is insufficient to withstand design-basis loads and, under such loading, the OWOL may fail without prior evidence of leakage.

By contrast, in a FSWOL, the overlay material that is less susceptible to PWSCC can be credited with minimizing crack growth into the overlay in the event that a large preexisting crack was missed by NDE or if design deficiencies or misapplication of the FSWOL results in unanticipated tensile residual stress fields. If large cracks occur in the original DMW under an FSWOL, the FSWOL can withstand full design loading without failing. The overlay material preserves the FSWOL load-carrying ability and minimizes the likelihood of pipe rupture.

In response to NRC's concern, the industry, through the Nuclear Energy Institute (NEI), performed a sensitivity study to determine the potential impact on the structural integrity of the OWOL of having a flaw $360^{\circ}$ around the circumference and $100 \%$ through the original weld thickness, as suggested by the NRC staff. Table 2.1 shows the allowable structural factors from the ASME Code, Section XI, and industry's proposed alternative OWOL structural factors for the postulated $360^{\circ}$ circumferential flaw $100 \%$ through the original weld. Industry used the net section collapse method to calculate the structural (i.e., safety) factors using piping loading from three nuclear plants as shown in Table 2.2.

As can be seen in Table 2.1, the industry proposed structural factors for Levels A, B, and C are the ASME Section XI required structural factors for Levels B, C, and D, respectively. These reduced structural factors were proposed by industry because the events addressed by Service Levels B, C, and D combined with the postulated flaw are less probable events to occur than the events addressed by Service Levels A, B, and C, respectively, with a design-basis flaw. A $360^{\circ}$ circumferential flaw $100 \%$ through the original weld would conceivably only occur in the unlikely event that either a large preexisting crack were missed by the pre-OWOL UT or if a pre-existing crack grows in the original DMW after the OWOL is applied because of an inadequate design or installation. It can be seen from Tables 2.1 and 2.2 that in all cases but one case (Plant B), the calculated structural factors meet the higher of the proposed limits (membrane or bending). For the nozzle in example Plant B, additional OWOL thickness would be required to meet the proposed limits. 
Table 2.1. Structural Factors per ASME Code, Section XI, and Industry Proposed Structural Factors for Special Flaw Assumption

\begin{tabular}{lcccc}
\hline & \multicolumn{2}{c}{$\begin{array}{c}\text { ASME Section XI Structural } \\
\text { Factors }\end{array}$} & \multicolumn{2}{c}{$\begin{array}{c}\text { Industry Proposed Structural } \\
\text { Factors }\end{array}$} \\
\cline { 2 - 5 } \multicolumn{1}{c}{ Service Level } & $\begin{array}{c}\text { Membrane } \\
\text { Stress }\end{array}$ & $\begin{array}{c}\text { Bending } \\
\text { Stress }\end{array}$ & $\begin{array}{c}\text { Membrane } \\
\text { Stress }\end{array}$ & $\begin{array}{c}\text { Bending } \\
\text { Stress }\end{array}$ \\
\hline Level A - Normal Operation & 2.7 & 2.3 & 2.4 & 2.0 \\
\hline Level B- Normal + OBE & 2.4 & 2.0 & 1.8 & 1.6 \\
Level C- Normal + SSE $^{(b)}$ & 1.8 & 1.6 & 1.3 & 1.4 \\
Level C- Normal + SSE + LOCA $^{(\mathrm{c})}$ & 1.3 & 1.4 & Not Applicable & Not Applicable \\
\hline
\end{tabular}

(a) operating basis earthquake (OBE)

(b) safe shutdown earthquake (SSE)

(c) loss-of-coolant accident (LOCA)

Table 2.2. Structural Factors for Three Sample OWOL Designs Assuming a 100\% Through-Wall Flaw in the Original Weld

\begin{tabular}{lccc}
\hline \multicolumn{1}{c}{ Service Level } & Plant A & Plant B & Plant C \\
\hline Level A - Normal Operation & 2.49 & 2.15 & 2.78 \\
Level B - Normal + OBE & 1.83 & 1.60 & 1.87 \\
Level C - Normal + SSE & 1.44 & 1.36 & 1.42 \\
\hline
\end{tabular}

On the basis that the occurrence of the proposed flaw is an unlikely event and that multiple defenses can prevent this concern from occurring, the NRC staff accepted the proposed structural factors that correspond to less likely events for the calculations for Service Level A, B, and C loadings. The NRC staff also agreed with the industry's request that the analysis for the postulated flaw $100 \%$ through the original pipe wall be treated as a beyond-design-basis condition. The NRC staff also acknowledged that the Level D service condition is not applicable because with the assumption that a loss-of-coolant accident has already occurred, the integrity of the primary RCS has already been compromised and further degradation would not need to be addressed. Because of this NRC staff concern, the NRC required in its adoption of Code Case N-770-1 in the regulations that each OWOL be inspected once each inspection interval. This inspection should have a high probability of detecting a large flaw. This condition is discussed in more detail in Appendix B.2 of this report. Industry's sensitivity analyses demonstrated that OWOLs are capable of maintaining structural integrity even under the beyond-designbasis condition of a postulated flaw $360^{\circ}$ around the circumference and $100 \%$ through the original pipe wall. Code Case N-754 requires that OWOLs be demonstrated to satisfy the additional structural requirements of a $360^{\circ}$ circumferential flaw $100 \%$ through the original weld that exhibits structural factors greater than or equal to the industry proposed factors shown in Table 2.1.

The crack growth studies summarized in Section 2.2 demonstrate that WOLs are effective in reducing the stress intensity of cracks that may exist in welds prior to the application of a WOL. The simplified crack growth calculations performed by BCL showed that even if WOLs are applied over a surge nozzle weld with a $360^{\circ}$ circumferential flaw $75 \%$ through-wall, the crack would be predicted to require greater than 80 years to grow through the remainder of the original wall. Contrary to the effect of MSIP on a 
weld with a deep crack, WOLs reduce the stress intensity of pre-existing cracks. The sensitivity studies requested by the NRC staff demonstrated that OWOLs retain margin against failure (i.e., structural factors greater than 1.3) even under the beyond-design-basis condition of a postulated flaw $360^{\circ}$ around the circumference and $100 \%$ through the original pipe wall.

\subsection{Welding Residual Stress Finite Element Analysis Validation Studies}

Improvements in computational efficiency have facilitated advances in WRS predictions, but no universally accepted guidelines for these analyses have been established. Therefore, assumptions and WRS estimation techniques vary from analyst to analyst, causing large variability in the predicted residual stress profiles for a given weld. The NRC staff and its contractors are completing a WRS analysis validation program aimed at both (1) refining computational procedures for residual stress simulations in DMWs and (2) developing and categorizing the uncertainties in the resulting residual stress predictions. This program consists of four phases, with each phase increasing in complexity. Parts of this program are being cooperatively completed with EPRI. These four phases are outlined in Table 2.3.

Table 2.3. NRC/EPRI Weld Residual Stress Validation Studies

\begin{tabular}{|c|c|c|}
\hline Phase/Title & $\begin{array}{c}\text { Organizational } \\
\text { Lead }\end{array}$ & Description of Work \\
\hline Phase 1: Plates and Cylinders & EPRI & $\begin{array}{l}\text { Validate WRS models with basic geometries } \\
\text { and monitored welding conditions }\end{array}$ \\
\hline $\begin{array}{l}\text { Phase 2: PZR Surge } \\
\text { Mockups }\end{array}$ & $\begin{array}{l}\text { NRC lead with } \\
\text { international round } \\
\text { robin }\end{array}$ & $\begin{array}{l}\text { Validate WRS analysis methods with plant } \\
\text { prototypic component and monitored welding } \\
\text { conditions }\end{array}$ \\
\hline $\begin{array}{l}\text { Phase 3: PZR Safety and } \\
\text { Relief Nozzles }\end{array}$ & EPRI & $\begin{array}{l}\text { Validate WRS analysis methods with small } \\
\text { components from cancelled plant }\end{array}$ \\
\hline $\begin{array}{l}\text { Phase 4: Cold-Leg OWOL } \\
\text { Validation }\end{array}$ & EPRI & $\begin{array}{l}\text { Validate WRS analysis methods with large } \\
\text { component from cancelled plant }\end{array}$ \\
\hline
\end{tabular}

This section summarizes the results of Phase 2. A summary of this phase was chosen because it provides insight into the differences that may be expected between WRS analysis predictions and measured results in a typical LBB piping nozzle.

As discussed in a paper on this topic presented at the ASME 2011 Pressure Vessel and Piping Conference (PVP), the second phase of this program consisted of an analytical international round robin for validation of predicted WRSs in a prototypical PZR surge nozzle geometry (Rathbun et al. 2011). The results from the round robin were validated through comparison of predicted residual stress fields with a variety of physical measurements performed on the mockup. The validation was double blind; that is, the FE analysis and measurement participants were not allowed to compare their results before submission, permitting the NRC staff to develop unbiased measures of uncertainties in WRS predictions. The prototypical surge nozzle was constructed of SA-205 carbon steel. The nozzle was welded to a F316L forged stainless steel safe end with an Alloy 82 weld. The stainless steel pipe was Schedule 160, 14-inch diameter, constructed of TP316 stainless steel. The pipe was welded to the safe end with TP 308 stainless 
steel. Mockup dimensions, materials, and material properties appropriate to the actual mockup and thermocouple data were provided to the analysts.

To provide data against which the FE analyses could be validated, a suite of WRS measurements were made on the round-robin mockup, including incremental hole drilling (IHD) and X-ray diffraction (XRD) for surface measurements, and deep hole drilling/incremental deep hole drilling (DHD/iDHD) (Kingston et al. 2006) for through-thickness measurements. One goal of the round-robin study was to assess the effect of the safe end-to-stainless steel pipe weld on stresses in the main DMW. Hence, the suite of WRS measurements described above was taken before and after completion of the safe end-tostainless steel weld. Only DHD/iDHD results were presented and discussed in Rathbun's PVP paper (Rathbun et al. 2011). The XRD and IHD results are to be presented in a future publication. To retain brevity in this report, only two sets of stress comparisons will be shown.

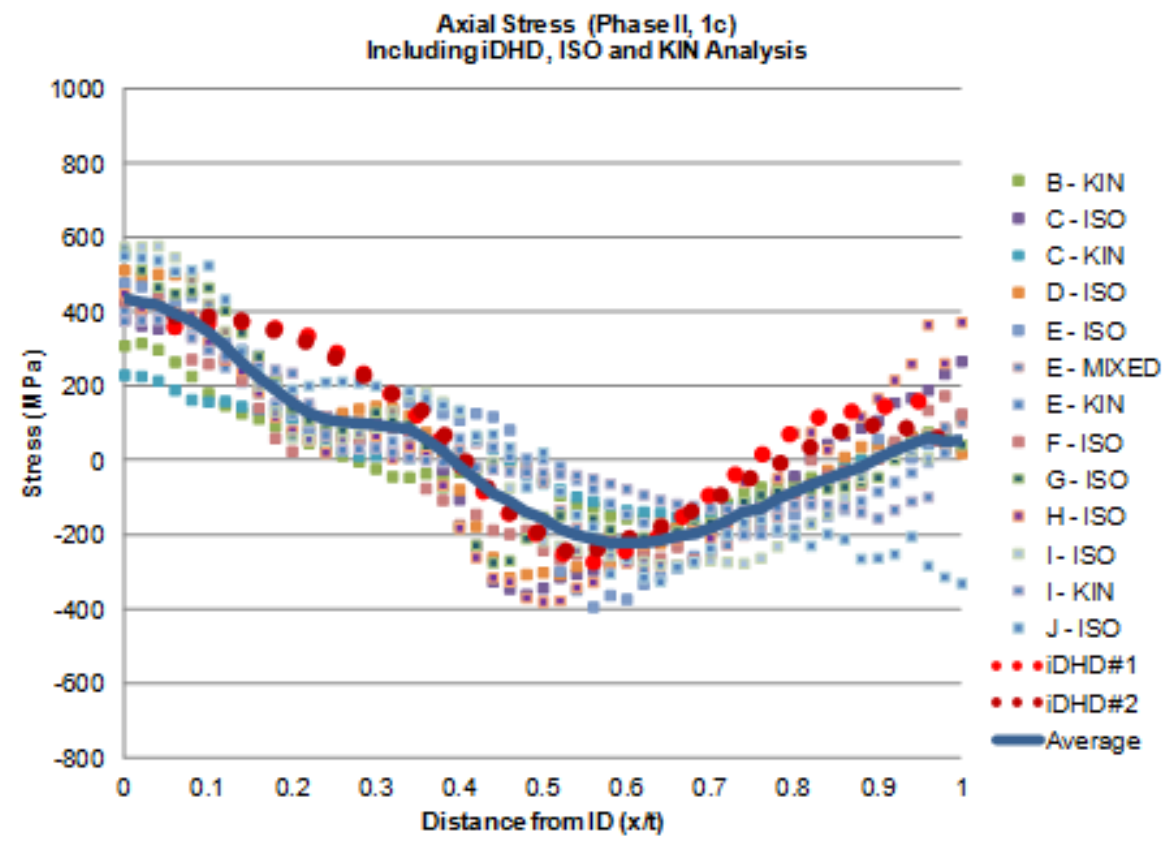

Figure 2.1. Axial Stress Before Stainless Steel Weld. Measured results (DHD/iDHD) are as indicated and the remaining data points are round-robin analyst $\mathrm{FE}$ results. ${ }^{(a)}$

(a) The axial stress results from Rathbun et al. (2011) were updated and provided in email correspondence from H. Rathbun to E. Sullivan, dated April 9, 2012; Figure 2.1 and Figure 2.2 reflect the updated results. 


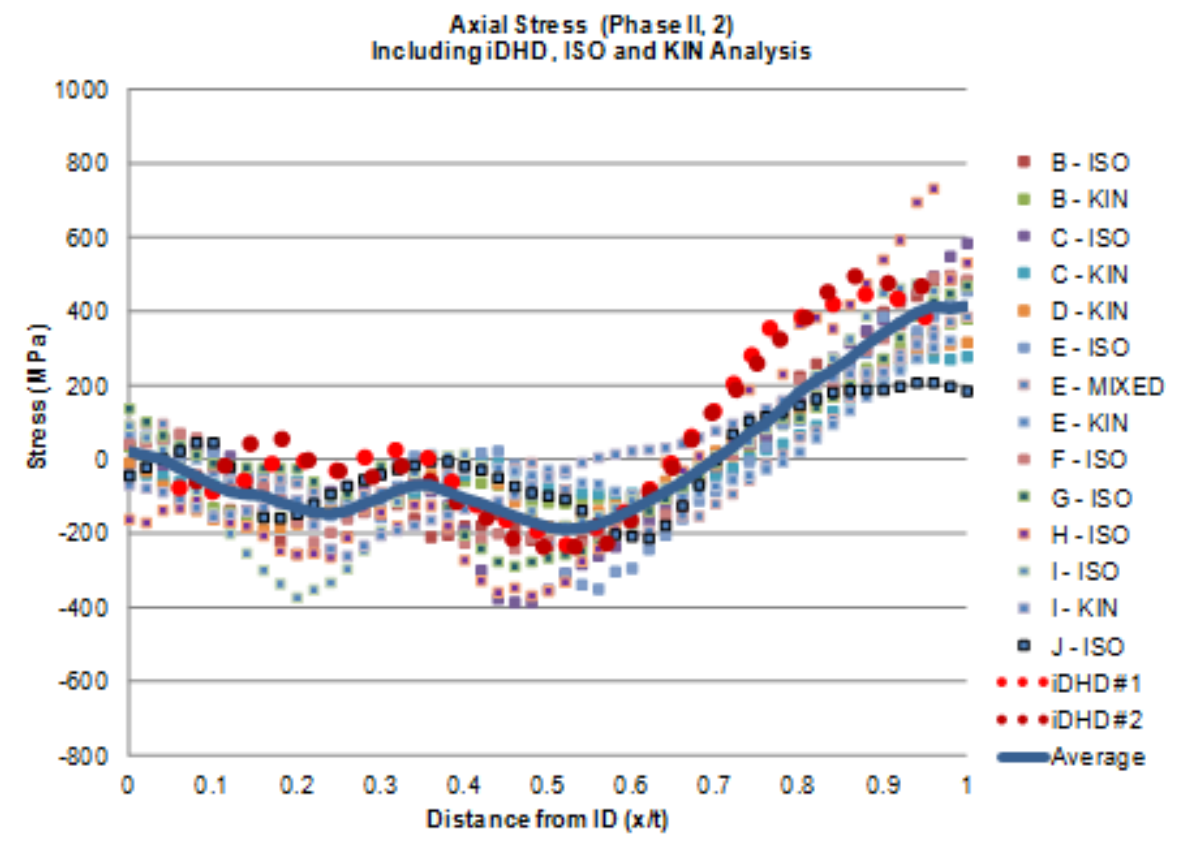

Figure 2.2. Axial Stress After Stainless Steel Weld. Measured results (DHD/iDHD) are as indicated and the remaining data points are round-robin analyst FE results.

For the axial stresses shown in Figure 2.1, the general trend in the average calculated result is in reasonable agreement with the measured results, although there is a significant difference of up to approximately $200 \mathrm{MPa}(29,000 \mathrm{psi})$ in some portions of the curves. The scatter in the FE results is large at approximately $\pm 200 \mathrm{MPa}(29,000 \mathrm{psi})$. For the axial stress component after application of the stainless steel safe end-to-pipe weld (Figure 2.2), the curves show a similar trend with the average calculated axial ID stress after application of the stainless steel weld being reduced at the ID by almost $400 \mathrm{MPa}$ $(58,000 \mathrm{psi})$ to near zero. For the hoop stresses (not shown here), the same general comments could be made.

There is a significant amount of scatter in the calculated residual stress profiles; it would be unreasonable to anticipate that a particular analysis result represents a highly accurate representation of a residual stress distribution in an actual component. Although the average measurements and individual FE analysis results differ in places by significant stress levels, given the overall scatter in the results, to a reasonable approximation, they do occupy the same distribution. Rathbun et al. (2011) discuss factors to which the stress results from the Phase 2 study were sensitive.

Based on the validation studies reported in this section, large uncertainties are expected in several areas, including: 
- actual WRS values,

- the depth of compression induced by WOL,

- the stress intensity factors for potential pre-existing flaws in MSIP welds, and

- flaw growth predictions.

WRS analyses may better predict or represent changes between pre- and post-WOL residual stress values than the actual WRSs. Large changes between the pre- and post-WOL ID residual stress values are shown to occur in the WOL WRS analyses performed by BCL (Fredette and Scott 2010). These analysis results are supported by favorable operating experience in BWRs and PWRs, which indicates that WOLs are an effective measure for reducing inner-wall WRS.

\subsection{Residual Stress and Crack Growth Conclusions}

The main conclusions of this assessment of weld residual stress and crack growth analyses are the following.

a. Based on the results of the WRS analyses, the full structural weld overlay technique is effective in producing compressive or low tensile values of axial and circumferential weld residual stresses in the inner region of welds, thereby minimizing the likelihood of initiation of PWSCC in Alloy 82/182 DMWs.

b. The results for the geometries considered indicate that the OWOL design is an effective technique for mitigating PWSCC in PWRs. For the case considered (i.e., the cold-leg/RCP outlet nozzle geometry), the stresses after application of the OWOL were at, or in some cases below, those for the post-FSWOL application.

c. Contrary to mitigation by MSIP, that if a deep crack were present prior to the application of a WOL, the overlay would act to lower the stress intensity factor of that crack, thus increasing the time required for that crack to potentially grow through the remaining thickness of the original weld.

d. Analysis of weld procedures, sequencing, and weld overlay thickness should be a standard part of designing full structural weld overlays for unique geometries. The weld sequencing sensitivity study showed that in designing a WOL, it is crucial that the WOL design that is rendered in the field be consistent with the design that is evaluated and approved.

e. The secondary SS weld has a significant effect of reducing the axial weld residual stresses at the inside surface of the DMW. This beneficial effect does not occur when the secondary SS weld is not in close proximity to the DMW. The sensitivity analyses conducted as part of this effort indicated that the FSWOL where there is not secondary SS weld would produce DMW residual stresses nearly as compressive as the post-FSWOL stresses for cases where a secondary SS weld is in close proximity to the DMW. 



\subsection{NDE Reliability}

\subsection{Assessment of Pre-WOL UT Examination Results}

As noted in Section 1.0 of this report, the OWOL design requires that the subject piping weld be inspected immediately prior to the overlay application, using an inspection technique qualified in accordance with ASME Section XI, Appendix VIII. The piping weld must be found to exhibit no evidence of cracking greater than $50 \%$ of the wall thickness in the original weld. If a detected flaw has a depth greater than 50\% through-wall, the OWOL design will not be applicable for the repair.

It was also noted in Section 1.0 that a weld is not required to be inspected prior to application of a FSWOL. If a pre-FSWOL inspection is not performed, then an initial flaw that is $75 \%$ through the original weld thickness is postulated. Any actual observed or postulated flaws in the DMW must be demonstrated, by a crack growth calculation, not to grow beyond the allowable size before the next scheduled in-service inspection (ISI). However, if pre-FSWOL inspection is conducted, an initial flaw size for crack growth calculation is specified in ASME Code Case N-740-2. For example, if a qualified UT examination is performed prior to application of a FSWOL, and no inside surface connected planar flaws are detected, initial flaws originated from the inside surface of the weldment equal to $10 \%$ of the original wall thickness shall be assumed in both the axial and circumferential directions.

This section provides a discussion and conclusions on NDE reliability issues related to detection and characterization of SCC in unmitigated welds. These NDE reliability issues are also relevant to the reliability of pre- and post-WOL inspections.

\subsubsection{Introduction}

On May 8 and 9, 2012, PNNL held a workshop in Richland, WA, with LMT, Inc., an NDE vendor for the commercial nuclear power industry. LMT uses UT examination methods qualified under ASME Code, Section XI, Appendix VIII. Both phased array (PA) and conventional UT techniques in encoded and non-encoded delivery modes are employed, as specified by the utility. LMT performs examinations of piping welds from the piping OD and has been involved with the inspection of a number welds in PWRs and BWRs in which indications were attributed to stress corrosion cracking (SCC).

The topics that follow were discussed during this workshop.

- Characterization of flaws attributed to SCC,

- Encoded versus non-encoded examinations,

- Characterization of embedded flaws in field welds, and

- Comparison of serviced-induced cracks with flaws in performance demonstration mockups.

\subsubsection{Discussion}

Encoded phased array UT techniques were used to detect and characterize SCC found in a BWR control rod drive (N9) nozzle DMW during a spring 2008 refueling outage and in a PZR surge line DMW during a spring 2007 refueling outage. In both cases, the stress corrosion cracking was subsequently 
mitigated with NRC-approved full structural weld overlays. Additionally, encoded UT examinations were performed in 2008 on safety and relief nozzle welds on a PZR removed from St. Lucie, Unit 1, to assess results obtained previously from manual non-encoded PA examinations.

In the case of the BWR N9 weld, the full ASME Code required inspection volume was not achieved with encoded PAUT techniques due to an interfering weld crown, geometry limitations from the nozzle contour, and the presence of an end cap. Only axial scanning for circumferentially oriented flaws was conducted using PA, as the component was being prepared for a full structural weld overlay procedure and full ASME Code UT volume coverage was not required.

With minor geometric reflections in this weld, a circumferential flaw was readily detected and was localized at the weld-to-butter interface, determined to be ID connected, and was attributed to intergranular stress corrosion crack (IGSCC). The overall thickness of the weld was approximately 19 $\mathrm{mm}(0.75$ in.) and the crack was depth sized at approximately $60 \%$ through-wall. A general observation made by LMT analysts during the workshop was that this circumferential flaw was relatively easy to detect and characterize on this somewhat thin-walled component. They noted that inspection of heavier walled components can present additional challenges.

Regarding the surge line flaw, full volumetric inspection of the flawed region was precluded by the specimen's taper and the presence of lugs nearby the nozzle weld. During the initial conventional manual (non-encoded) examination, an axial flaw was detected. A decision was made to remove the lugs and use encoded PAUT to fully characterize the axial flaw as well as to conduct a more complete inspection of the code required inspection volume. Using encoded PAUT, an ID-connected circumferential flaw was observed that was not initially detected by the manual conventional UT examination. The weld thickness is approximately $38 \mathrm{~mm}$ (1.50 in.) at the flaw location, and the flaw was depth sized at $34 \%$ through-wall. It is unclear whether interference by the lugs may have prevented detection of the circumferential flaw during the initial manual examination. However, general observations made by the LMT analysts were that use of the encoded PAUT technique facilitated detection and characterization of this flaw, which would not have been straightforward in this weld using manual non-encoded techniques, even with the lugs removed. This observation is based on the presence of spurious reflections caused by a short safeend, numerous geometrical reflections, and various mode conversion signals. The use of encoded techniques enabled the spurious reflections to be reviewed sufficiently to distinguish the circumferential flaw from the other reflections and characterize it properly.

In the case of the St. Lucie, Unit 1, PZR safety and relief nozzle welds, the conclusions of the initial manual (non-encoded) PA examinations were that the safety and relief nozzle welds contained deep non-uniform $360^{\circ}$ ID-connected circumferential flaws indicative of SCC. This result raised questions about the applicability of the Advanced Finite Element Analyses safety assessment performed after deep circumferential flaws were detected in 2006 in Wolf Creek PZR nozzles (EPRI 2007). The Wolf Creek flaws were attributed to PWSCC. A number of operating PWRs had delayed the PZR nozzle weld inspections to their next refueling outage based on the AFEA assessment. Because of the significance of the initial St. Lucie, Unit 1, inspection result to these operating PWR plants, the initial examinations were reevaluated and the welds were reexamined shortly thereafter with encoded techniques. A PNNL UT expert participated in the reexamination activity. Further scanning and data analysis indicated that the welds were not cracked, but rather contained embedded fabrication flaws, attributed to slag, porosity, and/or lack of fusion. The $360^{\circ}$ indications at the ID were weld root signals. Despite the abundance of fabrication flaws, a reevaluation of these flaws in accordance with ASME Code Section III criteria 
confirmed that the welds were acceptable. During the reevaluation numerous problems were found with the initial examinations. These problems included use of probes that were inappropriately focused for the welds being examined, improper execution of PDI qualified procedures, and the inability of the examiners to distinguish the signals from the weld root and embedded flaws from ID connected flaws with the manual techniques. The workshop participants noted the disadvantage of using manual PA techniques in this situation because of the inability to review the UT data and carefully determine the origin of the signals present. It was also noted at the workshop that the opportunities in the PDI qualification process to interpret false call signals from weld roots, counterbores, and fabrication flaws may not be sufficiently realistic. Thus, examiners may pass the PDI qualification process with manual (both conventional and PA) non-encoded techniques without sufficiently demonstrating the ability to distinguish ID connected flaws from other signals that may be expected to be present in a weld inspection volume, especially in DMWs.

Workshop participants indicated that there are numerous factors that affect the reliability of NDE to detect and characterize flaws. These factors include the ability of the techniques used to obtain full ASME Code-required coverage of the inspection volume, the presence of interfering signals from geometric or metallurgical reflectors, the use of manual versus encoded techniques, the reflectivity of the flaw, the impedance of the materials being examined, the signal attenuation and dispersion through those materials, and the experience and skill of the examiner. Other related factors may include the use of proper modeling methods to design the examination and the representativeness of the mockups used for performance demonstration. The St. Lucie, Unit 1 experience and the recent North Anna, Unit 1, experience in 2012 (discussed in Anderson et al. 2012), reinforce the importance of carefully considering these factors before conducting an examination. It was suggested that additional observations on NDE reliability could possibly be drawn if more encoded data on service-induced SCC were available for review.

A portion of the workshop was devoted to discussing preliminary results of a program at PNNL on comparing UT data from service-induced cracks with implanted flaws being used for demonstration testing. PAUT data was acquired on several specimens that contained a variety of different flaw or simulated flaw types. Data were presented to compare the responses observed from each flaw type. The flaw types consisted of hot isostatic pressed (HIP) notches produced by electro-discharge machining (EDM) and implanted thermal fatigue cracks (TFC) in wrought SS, implanted TFCs in CASS, IGSCC in Hatch and Nine Mile Point in specimens owned by EPRI, as well as TFCs implanted in CASS piping material. A primary goal of this work is to identify quantifiable variables that affect flaw responses, analyze the variables, and use this information to compare flaw types. It is of particular interest to identify the degree to which implanted flaws, such as those currently used by industry, are representative of service-induced flaws and, therefore, provide sufficiently challenging targets for performance demonstration.

In selectively comparing the implanted TFC and the HIP EDM notches, a general observance was that less overall gain was needed to produce similar responses for the HIP EDM notches. Overall, it was concluded that additional work on signal analysis will be needed to complete the program goals. 


\subsubsection{NDE Workshop Conclusions}

The conclusions of the workshop were the following.

1. The reliability of NDE to detect and accurately characterize service-induced SCC flaws is dependent upon a number of factors, including:

- ability of the applied NDE to obtain full coverage of the required inspection volume,

- the presence of interfering signals such as from geometric or metallurgical reflectors,

- use of non-encoded conventional or PA techniques versus encoded techniques,

- general reflectivity of service-induced flaws,

- acoustic impedance of the materials being examined and UT signal attenuation and dispersion through those materials,

- experience and skill of the examiners,

- the use of proper modeling methods to design and set-up examinations, and

- representativeness of the mockups used for performance demonstration to qualify UT examiners.

2. Given the factors and constraints of field conditions involving UT inspection of RCS DMWs, the use of encoded techniques offers a significant and distinct advantage over non-encoded techniques in detection and characterization of flaws, because of the ability to review the UT data off-line via imaging processes and carefully determine the origin of the signals present.

3. During the current UT qualification process, existing mock-ups and conditions may not provide sufficient opportunities for candidates to adequately demonstrate an ability to distinguish realistic false call signals generated from weld roots, counterbores, fabrication flaws, and metallurgical interfaces, with signals produced from simulated PWSCC. Thus, examiners may pass the PDI qualification process with non-encoded techniques without sufficiently demonstrating the ability to distinguish ID connected flaws from other signals that may be expected to be present in a weld inspection volume, especially in DMWs.

4. Additional work will be needed to determine the degree to which artificial implanted flaws are representative of service-induced flaws.

\subsection{Inspection of Dissimilar Metal Weld Overlay Specimens}

Industry has been installing weld overlays with the more resistant Alloy 52/152/690 as a means of corrective or pre-emptive action for PWSCC. The reliability of NDE of welds mitigated by overlays is important for determining whether any new flaws have initiated or existing flaws have propagated, and for assessing the effect of any potential flaws on the service life of the weld. In this regard, PNNL performed an ultrasonic NDE study to investigate the inspectability of weld overlay specimens. The Technical Evaluation Report that summarizes this work is Ultrasonic Evaluation of Two Dissimilar Metal Weld Overlay Specimens by Crawford et al. (2012).

To conduct this study, thermal fatigue cracks were implanted in two DMW specimens. The specimens were composed of a cast austenitic stainless steel pipe welded to a carbon steel nozzle with 
Alloy 82/182 weld material. Each specimen was evaluated with phased-array ultrasonic testing to determine flaw detection and characterization capabilities. An Alloy 82/182 WOL was added to the specimens, and they were again evaluated ultrasonically for flaw detection and characterization. A WOL made of Alloy 52/152 was cost-prohibitive, so Alloy 82/182 was selected instead; this choice does not impact ultrasonic propagation as it is essentially equivalent in both alloys. Flaw characterization included length and depth measurements as well as a signal-to-noise ratio (SNR) determination. Objectives of this work included determining ultrasonic detection capabilities in DMW specimens with a WOL and assessing ultrasonic examinations through cast austenitic stainless steel (CASS) material.

Specimen 10C-011 is a 516 Grade 70 nozzle and Alloy 82/182 butter section welded to a CASS pipe. Five circumferentially oriented ID-connected TFCs were implanted in the center of the weld during the welding process to prevent implantation artifacts that could show in the ultrasonic data. The flaw depths range from $49.8 \%$ to $89.9 \%$ through-wall deep, are tilted by 2 or 3 degrees, and are all circumferentially oriented. The flaw lengths vary from 3.8 to $6.4 \mathrm{~cm}$ (1.5 to $2.5 \mathrm{in}$.). This DMW mockup specimen is approximately $32.4 \mathrm{~cm}$ (12.8 in.) in diameter at the flaw position, and $68.4 \mathrm{~cm}$ (26.9 in.) in length, with a nominal $3.3 \mathrm{~cm}$ (1.3 in.) wall-thickness at the flaw location within the DMW. The weld overlay is approximately $2.0 \mathrm{~cm}(0.8 \mathrm{in}$.) thick at the weld location. The flaws were easily detected with ultrasound so specimen 9C-034 with shallower TFCs implanted in the weld-to-butter region was evaluated.

Specimen 9C-034 contains a DMW between a 516 Grade 70 carbon steel nozzle and a CASS pipe. The nozzle side butter and weld consisted of Alloy 82/182 material. Four thermal fatigue cracks (TFCs) were implanted in the weld-to-butter region with flaw depths ranging from $13 \%$ to $31 \%$ deep through the original weld thickness. The flaws are ID surface breaking with lengths at the ID in the range of 5.1 to $6.4 \mathrm{~cm}$ ( 2 to $2.5 \mathrm{in}$.). The flaws are vertical, have no tilt, are circumferentially oriented, and are ID surface connected. The individual section of CASS pipe was sent to FlawTech where it was welded to a carbon steel nozzle segment and the four TFCs were implanted into the butter region on the nozzle side of the welded specimen, reducing potential excavation and implantation artifacts. This DMW mockup specimen is approximately $32.5 \mathrm{~cm}$ (12.8 in.) in diameter at the flaw position and $58.4 \mathrm{~cm}(23 \mathrm{in}$.$) in$ length, with a nominal $3.3 \mathrm{~cm}$ (1.3 in.) wall-thickness at the flaw location within the DMW. The four TFCs were inserted via a coupon-implant technique and were all circumferentially oriented flaws. After the specimen was examined by UT, it was overlaid with Alloy 82/182 in a water-backed welding process. The weld overlay is approximately $2.0 \mathrm{~cm}(0.8 \mathrm{in}$.) thick at the weld location.

The thickness requirements for weld overlays are discussed in MRP-169 (EPRI 2008b). The minimum WOL thickness requirement for a FSWOL is one-third of the weld thickness. Based on the nominal weld thickness for Specimens 9C-034 and 10C-011, it is clear that the 2.0-cm-thick overlay represents a type of FSWOL.

A weld root signal was often ultrasonically detected and may have precluded a strong corner response from the flaw itself. The presence of a strong weld root signal that could not be separated from the flaw signal complicated flaw length sizing.

The specimens were examined using four phased-array (PA) probes: a 2.0-megahertz $(\mathrm{MHz})$ transmit-receive longitudinal (TRL) probe arrangement, a 1.5-MHz TRL probe, a 1.0-MHz TRL probe, and a $0.8-\mathrm{MHz}$ TRL probe. The $1.5-\mathrm{MHz}$ transducer was chosen based on frequencies commonly used in reactor inspections of stainless steels. The additional $0.8-, 1.0-$, and 2.0-MHz probes were employed to more fully evaluate the entire frequency spectrum and provide data to better assess lower and higher 
frequency limits for inspecting the various DMW components. The two lower frequencies were particularly applicable for evaluations in the increased specimen thickness in the post-WOL condition. Phased-array data were acquired on the nine flaws in the two specimens. In general, line scan and raster data were acquired from both sides of the flaw.

Phased-array data were acquired on Specimen 9C-034 prior to the application of the WOL from the CASS pipe side of the weld with the 1.5- and 2.0-MHz PA probes in both the line and raster styles of scanning. All four flaws were detected in this data.

The post-WOL data were acquired from both the nozzle and pipe sides of the weld with the 0.8-, 1.0-, 1.5-, and 2.0-MHz probes in the line and raster styles of scanning with one exception. Line scan data were not acquired at $0.8-\mathrm{MHz}$ from the pipe side.

The four flaws were detected in the post-WOL raster data at 1.5 and $2.0 \mathrm{MHz}$ from the pipe side. From the nozzle side, the smallest flaw was marginally detected at $1.5 \mathrm{MHz}$ but detected in the $2.0 \mathrm{-MHz}$ raster data. The other three flaws were detected in the 1.5- and 2.0-MHz raster data from the nozzle side. A summary of the post-WOL detection results is shown in Table 3.1 with yes, no, and marginal detection calls.

Table 3.1. Flaw Detection Table for Specimen 9C-034 Post-WOL

\begin{tabular}{cccccccccc}
\hline Frequency, & Side: & \multicolumn{4}{c}{ Nozzle } & \multicolumn{5}{c}{ Pipe } \\
\hline MHz & Flaw: & $\mathbf{1}$ & $\mathbf{2}$ & $\mathbf{3}$ & $\mathbf{4}$ & $\mathbf{1}$ & $\mathbf{2}$ & $\mathbf{3}$ & $\mathbf{4}$ \\
\hline 0.8 & Line & $\mathrm{M}$ & $\mathrm{M}$ & $\mathrm{N}$ & $\mathrm{Y}$ & --- & --- & --- & --- \\
& Raster & $\mathrm{N}$ & $\mathrm{Y}$ & $\mathrm{M}$ & $\mathrm{Y}$ & $\mathrm{N}$ & $\mathrm{M} / \mathrm{N}$ & $\mathrm{Y}$ & $\mathrm{Y}$ \\
\multirow{2}{*}{1.0} & Line & $\mathrm{M}$ & $\mathrm{Y}$ & $\mathrm{M}$ & $\mathrm{Y}$ & $\mathrm{N}$ & $\mathrm{N}$ & $\mathrm{M}$ & $\mathrm{N}$ \\
& Raster & $\mathrm{N}$ & $\mathrm{Y}$ & $\mathrm{M}$ & $\mathrm{Y}$ & $\mathrm{N}$ & $\mathrm{M}$ & $\mathrm{Y}$ & $\mathrm{M}$ \\
\multirow{2}{*}{1.5} & Line & $\mathrm{N}$ & $\mathrm{Y}$ & $\mathrm{Y}$ & $\mathrm{Y}$ & $\mathrm{N}$ & $\mathrm{Y}$ & $\mathrm{Y}$ & $\mathrm{Y}$ \\
& Raster & $\mathrm{M}$ & $\mathrm{Y}$ & $\mathrm{Y}$ & $\mathrm{Y}$ & $\mathrm{Y}$ & $\mathrm{Y}$ & $\mathrm{Y}$ & $\mathrm{Y}$ \\
2.0 & Line & $\mathrm{Y}$ & $\mathrm{Y}$ & $\mathrm{Y}$ & $\mathrm{Y}$ & $\mathrm{N}$ & $\mathrm{M}$ & $\mathrm{Y}$ & $\mathrm{Y}$ \\
& Raster & $\mathrm{Y}$ & $\mathrm{Y}$ & $\mathrm{Y}$ & $\mathrm{Y}$ & $\mathrm{Y}$ & $\mathrm{Y}$ & $\mathrm{Y}$ & $\mathrm{Y}$ \\
\hline $\mathrm{M}=$ marginal, N $=$ No, $\mathrm{Y}=\mathrm{Yes}$ & & & & & & & & \\
\hline
\end{tabular}

Phased-array line and raster data were acquired on Specimen 10C-011 prior to the application of the weld overlay with the $0.8-, 1.0-, 1.5-$, and $2.0-\mathrm{MHz}$ probes from both the nozzle and pipe sides. The exception was that no raster data were acquired from the nozzle side with the $0.8-\mathrm{MHz}$ probe. All five of the implanted TFCs were detected in this pre-WOL data.

Similarly, PA line and raster data were acquired on Specimen 10C-011 after the application of the weld overlay with the $0.8-, 1.0-, 1.5-$, and 2.0-MHz probes from both the nozzle and pipe sides. All five of the implanted TFCs were detected in this post-WOL data. In both the line and raster data, a weld root signal was often evident in the data and prevented the identification of an isolated flaw corner response. Upper specular reflections were evident and allowed good flaw detection and characterization. 
The errors in depth sizing measurements for all nine flaws as calculated by a root mean square error (RMSE) for the pipe side raster data were 3.9 and $4.0 \mathrm{~mm}(0.154$ and $0.157 \mathrm{in}$.) for the pre- and postWOL data, respectively. RMSE values for the nozzle side raster data were 6.6 and $3.3 \mathrm{~mm}(0.260$ and 0.130 in.) for the pre- and post-WOL data, respectively.

Line scan data for the four flaws in Specimen 9C-034 provided better depth sizing results than the raster scan data. The errors in depth sizing as calculated by an RMSE for the pipe side data were 1.8 and $1.9 \mathrm{~mm}(0.071$ and $0.075 \mathrm{in}$.) for the pre- and post-WOL data, respectively. RMSE values for the nozzle side data were $2.7 \mathrm{~mm}(0.106 \mathrm{in}$.) for both the pre- and post-WOL data. These values are within the ASME Code Section XI requirements of $3.2 \mathrm{~mm}(0.125 \mathrm{in}$.) for depth sizing error unlike the raster data shown above. Both line scan and raster data were acquired in the $30^{\circ}$ to $70^{\circ}$ or $87^{\circ}$ range. However, raster data were acquired with a $3^{\circ}$ increment while line scan data were acquired with a $1^{\circ}$ increment; that is, data were collected during line scanning at every $1^{\circ}$. This difference contributes to the larger error seen in the raster depth sizing data. Ideally, raster data would provide better sizing results as it captures data over many axial positions.

Additionally, the depth sizing error for the flaws that were $50 \%$ and greater in through-wall extent of the original material were considered. These flaws are of interest because only these flaws are contained within the required inspection volume for OWOLs. Data for this inspection volume was used because it is larger than the inspection volume for FSWOLs and the five flaws in Specimen 10C-011 fall within the OWOL inspection volume. These results are displayed in Table 3.2. The error values did not change appreciably, which illustrates the ability of the techniques used to depth size flaws smaller than required by ASME Code. Furthermore, a second analyst examined the post-WOL raster data from the flaws $50 \%$ deep and greater. These RMSE results, displayed in Table 3.2, show RMSE errors within the ASME requirements for depth sizing (3.2 $\mathrm{mm}$ [0.125 in.] or less). The second analyst emphasized tip diffraction sizing when tip signals were present; whereas, the first analyst relied on specular reflections from the upper parts of a flaw. This likely resulted in the better sizing results.

Table 3.2. Depth Sizing RMSE for Deep Flaws ( $\geq 50 \%$ deep)

\begin{tabular}{lccccc}
\hline & \multicolumn{3}{c}{ Raster } & \multicolumn{2}{c}{ Line } \\
\cline { 2 - 6 } & $\begin{array}{c}\text { Pre-WOL } \\
\text { mm (in.) }\end{array}$ & $\begin{array}{c}\text { Post-WOL } \\
\text { mm (in.) }\end{array}$ & $\begin{array}{c}\text { Post-WOL } \\
\text { mm (in.) }\end{array}$ & $\begin{array}{c}\text { Pre-WOL } \\
\text { mm (in.) }\end{array}$ & $\begin{array}{c}\text { Post-WOL } \\
\text { mm (in.) }\end{array}$ \\
\hline Pipe Side & $4.5(0.18)$ & $4.1(0.16)$ & $2.3(0.091)$ & $1.4(0.055)$ & $2.0(0.079)$ \\
Nozzle Side & $6.6(0.26)$ & $3.9(0.15)$ & $2.7(0.11)$ & $2.7(0.11)$ & $1.8(0.079)$ \\
\hline
\end{tabular}

(a) Data analyzed by second operator.

Length sizing was measured at both the $-6 \mathrm{~dB}$ level and the loss-of-signal (LOS) level when possible. The LOS level equates to an approximate $-12 \mathrm{~dB}$ level. Length sizing errors were greatest in the $9 \mathrm{C}-034$ post-WOL data. This specimen has the shallower flaws. RMSE values at the $-6 \mathrm{~dB}$ sizing level for the 9C-034 pre- and post-WOL raster data and the 10C-011 pre- and post-WOL raster data were 8.1, 39.6, 9.0, and $14.9 \mathrm{~mm}(0.32, \underline{1.56}, 0.35$, and $0.59 \mathrm{in}$.), respectively. All but the post-WOL 9C-034 data fall within the ASME allowable error of $19.1 \mathrm{~mm}(0.75 \mathrm{in}$.). RMSE values at the LOS sizing level, raster data, for the 9C-034 pre- and post-WOL data and the 10C-011 pre-and post-WOL data were 5.8, 26.1, 
7.9, and $10.5 \mathrm{~mm}(0.23, \underline{1.03}, 0.31$, and $0.41 \mathrm{in}$.$) , respectively. Again, all but the post-WOL 9C-034 data$ at the LOS sizing level fell within the ASME requirements. Line scan data showed similar trends.

It should be noted that Supplement 11, Qualification Requirements for Full Structural Overlaid Wrought Austenitic Piping Welds, states that, "For flaws in base metal grading units (as opposed to overlay fabrication flaws), the candidate shall estimate the length of that part of the flaw that is in the outer $25 \%$ of the base metal thickness." Draft Code Case N-653-1, which will augment Supplement 11 for OWOLs, will be based on the part of the flaw that is in the outer $50 \%$ of the base metal thickness. The examination volume for the OWOL includes the OWOL thickness plus the outer $50 \%$ of the base metal. The four flaws in post-WOL Specimen 9C-034 with flaw depths ranging from $13 \%$ to $31 \%$ deep through the original weld thickness would not be included in the length sizing requirements of either Supplement 11 or Code Case N-653-1 and, therefore, the high 9C-034 post-WOL length sizing RMSE data is of no consequence. It should also be noted that the length sizing measurements made on the flaws in Specimens 9C-034 and 10C-011 were made for the ID flaw length rather than for the part of the flaw that is in the outer $25 \%$ or $50 \%$ of the base metal thickness. The reason for this approach is that the flaw profiles were not known, making it impossible to calculate RMSE for length measurements at these depths. It is not clear why the Code requires length measurements of the part of the flaw that is in the outer $25 \%$ or $50 \%$ of the base metal thickness and comparison of these RMSE values with an acceptance standard since these length values appear to have no application to flaw evaluation rules. It may be appropriate to consider revising this requirement.

In summary, two DMW specimens, one with four shallow circumferential flaws ( $13 \%$ to $31 \%$ through-wall) and one with five deeper circumferential flaws (50\% to $90 \%$ through-wall) were ultrasonically examined. The DMW specimens were examined from the nozzle and the CASS pipe side with both raster and line scans using four PA probes in the 0.8 - to $2.0-\mathrm{MHz}$ frequency range, although not every combination of scan, scan direction, and frequency was used to examine each flaw. An Alloy $82 / 182$ WOL was added to each specimen and they were re-evaluated ultrasonically for flaw detection and characterization. All nine flaws were detected in the pre- and post-WOL condition.

For purposes of this report, sizing errors for only the flaws that were greater than or equal to $50 \%$ of the original material were considered because these flaws are contained within the required inspection volume for OWOLs. Using data from a second analyst who emphasized time-of-flight tip-diffraction sizing when these tip signals could be observed, pre- and post-WOL depth sizing RMSE for both the raster and line scan data were found to be within the ASME depth-sizing allowable of $3.2 \mathrm{~mm}(0.125 \mathrm{in}$.). Length-sizing error for these same flaws was calculated based on their ID the surface-breaking length. The pre- and post-WOL length-sizing RMSE values were found to be within the ASME qualification acceptance criterion of $19.1 \mathrm{~mm}(0.75 \mathrm{in}$.).

\subsection{Inspection Limitations}

Inspection limitations can affect the effectiveness of NDE requirements. A number of apparent inspection limitations are discussed in the following paragraphs. 
As discussed in Appendix B.1 of this report, Code Case N-770-1, Note (12) requires that stress improvement techniques meet the performance criteria in Appendix I of this Code Case, and requires that satisfaction of these criteria be demonstrated in an evaluation. In Code Case N-770-1, stress improvement techniques include OWOLs.

The criteria of Code Case N-770-1, Appendix I, Paragraph 5 require that, “An evaluation ... be performed to confirm that the required examination volume of the mitigated configuration is within the scope of an Appendix VIII supplement, or supplements, and that the examination procedures to be used have been qualified in accordance with the ASME Code, Section XI, Appendix VIII. Code Case N-7701, Appendix I, paragraph 6, requires that, "An examination qualified to Section XI, Appendix VIII performance demonstration requirements shall have been performed ... before the application of the mitigation process to identify and size any existing flaws." Any departure from these requirements of Code Case N-770-1, Appendix I, because of pre- or post-WOL inspection limitations beyond those permitted by Code Case N-770-1, as imposed by $\S 50.55 \mathrm{a}(\mathrm{g})(6)(\mathrm{ii})(\mathrm{F})$, have to be evaluated and an alternative examination authorized by the NRC staff.

Geometry or access may limit performing a complete pre-WOL weld examination. Information on limitations to performing inspections of typical Westinghouse and CE plant RCS Alloy 82/182 welds was obtained from LMT, Inc., an NDE vendor for the commercial nuclear power industry, during a workshop PNNL held in May 2012. Appendices C and D contain weld coverage assessment diagrams for these plants that show the probe angles used and percent coverage obtained with Section XI, Appendix VIII, qualified techniques. These appendices also indicate the materials of construction for the welds depicted. As noted above, qualified UT examinations are required prior to installing optimized weld overlays.

For the plant-specific designs used to prepare Appendices C and D, Tables 3.3 and 3.4 provide the Code-required volume coverage achievable for Alloy 82/182 RCS butt welds in the typical Westinghouse and Combustion Engineering plants used for this assessment. These tables indicate the welds for which Code required inspection coverage would not be achieved based on the plant specific designs used in the assessment. It should also be noted that the Westinghouse RPV nozzle welds in this study were examined from the OD, although the RPV nozzle welds in many Westinghouse plants are examined from the inside surface, where the inspection limitations differ and the CRV coverage obtained is generally understood to be higher.

In CE plants, the safe ends of medium and large bore piping are typically made of cast stainless steel (CSS). The CRV coverage presented in Table 3.4 takes credit for the scan coverage in the CSS safe ends using the Supplement 10 techniques used for the carbon steel and Alloy 82/182 volumes. This approach for reporting CRV coverage was used since Code Case N-770-1 requires that the examination volume to be examined by Appendix VIII procedures to the maximum extend practical, including $100 \%$ of the susceptible material volume. 
Table 3.3. RCS Alloy 82/182 Butt Weld Code Required Volume Coverage Obtained for a Typical Westinghouse Plant

\begin{tabular}{lcc}
\hline \multicolumn{1}{c}{ Description } & Axial Scan & Circumferential Scan \\
\hline PZR Surge Nozzle & $80 \%$ & $100 \%$ \\
PZR Spray Nozzle & $40 \%$ & $34 \%$ \\
PZR Safety \& Relief Nozzle & $0 \%$ & $0 \%$ \\
RPV Hot Leg Nozzle & $28.8 \%$ & $100 \%$ \\
SG Hot Leg Nozzle & $95.4 \%$ & $100 \%$ \\
SG Cold Leg Nozzle & $95.4 \%$ & $100 \%$ \\
RPV Cold Leg Nozzle & $100 \%$ & $100 \%$ \\
\hline PZR - pressurizer; RPV - reactor pressure vessel; SG - steam generator \\
\hline
\end{tabular}

Table 3.4. RCS Alloy 82/182 Butt Weld Code Required Volume Coverage Obtained for a Typical Combustion Engineering Plant

\begin{tabular}{lcc}
\hline \multicolumn{1}{c}{ Description } & Axial Scan & Circumferential Scan \\
\hline RCP Suction to RC Pipe & $100 \%$ & $44.3 \%$ \\
RCP Discharge to RC Pipe & $77 \%$ & $34 \%$ \\
RC Loop Surge Nozzle & $82.4 \%$ & $31.3 \%$ \\
Letdown \& Drain Nozzle & $100 \%$ & $100 \%$ \\
Hot Leg Drain Nozzle & $100 \%$ & $100 \%$ \\
Charging Inlet Nozzle & $100 \%$ & $100 \%$ \\
Safety Injection Nozzle & $94.3 \%$ & $26.6 \%$ \\
Shutdown Cooling Nozzle & $98 \%$ & $100 \%$ \\
Spray Nozzle & $100 \%$ & $100 \%$ \\
PZR Surge Nozzle & $100 \%$ & $100 \%$ \\
PZR Spray Nozzle & $100 \%$ & $68.9 \%$ \\
PZR Safety Nozzle & $100 \%$ & $100 \%$ \\
\hline RCP - reactor coolant pump; RC - reactor coolant; PZR - pressurizer \\
\hline
\end{tabular}

Inspection limitations exist for welds adjacent to cast stainless steel products. Since Appendix VIII, Supplement 9 requirements for examination of CSS piping welds have yet to be developed, there are no performance demonstration qualifications being performed for inspection of cast materials. Some NRC guidance on performing examinations of welds adjacent to cast stainless steel products is contained in the summary of the July 12, 2011, public meeting (Collins 2011) in the response to Question 31. The public meeting was held by the NRC to discuss implementation of Code Case N-770-1 (Collins 2011). Additional guidance may be found in the summary of the NRC public meeting with the PWROG on January 10, 2012. This meeting was held to discuss an industry template for a generic relief request from the requirements of Code Case N-770-1, as conditioned by the NRC (Rowley 2012). Consistent with the requirements of $-2500(\mathrm{~b})$ of the Code Case, this NRC guidance stipulates that $100 \%$ of the susceptible material volume (non-stainless steel volume) is to be examined with a qualified Appendix VIII procedure 
and the cast stainless steel portion of the required examination volume is to be examined to the maximum extent practical using an Appendix VIII procedure. Inspection limitations would be reviewed as part of the NRC process for authorizing the installation of WOLs.

ASME Section XI is preparing draft Code Case N-824, entitled, "Alternate Requirements for Ultrasonic Examination of Cast Austenitic Piping Welds from the Outer Diameter Surface." The requirements in this draft Code Case are deterministic rather than performance-based. However, this Code Case is considered to be a first step in the development of Supplement 9. NDE reliability would be expected to be improved by applying this Code Case in situations where $100 \%$ of the susceptible material cannot be examined from the ferritic side of the weld.

Research conducted by the NRC Office of Nuclear Regulatory Research on inspection of cast stainless steel demonstrated that the Appendix III UT techniques are inadequate when applied to cast materials. However, some of the techniques used during Appendix VIII qualifications may perform well on cast stainless steels, especially for thinner-walled cast stainless steel. NRC research has shown that, for piping less than approximately 4 to $5.1 \mathrm{~cm}$ (1.6 to $2.0 \mathrm{in}$.) in thickness, refracted longitudinal waves (transmit-receive L-waves) operating at frequencies between 0.8 and $2.0 \mathrm{MHz}$, work fairly well. Much lower frequency ranges, on the order of 0.4 to $1.0 \mathrm{MHz}$, are needed for primary system cast stainless steel piping (greater than $5.1 \mathrm{~cm}$ [2.0 in.] in thickness). To date using these frequencies, inspections can reliably detect flaws in the $25 \%-30 \%$ through-wall range. Additional information is contained in NUREG/CR-6933, Assessment of Crack Detection in Heavy-Walled Cast Stainless Steel Piping Welds Using Low-Frequency Ultrasonic Methods (Anderson et al. 2007). NUREG/CR-7122, An Evaluation of Ultrasonic Phased Array Testing for Cast Austenitic Stainless Steel Pressurizer Surge Line Piping Welds. (Diaz et al. 2011) provides information on crack detection with UT in thinner-walled cast stainless steel. The information in these NUREGs should be helpful to industry in improving the reliability of inspections and to NRR in evaluating relief requests and inspection-related issues involving cast stainless steel.

\subsection{NDE Reliability Conclusions}

The reliability of NDE is of interest to welds mitigated by weld overlays for several reasons. Pipe welds to be mitigated by optimized weld overlays are required to be inspected immediately prior to the overlay application, using an inspection technique qualified in accordance with ASME Section XI, Appendix VIII, and found to exhibit no evidence of cracking greater than $50 \%$ of the wall thickness in the original weld. Undetected or mischaracterized flaws could compromise the structural factors required for OWOLs. Reliable NDE is also of interest for pipe welds to be modified by FSWOLs. If a pre-FSWOL inspection is performed, the initial flaw size for the crack growth calculation is based on the results of the pre-FSWOL inspection. The calculated life of the FSWOL depends, in part, upon the reliability of the NDE performed.

PNNL held a workshop in May 2012 with LMT, Inc., a commercial nuclear NDE vendor, to review UT data from service-induced flaws and to discuss factors that affect the reliability of various NDE techniques qualified in accordance with Section XI. The conclusions of this workshop, which relate to inspection of pre-mitigated piping welds, indicate the following areas of concern. 
In assessing the overall reliability of the subject examinations to detect and accurately characterize service-induced SCC, there are a number of factors that must be considered. These include:

- ability of the applied NDE to obtain full coverage of the required inspection volume,

- presence of interfering signals such as from geometric reflectors,

- use of non-encoded versus encoded techniques,

- general reflectivity of the service-induced flaw,

- acoustic impedance of the materials being examined and the signal attenuation and dispersion through those materials,

- relative experience and skill of the examiner (and/or data analyst),

- use of modeling to design examination parameters, and

- representativeness of mockups used for performance demonstration qualifications.

Given these factors and the constraints of field conditions involving UT inspection of RCS DMWs, the use of encoded UT techniques offers a distinct and significant advantage over non-encoded techniques in detection and characterization of flaws, because of the ability to review the UT data off-line and carefully determine the origin of the signals present in the images produced.

Current mock-ups and protocols used by industry during the PDI qualification process may not provide sufficient opportunities such that candidates may demonstrate adequate skills for interpreting realistic false call signals from non-crack reflection sources that may be encountered in the field; for example, fabrication flaws, weld root response variations, or other geometrical/metallurgical responses. Thus, examiners may pass the PDI qualification process without sufficiently demonstrating the ability to distinguish ID connected flaws from other signals that may be expected to be present in a weld inspection volume, especially in DMWs.

The reliability of NDE of post-WOL welds is also important for determining whether any new flaws have initiated or existing flaws have propagated, and for assessing the effect of any potential flaws on the service life of the weld. In this regard, PNNL performed an ultrasonic NDE study to investigate the inspectability of weld overlay specimens, one with four shallow circumferential flaws (13\% to $31 \%$ through-wall) and one with five circumferential flaws (50\% to $90 \%$ through-wall). To conduct this study, thermal fatigue cracks were implanted in two DMW specimens. The specimens were composed of a cast austenitic stainless steel pipe welded to a carbon steel nozzle with Alloy 82/182 weld material. Each specimen was evaluated with phased-array ultrasonic testing to determine flaw detection and characterization capabilities. A nickel alloy WOL was added to the specimens, and they were again evaluated ultrasonically for flaw detection and characterization. This study produced the following results.

- All targeted flaws were detected in the pre- and post-WOL condition, based on the varied scans applied. The DMW specimens were examined from the nozzle and the CASS pipe side with both raster and line scans using four PA probes in the 0.8 - to $2.0-\mathrm{MHz}$ frequency range, although not every combination of scan, scan direction, and frequency was used to examine each flaw. 
- When time-of-flight tip-diffraction sizing methods (when tip signals were available) were performed, pre- and post-WOL depth-sizing root mean square error (RMSE) for both the raster and line scan data were found to be within the ASME depth sizing qualification acceptance criterion of $3.2 \mathrm{~mm}$ ( 0.125 in.). Only sizing errors for the flaws that were greater than or equal to $50 \%$ of the original material were considered because these flaws are contained within the required inspection volume for OWOLs.

- The pre- and post-WOL length-sizing RMSE values were found to be within the ASME length sizing qualification acceptance criterion of $19.1 \mathrm{~mm}(0.75 \mathrm{in}$.). The sizing error for the flaws that were greater than or equal to $50 \%$ of the original material was measured for the ID surface-breaking length.

Inspection limitations can affect the effectiveness of NDE requirements. The following issues were identified during a brief assessment of WOL inspection limitations.

- The criteria of Code Case N-770-1, Appendix I, Paragraph 5 require that a qualified pre-WOL examination be performed before the application of an OWOL. Any departure from these requirements of Code Case N-770-1, Appendix I because of pre- or post-WOL inspection limitations beyond those permitted by Code Case N-770-1, as imposed by $\S 50.55 \mathrm{a}(\mathrm{g})(6)(\mathrm{ii})(\mathrm{F})$, have to be evaluated and an alternative examination authorized by the NRC staff.

- Geometry or access may limit performing a complete pre-WOL weld examination. Information on limitations to performing inspections of typical Westinghouse and CE plant RCS Alloy 82/182 welds was obtained from LMT, Inc., an inspection vendor for the commercial nuclear power industry. Appendices $\mathrm{C}$ and $\mathrm{D}$ to this report contain weld coverage assessment diagrams that show the probe angles used and percent coverage obtained with Section XI, Appendix VIII, qualified techniques. CRV coverage was achievable for many, although not all, Westinghouse and CE Alloy 82/182 butt welds.

- Inspection limitations exist for welds adjacent to CSS products and there are no qualification requirements in Appendix VIII for inspection of cast piping welds. Code Case N-770-1 requires that the examination volume to be examined by Appendix VIII procedures to the maximum extend practical including $100 \%$ of the susceptible material volume. ASME Section XI is preparing draft Code Case N-824, entitled, "Alternate Requirements for Ultrasonic Examination of Cast Austenitic Piping Welds from the Outer Diameter Surface." NDE reliability would be expected to be improved by applying this Code Case in situations where $100 \%$ of the susceptible material cannot be examined from the ferritic side of the weld. 



\subsection{ASME Code Case N-770-1 Requirements}

\subsection{Background}

LBB evaluations and approvals did not depend directly upon the ongoing ISI program, because the qualitative screening evaluation of SRP 3.6.3 relied upon the results of past ISI and other monitoring programs to exclude welds from LBB consideration that were known to be susceptible to corrosion. The quantitative fracture mechanics analysis of SRP 3.6.3 did not depend upon ISI and no additional ISIrelated requirements or conditions were placed upon the LBB approvals. Furthermore, not all welds in piping systems approved for LBB were fully inspectable in accordance with ASME Code requirements.

NDE of welds has been relied upon for defense-in-depth except in cases where welds are known to be susceptible to degradation. When a degradation mechanism, such as PWSCC, is determined to be active, the role of NDE has to be shifted from defense-in-depth to being relied upon to help maintain the design bases.

After the events at V.C. Summer and Ringhals in 2000, the NRC began to evaluate the adequacy of the inspection requirements for Alloy 82/182 butt welds in the ASME Code, Section XI. Also, the NRC started considering the potential impact of these events on LBB.

The U.S. nuclear industry undertook certain activities to address PWSCC in Alloy 82/182 butt welds. Those activities included performing growth rate studies and undertaking an initiative known as Nuclear Energy Institute (NEI) 03-08, "Guideline for the Management of Materials Issues" (NEI 2003). This initiative established policy, direction, oversight, and support for industry programs involving the management of materials issues. The initiative committed each nuclear utility to adopt the responsibilities and processes described in NEI 03-08.

In September 2005, EPRI issued MRP-139, "Materials Reliability Program: Primary System Piping Butt Weld Inspection and Evaluation Guideline" (EPRI 2005c). In accordance with NEI 03-08, all PWR plants agreed to implement these guidelines. MRP-139 provided industry guidance for the volumetric and visual inspections of Alloy 82/182 butt welds in PWR primary systems. The MRP-139 inspections augmented inspections of these locations already required by Section XI of the ASME Code.

The industry actions to develop and implement the MRP-139 inspections allowed the NRC staff to pursue a process to codify new requirements. The ASME Code requirements for inspection of Alloy 82/182 butt welds were not considered frequent enough to ensure that ASME Code-allowable limits would continue to be met in the event that PWSCC initiates. The NRC staff concluded that the approach of working with ASME to revise inspection requirements and subsequently revise $\$ 50.55 \mathrm{a}$ was both necessary and in the best interest of protecting public health and safety. ASME Code inspection requirements, incorporated by reference to $\$ 50.55 \mathrm{a}$, provide a regulatory foundation for ensuring the integrity of pressure-retaining components.

In 2006 ASME approved the development of an ASME Code Case (Code Case N-770) on appropriate inspection requirements to address PWSCC in Class 1 butt welds containing Alloy 82/182. ASME Code Case N-770 was approved by ASME on January 30, 2009, and was published in Supplement 8 of the 2007 Edition of the ASME Boiler and Pressure Vessel Code Nuclear Code Cases book. The title of 
ASME Code Case N-770 is, "Alternative Examination Requirements and Acceptance Standards for Class 1 PWR Piping and Vessel Nozzle Butt Welds Fabricated with UNS N06082 or UNS W86182 Weld Filler Material With or Without the Application of Listed Mitigation Activities, Section XI, Division 1" (ASME 2009b).

Code Case N-770 was revised in response to a number of issues raised by the NRC. Code Case N-770-1 (ASME 2009a) was approved by the ASME in December 2009. On June 21, 2011, the NRC issued a final rule (76 FR 36232, p. 36278) incorporating ASME Code Case N-770-1 into the regulations by reference. The new rule is contained in $\$ 50.55 \mathrm{a}(\mathrm{g})(6)(\mathrm{ii})(\mathrm{F})$ and imposes Code Case N-770-1 with ten conditions the NRC concluded were necessary to provide adequate protection of the public health and safety.

Code Case N-770-1 requires the performance of UT qualified in accordance with Section XI, Appendix VIII, coupled with certain visual and surface examinations, to be performed at specified intervals. By imposing Code Case N-770-1, with conditions, the NRC concluded that the revised rule would ensure that potential PWSCC would be detected before pressure boundary integrity could be seriously challenged. At this time, the NRC has not issued any separate or supplemental requirements for Alloy 82/182 butt welds in piping systems approved for LBB. Based on NRC's safety basis for incorporating Code Case N-770-1 by reference into the regulations, adoption of these inspection requirements, in conjunction with NRC approval of weld mitigation techniques, where applicable, is necessary to ensure that ASME Code-allowable limits will not be exceeded and PWSCC will not lead to leaks or ruptures of piping welds.

Section 4.2 contains an overview of the Code Case N-770-1 requirements. A detailed assessment of these requirements, as imposed by the NRC, is provided in Appendix B. Appendix B.1 contains an assessment of the WOL-related requirements of Code Case N-770-1 and Appendix B.2 contains an assessment of the NRC implementing requirements; that is, the conditions imposed by $\S 50.55 \mathrm{a}(\mathrm{g})(6)(\mathrm{ii})(\mathrm{F})$. Appendix B contains a discussion of three recommendations for changes to the WOL-related requirements of Code Case N-770-1. These recommendations are also summarized in Section 4.2.

\subsection{Overview of Code Case N-770-1}

ASME Code Case N-770-1 provides examination methods, volumes or areas, and frequencies for Alloy 82/182 butt welds that are unmitigated as well as for Alloy 82/182 butt welds that have been mitigated against PWSCC by one of several specified mitigation methods. The requirements of this Code Case pertain to inspections to detect PWSCC. Other ASME Code, Section XI, requirements continue to apply to Alloy 82/182 (or Alloy 52/152) welds to monitor for other potential degradation mechanisms, such as fatigue. Code Case N-770-1 contains baseline and ISI requirements for unmitigated Alloy 82/182 butt welds and preservice and ISI requirements for mitigated Alloy 82/182 butt welds. The structure of Code Case N-770-1 is patterned after the requirements of Section XI, Subsection IWB. The Code Case has requirements in Sections -1000, -2000, and -3000 that parallel the requirements in Subsection IWB$1000,-2000$, and -3000 . Pressure test requirements are unaffected by the Code Case so there are no -5000 requirements in the Code Case. The examination requirements are contained in Table 1 of the Code Case in the -2000 section. Inspection Items in Table 1 are assigned for each "type and condition" of component. Inspection Items in the Code Case are similar to Examination Categories and Item Numbers 
used in the Section XI, Table IWB-2500-1. The "type and condition" of component refers to:

(1) unmitigated welds at three different service temperatures addressed by Inspection Items A-1, A-2, and B; and (2) cracked and uncracked welds, mitigated by one of several specified methods addressed by Inspection Items $\mathrm{C}$ through $\mathrm{K}$. The Code Case includes various figures needed to implement the examination requirements.

Table 1 contains the examination requirements and includes the parts examined, the examination volumes and surfaces shown in figures, examination methods, references to acceptance standards, extent and frequency of examination, and rules regarding deferral of the examination to the end of the interval. In Code Case N-770-1, Table 1 includes 18 explanatory notes that contain additional requirements. These notes are necessary because of the range of weld types and conditions covered by the Case.

As discussed in Appendix B.1, the examination requirements of Table 1 and the notes to Table 1 provide a set of comprehensive inspection requirements that parallel existing Section IWB Class 1 requirements. The Code Class 1 butt weld examination requirements of Section XI were based on a defense-in-depth philosophy for monitoring welds to ensure that the welds were not experiencing an active degradation mechanism. For consistency with this approach, the NRC imposed a number of additional conditions it believed necessary to appropriately monitor and assess the condition of these welds over their design life. These conditions are discussed in detail in Appendix B.2.

Code Case N-770-1 reflects the full range of ASME Code requirements that apply to other ASME Code Class 1 components. They deal with scope, baseline examination, preservice examination, inservice examination schedules, successive and additional examinations, examination requirements, and acceptance standards for the various types of examinations and resulting conditions that might arise. ASME adopted a WOL inspection frequency requirement of once per interval. The Code Case permits both FSWOLs and OWOLs to be placed into 25\% inspection samples, although, as discussed below, an NRC condition precludes inspection sampling of OWOLs. The once-per-interval inspection frequency reflects an implicit conclusion by the ASME, and, in imposing the Code Case, by the NRC that WOL techniques result in effective mitigation and that inspection of WOLs serves a defense-in-depth monitoring function rather than a degradation management function. The WOL-related conditions in the rule that imposed Code Case N-770-1 are conditions (F)(1), (2), (4), (6), (8), (9) and (10), which are discussed in detail in Appendix B.2. These conditions, which are over and above the Code Case requirements, were imposed by the NRC to ensure that the level of quality and safety provided by the requirements for WOLs is consistent with that provided by existing ASME and NRC requirements for butt welds in Code Class 1 systems that are not susceptible to PWSCC. The effectiveness of WOLs is discussed further in Section 5.0.

A discussion of two issues identified in the assessment in Appendix B of ASME Code Case N-770-1, as currently implemented, follows.

The first issue relates to the ability of a surface examination to detect cracks, because WOLs may decrease or eliminate the UT response of cracks. Notes (6)(b) and (12)(e) permit cold-leg nozzles mitigated by FSWOLs and OWOLs, respectively, to forego a pre-WOL examination provided that a postWOL preservice UT and surface examination is performed. The surface examination shall be performed on the butt weld inside surface, extent E-F of Fig. 1 (of the Code Case), and shall consist of an eddy current examination in accordance with IWA-2223. IWA-2223 requires that eddy current examination 
(ET) be conducted in accordance with Appendix IV. Appendix IV contains demonstration requirements only and allows the demonstrations to be performed on cracks. Since WOLs may decrease or eliminate the UT response of cracks, the ability of the surface examination to detect cracks takes on greater significance. Code Case N-773 contains ET performance demonstration requirements that may be used in lieu of Appendix IV, Supplement 2 when ET is used to complement UT performed on the inside surfaces of austenitic, DMW, and clad piping welds. Qualification of ET procedures and personnel by performance demonstration would increase the reliability of ET examination.

The second issue stems from the fact that ultrasonic procedures currently qualified via Appendix VIII, Supplement 10 for examining welds from the ID surface are limited to detection only, as depth sizing of flaws has not been adequately demonstrated. Note (8)(c) on inservice inspection of FSWOLs allows the examination volume of an unmitigated weld (Fig. 1 of the Code Case) to be used as an alternative to the examination volume of Note (8)(a), the overlay and the outer $25 \%$ of the original weld. This provision is in recognition that nozzle weld examinations may be performed from the ID. Note (8)(c) also specified that if cracking is detected beyond the examination volume of an unmitigated weld, that is, beyond the inner $1 / 3$ of the original weld, the examination of Note (8)(a) shall be performed and acceptance criteria of Note (8)(b) shall be used to determine the acceptability of the weld overlay. Note (8)(c) cannot be applied without regulatory approval, because there are currently no Appendix VIII, Supplement 10 procedures to examine welds from the ID that are qualified for depth sizing flaws in welds. In addition, as stated in the NRC staff's safety evaluation for MRP-169 (Blount 2010), "Existing inside surface examination procedures ... will require additional demonstration or qualification on weld overlay mockups to demonstrate that inside diameter connected flaws are still detectable after application of the overlay and the associated compressive stresses." This statement means that if personnel, equipment, and procedures are used to examine overlaid welds from the ID, they will have to be demonstrated in accordance with Appendix VIII requirements on specimens with ID-connected flaws to which overlays have been applied. NRC may want to address this issue raised on a licensee's potential use of Note (8)(c) in its reviews of applications to apply weld overlays to reactor vessel nozzle DMWs. This issue also applies to Note (13)(c) on inservice inspection of OWOLs.

Finally, it is recommended that operating experience and the tools developed under the xLPR, Version 2.0 project be used to reevaluate the sample examination provision of the Inspection Item $\mathrm{D}$ and E requirements and conclusions regarding the adequacy of WOLs for satisfying the requirements of GDC-4. 


\subsection{Evaluation of the Effectiveness of WOLs as a Mitigation Technique}

To provide effective mitigation against PWSCC, the mitigation technique should be able to satisfy the following factors. These factors are based on the criteria in Appendix I to ASME Code Case N-770-1.

- The mitigation technique has to minimize the likelihood of crack initiation.

- The effect on the susceptible weld material produced by the mitigation process has to be permanent.

- The capability to perform UT of the required inspection volume of the component cannot be adversely affected by the mitigation.

- The mitigation process cannot have degraded the component or adversely affected other components in the system.

- The mitigated weld has to be inspectable by a qualified process.

- Existing flaws, if any, have to be addressed as part of the mitigation.

- The effect of the mitigation on any existing flaws has to be analyzed.

\subsection{Crack Initiation}

As discussed in Sections 2.1 and 2.2, BCL showed from various analyses they conducted that application of a WOL led to significant reductions in axial and hoop residual stresses. The amount of reduction in WRS depended, in part, upon whether a secondary stainless steel weld was present, because the secondary weld tends to introduce compression into the DMW. In all the cases analyzed, the axial and hoop stresses at the inner surface after application of a WOL were compressive at operating temperature and pressure. In the RCP outlet nozzle weld, for example, the FSWOL lowered the inside surface axial stresses at the butter/ferritic steel interface from $480 \mathrm{MPa}(70 \mathrm{ksi})$ tension to $200 \mathrm{MPa}$ (30 ksi) tension while an OWOL applied to the RCP outlet nozzle weld reduced the stresses at this location to approximately $70 \mathrm{MPa}(10 \mathrm{ksi})$ tension. These post-overlay, inside surface axial stresses along the length of the DMW were further reduced into compression with the application of the operating temperature and pressure. Figure 62 from the BCL report (Fredette and Scott 2010) shows RCP outlet nozzle axial stress values after the operating pressure and temperature are applied. Figure 62 shows that both the OWOL and the FSWOL at operating pressure and temperature reduce the axial stresses in the Inconel weld area to be completely in compression. The OWOL and FSWOL results are very similar in the Inconel weld area with the OWOL giving better results by about $69 \mathrm{MPa}(10 \mathrm{ksi})$. The hoop stresses in this nozzle weld after application of operating temperature and pressure are also compressive.

Phase IV of the NRC/EPRI WRS validation program compared measured and predicted weld residual stress profiles through the dissimilar metal weld region of a cold-leg nozzle removed from a cancelled plant in the United States. The DMW had already been completed on the nozzle before use in the mockup program. A partial arc weld repair was made in a $30^{\circ}$ circumferential arc $25 \%$ through the thickness of the dissimilar metal weld from the inner diameter to simulate an assembly repair as part of the mockup process. The mockup was completed with the application of the stainless steel safe-end weld to a section of stainless steel pipe. Once the standard nozzle configuration was completed, an OWOL was placed on top the DMW. Weld residual stress measurements were taken in the DMW of the nozzle with 
and without the optimized weld overlay. WRS measurements were made in the weld repair area as well as $180^{\circ}$ from the weld repair area. Also, several independent finite element analysis predictions were made of the stress state in the DMW. This report compares the predicted stresses to those found by through-thickness measurement techniques (DHD and iDHD). The measurements confirm that the axial and hoop stress measurements made after application of an OWOL are compressive or low tensile values. Analysis results show that these stresses are lowered when evaluated at operating pressure and temperature conditions.

Code Case N-754 on design, installation, examination, and testing of OWOLs states that: the minimum thickness of the OWOL shall be sufficient to reduce residual stresses to less than $69 \mathrm{MPa}$ (10 ksi) tensile at operating temperature and pressure on the internal wetted surface of all SCCsusceptible materials. This requirement is not included in Code Case N-740 on FSWOLs. Based on the analyses performed by BCL, WOLs generally result in weld ID axial stresses at or below $69 \mathrm{MPa}$ (10 ksi). Similar results were obtained for weld ID hoop stresses. It is important to keep in mind that variations in WRS are likely to occur between calculated and measured results. While not all WOL analyses may show ID stress values less than $69 \mathrm{MPa}(10 \mathrm{ksi})$, it is clear from the BCL analyses that WOLs produce compressive stresses within the inner regions of the pipe wall and result in weld residual stresses at the ID that are compressive or substantially reduced tensile stresses. Also, the authors of this report are not aware of any cases where flaws have been found to initiate after application of a WOL. Therefore, it is reasonable to conclude that WOLs minimize the likelihood of PWSCC initiation.

\subsection{Permanent Mitigation}

To address the criterion that mitigation must be permanent, PNNL obtained the following information from BCL.

"The operating stresses are generally low in comparison to the (post-WOL) weld residual stresses. The (BCL) analysis models that include operating stresses and temperatures also include any effect on the WOL due to subsequent yielding at those loads. They show that the WOL continues to function with those stresses and temperatures applied. In fact, in most cases, the reduction of ID axial stress due to the WOL is further reduced by the addition of operating temperature. In the hoop direction, the hoop stress at the ID increases due to operating loads and temperatures, but only by about the same amount that it would have without the WOL, and it has the benefit from starting out at a lower stress state, so the same improvement remains.

"Also, if there is any small area of yielding with the first cycle of operating temperature and pressure, this will act like a proof test in which no yielding will occur on subsequent cycles to that same load point. This means that there are no cyclic fatigue issues. Any change in the residual stress state should be captured in the analysis of that first cycle which doesn't show degradation."(a)

Long-duration creep data for typical stainless steels is not available for temperatures below $538^{\circ} \mathrm{C}$ $\left(1000^{\circ} \mathrm{F}\right)$, which is well above the upper limit of the typical operating temperature for the PZR nozzles;

(a) Fredette LF. 2012. Email to Edmund Sullivan. RE: Battelle 2010 Report on weld overlays. Battelle Columbus Laboratory, Columbus, Ohio. March 12, 2012. 
that is $343^{\circ} \mathrm{C}\left(650^{\circ} \mathrm{F}\right)$. Furthermore, Paragraph NB-1120 (Temperature Limits) of Section III of the ASME Code states: "The rules of Subsection NB shall not be used for items which are to be subjected to metal temperatures that exceed the temperature limit in the applicability column shown in Section II, Part D, Subpart 1, Tables 2A, 2B, and 4 for design stress intensity values. Above these temperatures, the creep and stress rupture characteristics of materials permitted to be used become significant factors which are not presently covered by the rules of this Subsection." The temperature limits specified in Section II are typically $371^{\circ} \mathrm{C}\left(700^{\circ} \mathrm{F}\right)$ for ferritic and low alloy steels and $427^{\circ} \mathrm{C}\left(800^{\circ} \mathrm{F}\right)$ for austenitic and nickelbased alloys, which again are above the upper limit on the operating temperature for the PZR nozzle dissimilar metal welds. Creep effects on the deformation produced by WOLs would be expected to be negligible (Fredette and Scott 2009). Notwithstanding,

"if any creep were to occur over a very long time that would cause the effect of the WOL to fade over time (like a very long heat treatment to relieve stresses), one would expect the original weld residual stresses to also fade over time at the same rate. The final stress state would go to zero residual stresses which wouldn't be a problem either."(a)

The final stress state would go to zero residual stresses, which would be favorable from a crackinitiation and propagation point of view.

Therefore, it is reasonable to conclude that the effect on the susceptible weld material produced by WOLs is permanent.

\subsection{Capability to Perform UT}

This criterion states that the capability to perform UT of the required inspection volume of the component cannot be adversely affected by the mitigation. WOLs are inherently inspectable. WOLs create a new platform from which to perform inspections. In this sense, WOLs in most cases eliminate inspection limitations that arise from nozzle geometry, contours, and tapers. Supplement 11 was developed to provide qualification requirements for the required inspection volume of FSWOLs and techniques have been qualified to perform these inspections. Since Supplement 11 does not specifically address qualification of inspections for OWOLs, the ASME Code, Section XI has been developing ASME Code Case N-653-1, "Qualification Requirements for Overlaid Piping Welds." Until this Code Case is approved by the ASME and incorporated in the regulations by the NRC, licensee's must obtain authorization, and the NRC staff has indicated that it will review the inspection qualifications for OWOLs as part of the process for authorizing the installation of OWOLs and the subsequent use of the inspection frequencies in Code Case N-770-1. It is reasonable, therefore, to conclude that the capability to perform UT of the required inspection volume for WOLs is assured.

\subsection{Effect on Other Components}

Code Cases N-740 and N-754 on design, installation, examination, and testing of FSWOLs and OWOLs, respectively, contain the following requirement:

(a) Fredette LF. 2012. Email to Edmund Sullivan. RE: Battelle 2010 Report on weld overlays. Battelle Columbus Laboratory, Columbus, Ohio. March 12, 2012. 
"The effects of any changes in applied loads, as a result of weld shrinkage from the entire weld overlay, on other items in the piping system (e.g., support loads and clearances, nozzle loads, and changes in system flexibility and weight due to the weld overlay) shall be evaluated. Existing flaws previously accepted by analytical evaluation shall be evaluated in accordance with IWB-3640."

Because the WOL Code Cases contain applicable requirements and ASME Code acceptance criteria, and because these Code Cases form the basis for requests for NRC approval to install WOLs, it is reasonable to conclude that the designs for mitigation by WOLs address the effects of the mitigation on other components in the system.

\subsection{Inspectable by a Qualified Process}

ASME Code Case N-770-1 requires that UT inspections meet the applicable requirements of Section XI, Appendix VIII. Pre-WOL inspections are required for OWOLs and are optional for FSWOLs. Pre-WOL inspections would be performed in accordance with Appendix VIII, Supplements 9 and 10. Supplement 9 is for inspection of cast austenitic piping welds and is in the course of preparation. Supplement 10 is required to be used for dissimilar metal piping welds. A discussion of the limitations to complete inspection coverage because of access or geometric limitations or cast austenitic material adjacent to the DMW is contained in Section 3.3. Each case involving an inspection limitation that results in not satisfying the requirements of Code Case N-770-1, as imposed by $\S 50.55 \mathrm{a}(\mathrm{g})(6)(\mathrm{ii})(\mathrm{F})$, would be expected to result in a request for relief and an evaluation by the NRC. The acceptance criteria to authorize alternative inspection requirements is contained in $\$ 50.55 \mathrm{a}(\mathrm{a})(3)(\mathrm{i})$ or (ii). Based on NRC staff review of cases involving serious inspection limitation, it is reasonable to conclude that WOLs are inspectable by a qualified process or by an acceptable alternative authorized by the NRC.

\subsection{Address Existing Flaws}

This criterion states that existing flaws, if any, have to be addressed as part of the mitigation. As discussed in Section 1.0, the design requirements for overlays include provisions for inspections of weld overlays to determine whether any flaws are present in the weld prior to application of the overlay. With the exception allowed for cold-leg reactor vessel nozzle welds, UT examinations have to be performed prior to the application of OWOLs. After the application of an OWOL, a UT examination has to be performed as a baseline and to confirm that no flaws are located within the required inspection volume. FSWOLs do not have to be examined prior to the application of overlays. If a pre-FSWOL examination is performed and no flaws are found, the weld may be categorized as uncracked for the purpose of future examinations. If a pre-FSWOL examination is not performed, the weld overlay is assumed to be cracked and is classified Inspection Item F. A post-overlay examination has to be performed to determine whether any flaws are present within the required examination volume of the overlay and the outer $25 \%$ of the original weld.

A potential concern with the presence of flaws prior to application of a weld overlay is the possibility that a flaw is missed. For FSWOLs, if a shallow flaw were present in the pipe butt weld, through-wall flaw growth would likely be arrested by the compressive stress field introduced as a result of applying the WOL. If a deep flaw were missed during a pre-FSWOL examination, the pre-service examination after the FSWOL has been applied presents a second opportunity to detect the flaw. If the flaw is missed 
during the pre-service examination, there is a chance that the weld overlay would not be examined again because Code Case N-770-1 permits these welds to be placed into a population to be examined on a $25 \%$ sample basis. If a pre-FSWOL examination is not performed, Code Case N-770-1 requires two examinations - a pre-service examination and one inservice examination, separated by at least one fuel cycle - to be performed before the weld can be placed into a $25 \%$ sample population. In the unlikely event that deep pre-existing flaws are missed by each of the two required UT examinations, an undetected deep flaw would likely not challenge the structural integrity of the piping because the design basis flaw for a FSWOL is $100 \%$ through the original weld thickness; as previously stated, the flaw would likely arrest at the butt weld-FSWOL interface and not propagate into the WOL.

Similarly for OWOLs, if a shallow flaw were present, the flaw would also likely be arrested by compressive stresses resulting from the WOL application. If a deep flaw were missed during the preOWOL examination, the pre-service examination presents a second opportunity to detect the flaw. If the unlikely event that a flaw is missed by both the pre-OWOL examination and the pre-service examination, OWOLs have to be inspected once per interval in accordance with NRC condition $\S 50.55 \mathrm{a}(\mathrm{g})(6)(\mathrm{ii})(\mathrm{F})(8)$. As noted in Section 2.2, "Industry's sensitivity analyses demonstrated that OWOLs are capable of maintaining structural integrity even under the beyond-design-basis condition of a postulated flaw $360^{\circ}$ around the circumference and 100\% through the original pipe wall."

Based on the preceding, it would be reasonable to conclude that the requirements of mitigation by WOL address the possibility of pre-existing flaws. Multiple inspections are required and provide a high probability of detecting any pre-existing flaws. If there are no significant limitations to inspection coverage, it is unlikely that pre-existing flaws would go undetected. Limitations that prevent complete inspection coverage have to be reviewed by the NRC to ensure that alternative inspections satisfy regulatory criteria. Nevertheless, even if flaws were to propagate through the original weld thickness, WOLs provide reinforcement sufficient to maintain structural integrity under design-basis loading, although for OWOLs not necessarily to the factors required by the ASME Code.

\subsection{Analyze Existing Flaws}

This criterion states that the effect of the mitigation on any existing flaws has to be analyzed. Code Case N-740 for FSWOLs and Code Case N-754 for design of OWOLs require that the size of all flaws detected be used to define the life of the overlay. Requirements for structural design and sizing of overlays are required to satisfy ASME Code Section XI, IWB-3640. These requirements combined with the requirements of the preceding criterion to address existing flaws ensure that the effect of the mitigation on any existing flaws is analyzed and that existing flaws satisfy ASME criteria on crack growth and stability.

\subsection{Conclusions for WOL as a Mitigation Technique}

As noted above, to provide effective mitigation against PWSCC, the mitigation technique should be able to satisfy the seven factors or criteria contained in Appendix I to ASME Code Case N-770-1. The preceding discussion of these seven factors or criteria provides an evaluation of the effectiveness of WOLs to mitigate the effects of PWSCC. It is clear that WOLs produce significant compression in the inner regions of the pipe wall and result in weld residual stresses at the ID that have compressive or substantially reduced tensile stresses. This effect minimizes the possibility that flaws would initiate in an 
overlaid weld. Based on creep properties of the materials involved, the operating temperature of WOLs, and analyses BCL performed showing that re-yielding does not occur on subsequent loading, the WOL mitigation method is expected to be permanent. Analyses are required to be performed on the effect of WOLs on other components in the system and ASME Code criteria are required to be satisfied. Weld overlays are required to be examined by a qualified process and WOLs tend to provide an improved platform for performing examinations. Any flaw detected must satisfy the structural factors required by the ASME Code, Section XI, under all postulated loading conditions. Limitations that prevent complete inspection coverage have to be reviewed by the NRC to ensure that alternative inspections satisfy regulatory criteria. Nevertheless, even if flaws were not detected and propagate completely through the original weld thickness, WOLs provide reinforcement sufficient to maintain structural integrity under design-basis loading. Under these conditions OWOLs satisfy safety factors required by SRP 3.6.3 for LBB, although not necessarily the factors required by the ASME Code. On this basis, it is reasonable to conclude that WOLs provide effective mitigation against PWSCC.

Regarding the effectiveness of WOLs for LBB welds, it is believed this mitigation process may provide an effective means for preventing the initiation of new cracks. To address uncertainties regarding growth of pre-existing flaws that may be present, or the unlikely potential of initiating new cracks, a set of comprehensive examination requirements for monitoring the condition of WOLs throughout their service life is contained in Code Case N-770-1, as imposed by NRC. These inspection requirements parallel existing Section IWB, Class 1, requirements and are consistent with or more conservative than the requirements in the ASME Code, Section XI, for Class 1 welds. For this monitoring to perform as intended, effective and reliable NDE must be applied. In the unlikely event that flaws through the thickness of the original weld are not detected, it has been shown that WOLs are capable of maintaining structural integrity under design-basis loading. This layered approach is expected to address the qualitative screening criteria in SRP 3.6.3 regarding corrosion. Although not discussed further in this report, a licensee's WOL design is expected to address the regulatory requirements discussed in RIS 2010-07 (NRC 2010) for demonstrating that the flaw tolerance analysis provisions of SRP 3.6 .3 are met for WOLs. On the basis of this evaluation, mitigation by WOL addresses the qualitative and quantitative screening criteria in SRP 3.6.3 and would be expected to preclude PWSCC from being a potential source of pipe rupture. 


\subsection{Overall Assessment}

This report provides an assessment of the effectiveness of WOLs for mitigating PWSCC in LBB systems. The authors focused on four key areas related to weld overlays; namely, (1) weld residual stress and crack growth analyses performed during the design phase, (2) the reliability of pre- and post-WOL NDE, and (3) ASME Code Case N-770-1 examination requirements, with conditions, as imposed by $\mathrm{NRC}$, and (4) the overall effectiveness of WOLs as a mitigation technique.

Based on the results of the WRS analyses, the full structural weld overlay technique, if properly designed and implemented, is effective in producing compressive or low tensile values of axial and circumferential weld residual stresses in the inner region of welds, thereby minimizing the likelihood of initiation of PWSCC in Alloy 82/182 DMWs. The results of the WRS analyses for the geometries considered indicate that the OWOL design is also an effective technique for mitigating PWSCC in PWRs. For the case considered (i.e., the cold-leg/RCP outlet nozzle geometry), the stresses after application of the OWOL were at, or in some cases below, those for the post-FSWOL application. Contrary to mitigation by MSIP, if a deep crack were present prior to the application of a WOL, the overlay would act to lower the stress intensity factor of that crack, thus increasing the time required for that crack to potentially grow through the remaining thickness of the original weld.

The reliability of pre-WOL NDE is of interest for determining the service life of weld overlays. The reliability of NDE of post-WOL welds is important for determining whether any new flaws have initiated or existing flaws have propagated and for assessing the effect of any potential flaws on the service life of the weld. NDE effectiveness and reliability for both pre- and post-WOL can be affected by a number of factors. For example, geometry or access may limit performing a complete pre-WOL weld examination. Information on limitations to performing inspections of typical Westinghouse and CE plant RCS Alloy 82/182 welds was obtained from an NDE vendor for the commercial nuclear power industry. ASME Code-required volumetric coverage appears achievable for many, although not all, Westinghouse and CE Alloy 82/182 butt welds.

The ability to reliably detect and characterize PWSCC can be distinctly and significantly improved by performing UT modeling analyses when designing the inspection, using encoded techniques qualified by performance demonstration, and having analysts experienced in distinguishing service induced flaw signals from other UT signals that may be present. In the case of CSS materials adjacent to the weld mitigated, studies have demonstrated that, although ASME qualified procedures for inspecting CSS piping welds have not been developed, low frequency techniques discussed in the report are capable of detecting and characterizing flaws to within ASME sizing tolerances.

An assessment of the ASME Code Case N-770-1 requirements, with NRC conditions that are applicable to WOLs, was performed. Overall, it is concluded that these requirements are comprehensive and will provide an appropriate defense-in-depth function for monitoring the condition of WOL welds. It is recommended that in those cases where ET is required to complement UT, the performance demonstration requirements of Code Case N-773 be used in lieu of the currently specified requirements.

Using the criteria in ASME Code Case N-770-1 to evaluate the effectiveness of WOLs as a mitigation technique, it is concluded that WOLs provide effective mitigation against the initiation of PWSCC and against the growth of existing PWSCC allowed by the design to remain in service. With regard to 
uncertainties for pre-existing flaw growth, or the potential that new flaws initiate post-mitigation, comprehensive examination requirements for monitoring WOLs during their service lifetimes are contained in Code Case N-770-1, as imposed and conditioned by NRC. For this monitoring to perform as intended, the NDE being applied must be effective and reliable. However, in the unlikely event that undetected flaws were to grow through the thickness of the original weld, it has been shown that WOLs are capable of maintaining structural integrity under design-basis loading. This layered approach is expected to address the qualitative screening criteria in SRP 3.6.3 regarding corrosion. Per the staff guidance in RIS 2010-07, licensees are also expected to ensure the quantitative criteria of SRP 3.6.3 are satisfied by WOLs. Based on the above, WOLs would be expected to preclude PWSCC from being a potential source of pipe rupture.

Finally, it is recommended that operating experience and the tools developed under the xLPR, Version 2.0 project be used to reevaluate the sample examination provision of the Inspection Item $\mathrm{D}$ and E requirements and the adequacy of WOLs for satisfying the requirements of GDC -4 . 


\subsection{References}

10 CFR 50.55a. 2011. "Codes and Standards." U.S. Nuclear Regulatory Commission.

75 FR 24324. May 4, 2010. "10 CFR Part 50 American Society of Mechanical Engineers (ASME) Codes and New and Revised ASME Code Cases; Proposed Rule: 24324-24361." Federal Register 75(85):24324-24361. Nuclear Regulatory Commission, Washington, D.C.

76 FR 36232. June 21, 2011. "American Society of Mechanical Engineers (ASME) Codes and New and Revised ASME Code Cases." Federal Register 76(119):36232-36279. Nuclear Regulatory Commission, Washington, D.C.

Anderson MT, SL Crawford, SE Cumblidge, KM Denslow, AA Diaz and SR Doctor. 2007. Assessment of Crack Detection in Heavy-Walled Cast Stainless Steel Piping Welds Using Advanced Low-Frequency Ultrasonic Methods. NUREG/CR-6933, PNNL-16292, U.S. Nuclear Regulatory Commission, Washington, D.C.

Anderson MT, AA Diaz and SR Doctor. 2012. Evaluation of Manual Ultrasonic Examinations Applied to Detect Flaws in Primary System Dissimilar Metal Welds at North Anna Power Station. PNNL-21546, Pacific Northwest National Laboratory, Richland, Washington. ADAMS Accession No. ML12200A216.

ASME. 2006. Code Case N-504-4, Alternative Rules for Repair of Classes 1, 2, and 3 Austenitic Stainless Steel Piping, Section XI, Division 1. American Society of Mechanical Engineers, New York. Approved July 14, 2006.

ASME. 2008. Code Case N-740-2, Full Structural Dissimilar Metal Weld Overlay for Repair or Mitigation of Class 1, 2, and 3 Items, Section XI, Division 1. American Society of Mechanical Engineers, New York. Approved November 10, 2008.

ASME. 2009a. Code Case N-770-1, Alternative Examination Requirements and Acceptance Standards for Class 1 PWR [pressurized water reactor] Piping and Vessel Nozzle Butt Welds Fabricated with UNS N06082 or UNS W86182 Weld Filler Material With or Without the Application of Listed Mitigation Activities, Section XI, Division 1. American Society of Mechanical Engineers, New York. Approved December 25, 2009.

ASME. 2009b. Code Case N-770, Alternative Examination Requirements and Acceptance Standards for Class 1 PWR [pressurized water reactor] Piping and Vessel Nozzle Butt Welds Fabricated with UNS N06082 or UNS W86182 Weld Filler Material With or Without the Application of Listed Mitigation Activities, Section XI, Division 1. American Society of Mechanical Engineers, New York. Approved January 26, 2009.

ASME. 2011. Code Case N-754, Optimized Structural Dissimilar Metal Weld Overlay for Mitigation of PWR Class 1 Items, Section XI, Division 1. American Society of Mechanical Engineers, New York. Approved June 25, 2011.

Bartley JH. 2009. Letter to JR Morris. "Catawba Nuclear Station, Units 1 and 2 - NRC Integrated Inspection Report, 05000413/2009002, 05000414/2009002." April 28, 2009, U.S. Nuclear Regulatory Commission, Region II, Atlanta, Georgia. ADAMS Accession No. ML091190050. 
Bateman WH. 2002. Letter to Mr. Carl Terry. "Final Safety Evaluation of the 'BWRVIP Vessel and Internals Project, BWR Vessel and Internals Project, Technical Basis for Revisions to Generic Letter 8801 Inspection Schedules (BWRVIP-75),' EPRI Report TR-113932, October 1999." May 14, 2002, U.S. Nuclear Regulatory Commission, Washington, D.C. ADAMS Accession No. ML021350645.

Blount TB. 2010. Letter to JH Riley. "Final Safety Evaluation for Nuclear Energy Institute Topical Report Materials Reliability Program (MRP): Technical Basis for Preemptive Weld Overlays for Alloy 82/182 Butt Welds in Pressurized Water Reactors (MRP-169)." August 9, 2010, U.S. Nuclear Regulatory Commission, Washington, D.C. ADAMS Accession Nos. ML101660519 and ML101660468.

Collins JW. 2011. Memorandum to TR Lupold. "Summary of Public Meeting Between the Nuclear Regulatory Commission Staff and Industry Representatives on Implementation of ASME Code Case N770-1." August 12, 2011, U.S. Nuclear Regulatory Commission, Washington, D.C. ADAMS Accession No. ML112240818.

Crawford SL, AD Cinson, MS Prowant, TL Moran and MT Anderson. 2012. Ultrasonic Evaluation of Two Dissimilar Metal Weld Overlay Specimens, Technical Letter Report. PNNL-21502, Pacific Northwest National Laboratory, Richland, Washington. ADAMS Accession No. ML12213A437.

Diaz AA, AD Cinson, SL Crawford, R Mathews, TL Moran, MS Prowant and MT Anderson. 2011. An Evaluation of Ultrasonic Phased Array Testing for Cast Austenitic Stainless Steel Pressurizer Surge Line Piping Welds. NUREG/CR-7122, PNNL-19497, U.S. Nuclear Regulatory Commission, Washington, D.C.

Dyer JE. 2005. Letter to GC Park. "Primary Water Stress Corrosion Cracking in Reactor Coolant System Nickel-Based Alloy Butt Welds." December 20, 2005, U.S. Nuclear Regulatory Commission, Washington, D.C. ADAMS Accession No. ML053480359.

EPRI. 1991. Justification for Extended Weld-Overlay Design Life. EPRI NP-7103-D, Electric Power Research Institute, Palo Alto, California.

EPRI. 1999. Technical Justification for the Extension of the Interval between Inspections of Weld Overlay Repairs. EPRI Report TR-110172, Electric Power Research Institute, Palo Alto, California.

EPRI. 2005a. Materials Reliability Program: Leak-Before-Break Evaluation for PWR Alloy 82/182 Welds (MRP-140). EPRI Report 1011808, Electric Power Research Institute, Palo Alto, California.

EPRI. 2005b. Materials Reliability Program: Leak-Before-Break Evaluation for PWR Alloy 82/182 Welds (MRP-140NP). EPRI Report No. 1011808, Electric Power Research Institute, Palo Alto, California. U.S. Nuclear Regulatory Commission, ADAMS Accession No. ML052140050.

EPRI. 2005c. Materials Reliability Program: Primary System Piping Butt Weld Inspection and Evaluation Guidelines (MRP-139). EPRI Report 1010087, Electric Power Research Institute, Palo Alto, California.

EPRI. 2006. Letter to T Mensah. "MRP 2006-050, PWR Fleet Survey - MRP-139 Implementation Plans for Pressurizers - Revision 1." December 18, 2006, U.S. Nuclear Regulatory Commission, Washington, D.C. ADAMS Accession No. ML063560374.

EPRI. 2007. Materials Reliability Program: Advanced FEA Evaluation of Growth of Postulated Circumferential PWSCC Flaws in Pressurizer Nozzle Dissimilar Metal Welds: Evaluations Specific to 
Nine Subject Plants. MRP-216, Rev. 1, EPRI Report No. 1015499, Electric Power Research Institute, Palo Alto, California. ADAMS Accession Nos. ML072410240 and ML072410241.

EPRI. 2008a. Materials Reliability Program: Primary System Piping Butt Weld Inspection and Evaluation Guideline (MRP-139, Revision 1). EPRI Report 1015009, Electric Power Research Institute, Palo Alto, California.

EPRI. 2008b. Materials Reliability Program: Technical Basis for Preemptive Weld Overlays for Alloy 82/182 Butt Welds in PWRs (MRP-169). EPRI Report 1016602, Rev. 1, Electric Power Research Institute, Palo Alto, California. ADAMS Accession No. ML082610253.

Fredette L and PM Scott. 2009. Evaluation of the Mechanical Stress Improvement Process (MSIP) as a Mitigation Strategy for Primary Water Stress Corrosion Cracking in Pressurized Water Reactors. Battelle Columbus, Columbus, Ohio. ADAMS Accession No. ML092990646.

Fredette L and PM Scott. 2010. Evaluation of Full Structural and Optimized Weld Overlays as Mitigation Strategies for Primary Water Stress Corrosion Cracking in Pressurized Water Reactors. Battelle Columbus, Columbus, Ohio. ADAMS Accession No. ML101260540.

Hoots DM. 2006a. Letter to NRC Document Control Desk. "Byron Station, Units 1 and 2, Third 10Year Inservice Inspection Interval, Relief Request 13R-08, Structural Weld Overlays on Pressurizer Spray, Relief, Safety and Surge Nozzle Safe-Ends and Associated Alternative Repair Techniques." April 28, 2006, U.S. Nuclear Regulatory Commission, Washington, D.C. ADAMS Accession No.

ML061180496.

Hoots DM. 2006b. Letter to NRC Document Control Desk. "Response to NRC Request for Additional Information to Byron Station Relief Request 13R-08." August 18, 2006, U.S. Nuclear Regulatory Commission, Washington, D.C. ADAMS Accession No. ML062300200.

Jury KR. 2006. Letter to NRC Document Control Desk. "Commitment Regarding Byron Station Relief Request 13R-08." September 14, 2006, U.S. Nuclear Regulatory Commission, Washington, D.C. ADAMS Accession No. ML062580460.

Kingston EJ, D Stefanescu, AH Mahmoudi, CE Truman and DJ Smith. 2006. "Novel Applications of the Deep-Hole Drilling Technique for Measuring Through-Thickness Residual Stress Distributions." Journal of ASTM International 3(4). Paper ID JAI2568.

Klecker RW, SH Bush, SH Hou, J Strosnider and KR Wichman. 1984. Report of the U.S. Nuclear Regulatory Commission Piping Review Committee - Evaluation of Potential for Pipe Breaks. NUREG1061, Vol. 3, U.S. Nuclear Regulatory Commission, Washington, D.C. ADAMS Accession No. ML093170485.

Mahoney M. 2010. Letter to B. S. Allen. "Davis-Besse Nuclear Power Station, Unit 1 - Issuance of Amendment Re: Application to Update the Leak-Before-Break Evaluation of the Reactor Coolant Pump Suction and Discharge Nozzle Dissimilar Metal Welds." March 24, 2010, U.S. Nuclear Regulatory Commission, Washington, D.C. ADAMS Accession No. ML100640506.

Marshall ML, Jr. 2007. Letter to CM Crane. "Byron Station, Unit No. 1 - Evaluation of Relief Request 13R-08 Pertaining to Structural Weld Overlays (TAC No. MD1761)." January 29, 2007, U.S. Nuclear Regulatory Commission, Washington, D.C. ADAMS Accession No. ML062510169. 
NEI. 2003. Guideline for the Management of Materials Issues. NEI 03-08, Nuclear Energy Institute (NEI), Washington, D.C. ADAMS Accession No. ML032190048.

NRC. 1987. Standard Review Plan for the Review of Safety Analysis Reports for Nuclear Power Plants: LWR Edition, Section 3.6.3, Leak-Before-Break Evaluation Procedures. NUREG-0800, U.S. Nuclear Regulatory Commission, Washington, D.C. Formerly issued as NUREG-75/087.

NRC. 2002. Recent Experience with Degradation of Reactor Pressure Vessel Head. Information Notice 2002-11, U.S. Nuclear Regulatory Commission, Washington, D.C. March 12, 2002. U.S. NRC Agencywide Data Access and Management System (ADAMS) Accession Number ML020700556.

NRC. 2007. Standard Review Plan for the Review of Safety Analysis Reports for Nuclear Power Plants: LWR Edition, Section 3.6.3, Leak-Before-Break Evaluation Procedures, Revision 1. NUREG-0800, Rev. 1, U.S. Nuclear Regulatory Commission, Washington, D.C.

NRC. 2008. Regulatory Approach for Primary Water Stress Corrosion Cracking of Dissimilar Metal Butt Welds in Pressurized Water Reactor Primary Coolant System Piping. Regulatory Information Summary 2008-25, U.S. Nuclear Regulatory Commission, Washington, D.C. October 22, 2008. U.S. NRC Agencywide Data Access and Management System (ADAMS) Accession Number ML081890403.

NRC. 2010. Regulatory Requirements for Application of Weld Overlays and Other Mitigatiion Techniques in Piping Systems Approved for Leak-Before-Break. RIS 2010-07, U.S. Nuclear Regulatory Commission, Washington, D.C. ADAMS Accession No. ML101380231.

Price JA. 2011. Letter to NRC Document Control Desk. "Virginia Electric and Power Company (Dominion) North Anna Power Station Unit 1 - N1-I4-CMP-001, Use of Weld Overlays as an Alternative Repair Technique for Steam Generator Hot Leg Nozzles." March 30, 2011, Virginia Electric and Power Company, Richmond, Virginia. U.S. Nuclear Regulatory Commission, ADAMS Accession No. ML110900566.

Rathbun HJ, LF Fredette, PM Scott, AA Csontos and DL Rudland. 2011. "NRC Welding Residual Stress Validation Program International Round Robin Program and Findings." In Proceedings of the ASME Pressure Vessels and Piping Conference, 2011 (PVP2011). July 17-21, 2011, Baltimore, Maryland. American Society of Mechanical Engineers, New York. Paper PVP2011-57642. U.S. Nuclear Regulatory Commission, ADAMS Accession No. ML111680405.

Rowley JG. 2012. Memorandum to JR Jolicoeur. "Summary of January 10, 2012, Meeting with the Pressurized Water Reactor Owners Group Regarding Relief Request from the Requirements of Code Case N-770-1." March 5, 2012, U.S. Nuclear Regulatory Commission, Washington, D.C. ADAMS Accession No. ML120460312 (package ML12047A099).

Salgado NL. 2011. Letter to GH Gellrich. "Calvert Cliffs Nuclear Power Plant, Unit Nos. 1 and 2 Relief from the Requirements of the ASME Code (TAC Nos. ME3963 and ME3964)." February 24, 2011, U.S. Nuclear Regulatory Commission, Washington, D.C. ADAMS Accession No. ML110410062.

Salgado NL. 2012. Letter to DA Heacock. "North Anna Power Station, Unit No. 1, Relief Request N 114-CMP-001, Regarding Use of Weld Overlays as an Alternative Repair Technique, TAC No. ME5965." January 27, 2012, U.S. Nuclear Regulatory Commission, Washington, D.C. ADAMS Accession No. ML11348A219. 
Scott PM. 1987. Assessment of Design Basis for Load-Carrying Capacity of Weld-Overlay Repairs. NUREG/CR-4877; BMI-2150, U.S. Nuclear Regulatory Commission, Washington, D.C.

Sullivan EJ and MT Anderson. 2011. Technical Letter Report Assessment of Battelle Columbus Reports Evaluating Mechanical Stress Improvement and Weld Overlays as Mitigation Strategies for Primary Water Stress Corrosion Cracking in Pressurized Water Reactors. PNNL-20580, Pacific Northwest National Laboratory, Richland, Washington.

White S. 2010. Summary of Weld Overlay Ultrasonic Examinations for Reactor Coolant Pump Suction and Discharge Nozzle Welds, Core Flood Nozzle Welds, and Cold Leg Drain Nozzle Welds at Davis-

Besse Nuclear Power Station, Unit 1. Report No. 0800368.408, Structural Integrity Associates, Inc., San Jose, California. U.S. Nuclear Regulatory Commission, ADAMS Accession No. ML101230641. 

Appendix A

Background on Leak-Before-Break Per the Requirements of 10 CFR 50, Appendix A, General Design Criterion-4 



\section{Appendix A}

\section{Background on Leak-Before-Break Per the Requirements of 10 CFR 50, Appendix A, General Design Criterion-4}

The governing requirement for leak-before-break (LBB) is General Design Criterion (GDC)-4. GDC-4, "Environmental and Dynamic Effects Design Bases," in Appendix A, "General Design Criteria for Nuclear Power Plants," to 10 CFR Part 50 requires, in part, that nuclear power facilities be protected against the effects of postulated pipe ruptures. GDC-4 states that "dynamic effects associated with postulated pipe ruptures in nuclear power units may be excluded from the design basis when analyses reviewed and approved by the Commission demonstrate that the probability of fluid system piping rupture is extremely low under conditions consistent with the design basis for the piping."

Technical procedures and criteria for using LBB analysis are provided in NUREG-1061, Report of the U.S. Nuclear Regulatory Commission Piping Review Committee, Volume 3, "Evaluation of Potential for Pipe Breaks," issued in November 1984 (Klecker et al. 1984). The NRC subsequently incorporated the procedures and criteria of NUREG-1061, Volume 3, into Section 3.6.3, "Leak-Before-Break Evaluation Procedures," of NUREG-0800, Standard Review Plan (SRP) for the Review of Safety Analysis Reports for Nuclear Power Plants: LWR [light-water reactor] Edition, issued March 1987 (NRC 1987).

Section 3.6.3 of NUREG-0800, Revision 1, was issued in March 2007 (NRC 2007). It provides review procedures and acceptance criteria for the NRC staff to evaluate licensees' LBB submittals and determine whether they satisfy the requirements of GDC-4 for eliminating the dynamic effects of postulated pipe rupture.

The first part of the SRP Section 3.6.3 is a qualitative screening evaluation. SRP Section 3.6.3 specifies that the NRC reviewer should evaluate the material susceptibility to corrosion, the potential for high residual stresses, and potential for high loading such as water hammer and environmental conditions that could lead to degradation by stress corrosion cracking. This SRP further specifies that the NRC reviewer's evaluation should demonstrate that stress corrosion cracking is not a potential source of pipe rupture.

The second part of the SRP Section 3.6.3 review is set of a quantitative LBB analyses to support an LBB application. LBB analyses consist of a leakage rate calculation and a fracture mechanics calculation. The leakage calculation determines the size (arc length) of a postulated, idealized throughwall crack that would leak at a specified flow rate based on the capability of the applicable leakage detection systems multiplied by a margin of 10 . This is called the leakage size crack. The fracture mechanics calculation ensures that the largest crack (i.e., critical crack) that satisfies the fracture mechanics acceptance criteria in SRP Section 3.6.3 is at least two times larger than the leakage size crack. LBB analysis applies only to an entire piping system or a portion thereof that can be analyzed. Portions of the piping system that can be analyzed are typically segments located between anchor points. When LBB technology is applied, all potential pipe rupture locations are examined. An LBB analysis examines or calculates the leakage and fracture mechanics margins at critical locations in the analyzed segment, and the analysis summary typically includes the margins for the location(s) with the lowest margins in each piping system. Critical locations would generally include the locations that have the least favorable 
combination of stress and material properties for base metal, weldments, nozzles, and safe ends relative to the leakage and fracture mechanics margins.

The quantitative analysis described above is essentially a flaw tolerance evaluation. The Commission reviewed and approved the various plant-specific evaluations before it authorized the removal of the dynamic effects of postulated high-energy pipe ruptures from the design bases. Licensee applications for approval of LBB analyses have been made through the license amendment process.

GDC -4 is stated in terms of probability. When the LBB review criteria were adopted, the NRC staff concluded that a reliable approach for demonstrating compliance with GDC-4 was satisfaction of the SRP Section 3.6.3 deterministic criteria; that is, through a comprehensive screening evaluation and a fracture mechanics analysis demonstrating high margins against rupture. 
Appendix B

Assessment of ASME Code Case N-770-1 as Implemented in 10 CFR $50.55 \mathrm{a}(\mathrm{g})(6)(\mathrm{ii})(\mathrm{F})$ 



\section{Appendix B}

\section{Assessment of ASME Code Case N-770-1 as Implemented in 10 CFR 50.55a(g)(6)(ii)(F)}

\section{B.1 Assessment of ASME Code Case N-770-1 Requirements for Butt Welds Mitigated by WOLs}

\section{B.1.1 Table 1}

There are two Inspection Items in Code Case N-770-1 pertaining to butt welds mitigated by full structural weld overlays (FSWOLs). Inspection Item C applies to uncracked butt welds mitigated with FSWOLs and Inspection Item F applies to cracked butt welds mitigated with FSWOLs. There are two Inspection Items that pertain to butt welds mitigated by optimized weld overlays (OWOLs). In Code Case N-770-1, an OWOL is categorized as a stress improvement technique and utilizes the same Inspection Items as used for welds mitigated by the mechanical stress improvement process (MSIP). Inspection Item D applies to uncracked butt welds mitigated with OWOLs and Inspection Item E applies to cracked butt welds mitigated with OWOLs. Welds with these Inspection Items are required to be volumetrically examined as discussed below. There are no visual inspection requirements for welds mitigated by WOLs.

Inspection Item C welds (uncracked welds with FSWOLs) are required to be placed into a sample population. Twenty-five percent of this population is required to be examined once each inspection interval. Inspection Item F welds (cracked welds with FSWOLs) are required to be examined during the first or second refueling outage following application of the WOL. WOL examination volumes that show no indication of crack growth or new cracking are required to be placed into a sample population. Twenty-five percent of this population is required to be examined once each inspection interval.

Inspection Item D welds (uncracked welds with OWOLs) are required to be examined within 10 years following application of the OWOL. If the examination volumes of the welds show no indication of cracking, the welds are required to be placed into a population to be examined on a sample basis. Twenty-five percent of this population shall be examined once each interval. The examination requirements for Inspection Item E welds (cracked welds with OWOLs) only differ from the requirements for Inspection Item D welds in that these welds are required to be examined once during the first or second refueling outage after application of the OWOL, rather than within 10 years. The examination volume for welds mitigated by FSWOLs is shown in Figure 2 of the Code Case and the examination volume for welds mitigated by OWOLs is shown in Figure 5.

The Code Case provides examination frequency requirements of $25 \%$ sampling for welds mitigated by WOLs, which are similar to the Section XI requirements for B-J welds and the provisions of BWRVIP-75 for Category E FSWOLs made of resistant material. These provisions of BWRVIP-75 were found acceptable by the NRC in its safety evaluation issued in 2002 (Bateman 2002). However, as discussed in Appendix B.2, the NRC took exception to the sample inspection requirement for welds mitigated by OWOLs in Condition $\S 50.55 \mathrm{a}(\mathrm{g})(6)(\mathrm{ii})(\mathrm{F})(8)$. 
Adopting WOL inspection frequency requirements of once per interval, with or without sampling, reflects an implicit conclusion that WOL techniques result in effective mitigation and that the inspection serves a defense-in-depth function rather than a degradation management function. The effectiveness of WOLs is discussed in detail in Section 5.0.

\section{B.1.2 Table 1 Notes}

The notes to Table 1 that are applicable to FSWOL welds in Inspection Item C (uncracked FSWOLs) are Notes (4), (6), (7), (8), (9), (10), and (11). The notes to Table 1 that are applicable to FSWOL welds in Inspection Item F are Notes (4), (6), (8), (9), (10), and (11). Since note (7) pertains to materials used for weld overlays, Note (7) should also be applicable to Inspection Item F welds. This omission was corrected in Code Case N-770-2. Table 1 does not indicate that Note (6) is applicable to Inspection Items C and F. The title of Note (6) is "Pre-Weld Overlay Examination for Full Structural Weld Overlay," so it clearly applies to the FSWOL inspection items. This omission was partially corrected in Code Case N-770-2.

Note (4) states, "Ultrasonic volumetric examination shall be used and shall meet the applicable requirements of Appendix VIII." This note requires UT examinations to be qualified in accordance with requirements that the NRC has found to be acceptable.

Note (6) pertains to pre-weld overlay examinations for FSWOLs and has three parts.

(1) Note (6)(a) requires that, except for reactor vessel nozzle welds at cold-leg temperatures requiring the core internals to be removed to perform the examination, "if volumetric examination was not performed on the weld prior to structural weld overlay, the weld shall be assumed cracked and shall be classified Inspection Item F. This examination prior to weld overlay shall include the examination volume of Figure 1." (Figure 1 of the Code Case applies to unmitigated welds.) If a weld is not examined prior to applying a FSWOL and assumed to be cracked, the preservice examination required by Note (9) is used to confirm that flaws have not propagated into the outer $25 \%$ of the original weld volume. This note is consistent with the design requirements for FSWOLs.

(2) Note (6)(b) states that, "For reactor vessel nozzle welds at cold-leg temperatures requiring the core internals to be removed to perform the examination, the volumetric examinations are not required prior to application of the weld overlay. If the pre-weld overlay volumetric examination is not performed, a post-weld overlay preservice examination consisting of a surface examination and a volumetric examination shall be performed after removal of the core internals. If these examinations do not detect cracks, the weld shall be considered uncracked and shall be subject to the examination requirements of Inspection Item C. This post-weld overlay volumetric examination shall include the examination volume shown in Fig. 1 and the examination volume of Fig 2(a). The post-weld overlay surface examination shall be performed on the weld inside surface, extent E-F of Fig. 1, and shall consist of an eddy current examination in accordance with IWA-2223." There are currently no Appendix VIII, Supplement 10 procedures for examining the volume shown in Fig. 1 from the ID that are qualified for depth sizing flaws in welds. The compressive stresses in the mitigated weld may cause crack faces to close or partially close and change the UT response of the flaws. This phenomenon may increase the difficulty of qualifying procedures for depth sizing. Examination of the required volume on Fig. 2(a) is also required to 
be performed to locate and size any planar flaws that have propagated into the outer $25 \%$ of the original weld or base metal thickness or into the weld overlay. If during the post-weld overlay examinations the weld is determined to be cracked, for example by the surface examination, and if no flaw is found in the UT examination of the volume in Fig. 2(a), licensees would have to assume a flaw that is $75 \%$ through the original weld, in accordance with FSWOL design requirements, and verify that IWB-3600 requirements are satisfied. Assuming that acceptable results are obtained, Inspection Item F (cracked FSWOLs) would apply.

As stated above, Note (6)(b) requires that a surface examination be performed by eddy current in accordance with IWA-2223, which in turn requires that eddy current testing (ET) be conducted in accordance with Appendix IV. Appendix IV contains a Supplement 2 with limited qualification requirements for surface examination of piping and vessels. It contains requirements for demonstration specimens and has requirements comparable to Section V, Article 14, low rigor. Because WOLs generate compression in the inner region of the weld, the UT response of cracks may be diminished and the ability of the surface examination to detect cracks takes on greater significance. Code Case N-773 contains ET performance requirements that may be used in lieu of Appendix IV, Supplement 2 when ET is used to complement UT performed on the inside surfaces of austenitic, dissimilar metal weld, and clad piping welds. This code case was specifically developed for ID examinations of dissimilar metal welds for flaws such as PWSCC. This code case has requirements for demonstrating procedures and qualifying personnel using numbers of flaws and acceptance criteria similar to Appendix VIII criteria. Code Case N-773 is being incorporated into Regulatory Guide 1.147. A robust qualification of ET procedures and personnel by performance demonstration, similar to the approach used in Appendix VIII for ultrasonic testing, would increase the reliability of this ET examination.

(3) Note (6)(c) states that, "If the crack is completely removed by a repair/replacement activity in accordance with IWA-4000 and the weld overlay is then applied, the weld shall be reclassified as Inspection Item C." Inspection Item C is uncracked butt welds reinforced by full structural weld overlay of Alloy 52/152 material. This note clarifies that if a crack in a butt weld is completely removed and repaired in accordance with Code requirements, it may be treated as an uncracked weld.

Note (7) specifies the UNS and SFA material designations that are commonly abbreviated as Alloy 52, Alloy 152, and other similar designations. This note provides a link to the specific materials allowed to be used for WOLs by Inspection Items $\mathrm{C}$ and, by implication, Inspection Item F.

Note (8) pertains to ISI of FSWOLs and has five parts.

(1) Note (8)(a) specifies that the examination volume is in Figure 2(a) and specifies the angle beam directions that shall be used. It also specifies that the portion of the examination volume where propagation of new or existing cracks have to be evaluated for acceptability is the outer $25 \%$ of the original weld or base material or into the overlay. This note is consistent with the design requirements for FSWOLs.

(2) Note (8)(b) specifies the examination standards to be used if cracks are detected in or beyond the outer $25 \%$ of the original weld or base material. This note also provides requirements on the thicknesses to be used in applying IWB-3514. Because there are two materials involved with differing susceptibility to PWSCC, this part of Note (8) is needed to apply the acceptance 
standards consistent with Section XI rules. Note (8)(b) also states that any indication characterized as having flaw extension into the weld overlay material is unacceptable, which is consistent with the design requirements because the design-basis flaw for a FSWOL is $100 \%$ through the original weld.

(3) Note (8)(c) allows the examination volume of an unmitigated weld (Fig. 1 of the Code Case) to be used as an alternative to the examination volume of Note (8)(a). This provision is in recognition that nozzle weld examinations may be performed from the ID. Note (8)(c) also specifies that if cracking is detected beyond the examination volume of an unmitigated weld, that is, beyond the inner $1 / 3$ of the original weld, the examination of Note (8)(a) shall be performed and acceptance criteria of Note (8)(b) shall be used to determine the acceptability of the weld overlay. Note (8)(c) cannot be applied without regulatory approval, because there are currently no Appendix VIII, Supplement 10 procedures to examine welds from the ID that are qualified for depth sizing flaws in welds. In addition, as stated in the NRC staff's safety evaluation for MRP169 (Blount 2010), "Existing inside surface examination procedures ... will require additional demonstration or qualification on weld overlay mockups to demonstrate that inside diameter connected flaws are still detectable after application of the overlay and the associated compressive stresses." This statement in the SE was written for ID examination of OWOLs but would be equally applicable to ID examination of FSWOLs. This statement appears to be saying that if personnel, equipment, and procedures are used to examine overlaid welds from the ID, they will have to be demonstrated in accordance with Appendix VIII requirements on specimens with ID connected flaws to which overlays have been applied. NRC may want to address this issue raised on a licensee's potential use of Note (8)(c) in its reviews of applications to apply weld overlays to reactor vessel nozzle DMWs.

(4) and (5) Notes (8)(d) and (8)(e) provide the requirements for subsequent examinations if the inservice examinations of (8)(a)-(c) reveal crack growth meeting the acceptance standards. The requirements of these notes are consistent with Section XI requirements.

Note (9) pertains to preservice inspection for a FSWOL and has three parts.

(1) Note (9)(a) specifies that the examination volume is in Figure 2(a) and specifies the angle beam directions that shall be used. Section XI, Appendix VIII does not yet provide requirements for performing qualified examinations through cast austenitic stainless steel (CASS). Therefore, provided a $100 \%$ through-wall flaw is used in the design crack growth analysis, Note (9)(a) only requires locating and sizing planar flaws that have propagated into the weld overlay or are in the weld overlay for FSWOLs over the CASS material. This note is needed to provide a technically acceptable approach to address inspection limitations with CASS material adjacent to the weld.

(2) Note (9)(b) specifies the preservice examination standards to be used for flaws detected in the outer $25 \%$ of the original weld or base material or in the weld overlay and, similar to Note (8)(b), the thicknesses to be used in applying IWB-3514. This note is needed to apply the acceptance standards consistent with Section XI rules.

(3) Note (9)(c) prohibits the use of IWB-3640 for planar flaws in the weld overlay material identified during the preservice examination. Consistent with ASME Code philosophy, this note precludes 
the use of inservice examination flaw acceptance standards for addressing fabrication flaws when a component is first placed in service.

Note (10) requires that the " $25 \%$ sample consist of the same welds in the same sequence during successive intervals to the extent practical provided the $25 \%$ sample contains the welds that experience the highest operating temperature in the Inspection Item. If hot leg and cold leg welds are included in the same Inspection Item, the initial 25\% sample does not need to include the cold leg welds. Those welds not included in the $25 \%$ sample shall be examined prior to the end of the mitigation evaluation period if the plant is to be operated beyond that time." These requirements bias the $25 \%$ sample in the conservative direction and ensure that all welds are examined before reaching the end of life.

Note (11) pertains to deferral of examinations and, in this context, relates to Inspection Items $\mathrm{C}$ and $\mathrm{F}$. Note (11)(a) provides that the examination of welds originally classified Table IWB 2500-1, Category B-J welds (piping welds) prior to the mitigation are not permitted to be deferred to the end of the interval. Examination of these welds does not need to be performed in conjunction with the RPV examinations so this note prohibits deferral of these examinations.

For welds originally classified Table IWB 2500-1, Category B-F welds (nozzle welds) prior to the mitigation, Note (11)(b) permits deferral of the initial examination of Inspection Item C (uncracked butt welds with FSWOLs) to the end of the interval coincident with vessel nozzle examinations required by Category B-D. This note permits deferral of the initial Inspection Item $\mathrm{C}$ weld examination because a FSWOL over an uncracked weld is expected to be unflawed, is expected to prevent the initiation of PWSCC, and can satisfy design-basis loadings even if a crack were to propagate through the original pipe wall. Note (11)(b) in combination with the NRC condition $\$ 50.55 \mathrm{a}(\mathrm{g})(6)(\mathrm{ii})(\mathrm{F})(9)$ requires that the first examination of Inspection Item F welds (cracked butt welds with FSWOLs) to be performed as specified in Table 1 and, therefore, the first examination has to be performed during the first or second refueling outage following overlay. Although a crack in a weld mitigated by a FSWOL is addressed in the design, Inspection Item $\mathrm{F}$ welds are required by the Code Case to have an initial examination soon after installation, possibly as a check on uncertainties with the pre-FSWOL examination and other aspects of the design. Subsequent examinations of Inspection Item F welds may be performed coincident with the vessel nozzle examinations required by Category B-D. Therefore, Note 11(b) does not permit deferral of the initial examination beyond the interval specified in Table 1. For successive inspection intervals following FSWOL, examinations may be deferred to the end of the interval, provided no additional repair/replacement activities have been performed on the examination item, and no flaws or relevant conditions requiring successive examinations are contained in the mitigated weld.

The notes to Table 1 that are applicable to the OWOL welds of Inspection Items D and E are (4), (10), (11), (12), (13), (14), and (18). Note (4) requires that volumetric examinations be used and meet the applicable Section XI, Appendix VIII requirements. Because Note (7) pertains to materials used for weld overlays, Note (7) should also be applicable to OWOLs. This omission was corrected in Code Case N-770-2. Note (10) was discussed in connection with FSWOLs. This note is essentially rendered nonapplicable to OWOLs by NRC Condition (F)(8), which is discussed in Appendix B.2.

Note (11) pertains to deferral of examinations, and in this context, relates to Inspection Items D and $\mathrm{E}$. 
(1) Note (11)(a) provides that examination of welds originally classified Table IWB 2500-1, Category B-J welds (piping welds) prior to the mitigation are not permitted to be deferred to the end of the interval. The reason for Note (11)(a) is that examination of these welds does not need to be performed in conjunction with the RPV examinations, so this note prohibits deferral.

(2) For welds originally classified Table IWB 2500-1, Category B-F welds (nozzle welds) prior to the mitigation, Note (11)(b) in conjunction with the NRC condition $\S 50.55 \mathrm{a}(\mathrm{g})(6)(\mathrm{ii})(\mathrm{F})(9)$ requires that the first examination of welds with OWOLs in Inspection Items D (uncracked OWOLs) be performed no sooner than the third refueling outage and no later than 10 years after the OWOL was applied, thereby prohibiting deferral of the initial examination. This condition was provided to resolve an inconsistency between the Code Case N-770-1, Table 1 and Note (11)(b), initial examination requirements of Inspection Item D welds. Note (11)(b) in conjunction with NRC condition $\$ 50.55 \mathrm{a}(\mathrm{g})(6)(\mathrm{ii})(\mathrm{F})(9)$ requires that the first examination of welds with OWOLs in Inspection Item E (cracked OWOLs) be performed during the first or second refueling outage after the OWOL was applied. Although a crack in a weld mitigated by a an OWOL is addressed in the design, Inspection $\mathrm{E}$ welds are required by the Code Case to have an initial examination soon after installation, possibly as a check on uncertainties with the pre-WOL examination and other aspects of the design. Subsequent examinations of Inspection Item D and E welds may be performed coincident with the vessel nozzle examinations required by Category B-D. For successive inspection intervals following OWOL, examinations may be deferred to the end of the interval, provided no additional repair/replacement activities have been performed on the examination item, and no flaws or relevant conditions requiring successive examinations are contained in the mitigated weld. The requirements for Inspection Items D (uncracked OWOLs) do not permit deferral of the initial examinations, which is more conservative than the requirements for Inspection Items C (uncracked FSWOLs), which permit the deferral of the initial examination.

Note (12) contains additional requirements related to examinations, acceptance standards, and evaluations of stress improvements and has five parts.

(1) Note (12)(a) requires that, except for reactor vessel nozzle welds at cold-leg temperatures requiring the core internals to be removed to perform the examination, "volumetric exams shall be performed ... before the stress improvement (OWOL) techniques are applied. The pre-stress improvement (OWOL) exam shall be conducted in the same outage as the application of stress improvement (OWOL) or, for non-cracked welds, no more than one cycle previous to the application of stress improvement (OWOL). The examination volume Fig. 1 (of the Code Case, i.e., for unmitigated welds) applies." Prior examination is required because Code Case N-754, which governs the design of OWOLs, is limited to mitigation repair of as-found inside surface and subsurface flaws that measure not more than $50 \%$ in depth from the inside surface. Allowing one cycle of operation between the pre-OWOL examination and application of the OWOL is based on the engineering judgment that it is unlikely that PWSCC would initiate and grow during the cycle prior to OWOL to the extent that it could adversely affect weld integrity.

(2) Note (12)(b) states that, "Post-stress improvement examinations are required and shall be considered the preservice baseline examination." Notes 12(b)(1)-(3) provide the acceptance standards to evaluate new flaws or changes in the size of previously detected flaws. These 
acceptance standards are consistent with ASME Code, Section XI, standards and with the philosophy that no new planar surface-connected flaws should originate in stress improved welds.

(3) Note (12)(c) states that, "If the crack is completely removed by repair/replacement activity in accordance with IWA-4000 and the stress improvement (OWOL) is then applied, the weld will be restored to Item number D." This note clarifies that if a crack in a butt weld is completely removed and repaired in accordance with Code requirements, it may be treated as an uncracked weld. This note should say "Inspection Item D" rather than "Inspection number D." Inspection Item $\mathrm{D}$ is uncracked butt welds mitigated with stress improvement (OWOL). (This note was not corrected in Code Case N-770-2.)

(4) Note (12)(d) states that, "A documented evaluation demonstrating that the stress improvement technique meets the performance criteria in Appendix I shall be completed." Because the OWOL technique is categorized as a stress improvement technique in Code Case N-770-1, this note requires a documented evaluation to demonstrate that each OWOL satisfies the performance criteria of Appendix I. The requirements of Appendix I are discussed below. In Code Case N-770-2, this does not apply to OWOLs because the ASME considered that requirements of Code Cases N-754 would produce the same result.

(5) Note (12)(e) states that, "For reactor vessel nozzle welds at cold leg temperatures requiring the core internals to be removed to perform the examination, the volumetric examinations are not required prior to application of the stress improvement technique. If the pre-stress improvement volumetric examination is not performed, a post stress improvement preservice surface examination and volumetric examination shall be performed after removal of the core internals. If these examinations do not detect cracks, the weld will be considered uncracked and be subject to the examination requirements of Inspection Item D. This post stress improvement preservice volumetric examination must include the examination volume shown in Fig. 1. The examination volume of Fig. 1 applies in addition to the examination volume of Fig 5(a) when weld overlay is used as stress improvement in accordance with this Note 12(e). The post stress improved preservice surface examination shall be performed on the butt weld inside surface, extent E-F of Fig. 1, and shall consist of an eddy current examination in accordance with IWA-2223." There are currently no Appendix VIII, Supplement 10 procedures for examining the volume shown in Fig. 1 from the ID that are qualified for depth sizing flaws in welds. The compressive stresses in the mitigated weld may cause crack faces to close or partially close and change the UT response of the flaws. This phenomenon may increase the difficulty of qualifying procedures for depth sizing. Examination of the required volume on Fig. 5(a) is required to be performed to locate and size any planar flaws that have propagated into the outer $50 \%$ of the original weld or base metal thickness or into the weld overlay. If during the post-weld overlay examinations the weld is determined to be cracked, for example by the surface examination, and if no flaw is found in the UT examination of the required volume in Fig. 5(a), licensees would have to assume a flaw that is $50 \%$ through the original weld and verify that IWB-3600 requirements are satisfied. Assuming that acceptable results are obtained, Inspection Item F (Cracked FSWOLs) would apply.

As stated above, Note (12)(e) requires that a surface examination be performed by eddy current in accordance with IWA-2223, which in turn requires that eddy current testing (ET) be conducted in accordance with Appendix IV. Appendix IV contains a Supplement 2 with limited qualification requirements for surface examination of piping and vessels. It contains requirements for demonstration 
specimens and has requirements comparable to Section V, Article 14, low rigor. Because WOLs generate compression in the inner region of the weld, the UT response of cracks may be diminished and the ability of the surface examination to detect cracks takes on greater significance. Code Case N-773 contains ET performance requirements that may be used in lieu of Appendix IV, Supplement 2 when ET is used to complement UT performed on the inside surfaces of austenitic, dissimilar metal weld, and clad piping welds. This Code Case was specifically developed for ID examinations of dissimilar metal welds for flaws such as PWSCC. This Code Case has requirements for demonstrating procedures and qualifying personnel using numbers of flaws and acceptance criteria similar to Appendix VIII criteria. Code Case N-773 is being incorporated into Regulatory Guide 1.147. A robust qualification of ET procedures and personnel by performance demonstration, similar to the approach used in Appendix VIII for ultrasonic testing, would increase the reliability of this ET examination.

Note (13) pertains to ISI of OWOLs and has six parts.

(1) Note (13)(a) specifies that the examination volume is shown in Figure 5(a) and specifies the angle beam directions that shall be used. It also specifies the portion of the examination volume where propagation of new or existing cracks have to be evaluated for acceptability; that is, the outer $50 \%$ of the original weld or base material or into the overlay. This note is consistent with the design requirements for OWOLs.

(2) Note (13)(b) specifies the examination standards to be used if cracks are detected in or beyond the outer $50 \%$ of the original weld or base material. This note also provides requirements on the thicknesses to be used in applying IWB-3514. Because there are two materials involved with differing susceptibility to PWSCC, this part of the note is needed to apply the acceptance standards consistent with Section XI rules. Note (13)(b) also states that any indication characterized as having flaw extension into the weld overlay material is unacceptable, which is consistent with the design requirements.

(3) Note (13)(c) allows the examination volume of an unmitigated weld (Fig. 1 of the Code Case) to be used as an alternative to the examination volume of Note (13)(a). This provision is in recognition that nozzle weld examinations may be performed from the ID. Note (13)(c) also specifies that if cracking is detected beyond the examination volume of an unmitigated weld, that is, beyond the inner $1 / 3$ of the original weld, the examination of Note (13)(a) (i.e., the examination from the OD of the weld overlay and the outer $50 \%$ of the original weld) shall be performed and acceptance criteria of Note (13)(b) shall be used to determine the acceptability of the weld overlay. This note cannot be applied without regulatory approval, because there are currently no Appendix VIII, Supplement 10 procedures to examine welds from the ID that are qualified for depth sizing flaws in welds. In addition, as stated in the NRC staff's safety evaluation for MRP-169 (Blount 2010), "Existing inside surface examination procedures ... will require additional demonstration or qualification on weld overlay mockups to demonstrate that inside diameter connected flaws are still detectable after application of the overlay and the associated compressive stresses." This statement appears to be saying that if personnel, equipment, and procedures are used to examine overlaid welds from the ID, they will have to be demonstrated in accordance with Appendix VIII requirements on specimens with ID connected flaws to which overlays have been applied. NRC may want to address this issue raised on a licensee's potential use of Note (13)(c) in its reviews of applications to apply weld overlays to reactor vessel nozzle DMWs. 
(4) Note (13)(d) applies to stress improvement without welding; that is, MSIP.

(5) and (6) Notes (13)(e) and (13)(f) provide the requirements for subsequent examinations if the inservice examinations of (13)(a)-(c) reveal crack growth meeting the acceptance standards. The requirements of these notes are consistent with the OWOL design requirements and with Section XI requirements.

Note (14) pertains to preservice inspection for an OWOL and has three parts.

(1) Note (14)(a) specifies that the examination volume is in Figure 5(a) and specifies the angle beam directions that shall be used. It also specifies that the portion of the examination volume where propagation of new or existing cracks have to be evaluated for acceptability is the outer $50 \%$ of the original weld or base material or into the overlay. Section XI, Appendix VIII does not yet provide requirements for performing qualified examinations through cast austenitic stainless steel (CASS). Note (14)(a) only requires locating and sizing planar flaws that have propagated into the weld overlay or are in the weld overlay for OWOLs over the CASS material. This note is needed to provide a technically acceptable approach to address inspection limitations with CASS material adjacent to the weld.

(2) Note (14)(b) specifies the preservice examination standards to be used for flaws detected in the outer $50 \%$ of the original weld or base material or, in the weld overlay, the thicknesses to be used in applying IWB-3514. This note is needed to apply the acceptance standards consistent with Section XI rules.

(3) Note (14)(c) prohibits the use of IWB-3640 for planar flaws in the weld overlay material identified during the preservice examination. Consistent with ASME Code philosophy, this note precludes the use of inservice examination flaw acceptance standards for addressing fabrication flaws when a component is first placed in service.

Note (18) states that, "For the purposes of this Case, processes commonly referred to as optimized weld overlay are included in Inspection Items D and E." That is, OWOLs are considered a stress improvement technique by welding. In Code Case N-770-2, OWOLs and stress improvement without welding are categorized separately.

\section{B.1.3 Appendix I to Code Case N-770-1}

Appendix I to the Code Case contains seven performance criteria that have to be met by welds mitigated by stress improvement, which in Code Case N-770-1 includes OWOLs. Each of the seven performance criteria is followed by a measurement or quantification criterion. A brief discussion of these criteria follows.

- To minimize the likelihood of crack initiation, Criterion 1 stipulates that the process shall have resulted in a compressive state in the susceptible material along the entire wetted surface under steady-state operation.

- Criterion 2 stipulates that the mitigation process shall be permanent. 
- Criterion 3 stipulates that the capability to perform ultrasonic examinations of the relevant volume shall not have been adversely affected by the process.

- Criterion 4 states that the mitigation process shall not have degraded the component or adversely affected other components in the system.

- Criterion 5 stipulates that the mitigated weld shall be inspectable by a qualified process.

- Criterion 6 stipulates that existing flaws, if any, shall be addressed as part of the mitigation.

- Criterion 7 states that the effect of mitigation on the presence of existing flaws shall be analyzed.

These criteria were developed to provide requirements to ensure that stress improvement is an effective mitigation technique for preventing the initiation of PWSCC or the growth of existing PWSCC. These criteria were developed for stress improvement by MSIP because MSIP does not involve welding and this process has traditionally been performed outside of Code requirements; that is, Code requirements are considered not to apply. Code Case N-770-1 was constructed using Inspection Items D and $\mathrm{E}$ for stress improvement with and without welding. Accordingly, the Code Case requires that Appendix I apply to both types of stress improvement. The application of the requirements of Appendix I to OWOLs was removed from Code Case N-770-2 because the design for OWOLs addresses these or similar requirements.

The requirements of Appendix I constitute a performance-based approach for ensuring that the basic objectives of Section XI for maintaining structural integrity are met. They were developed by a task group under the Section XI Subgroup on Flaw Evaluation. They address the intent of accomplishing effective mitigation to inhibit crack initiation, prevent undesirable effects of mitigation on other components, ensure that examinations qualified in accordance with Section XI requirements are performed, and require that flaws are evaluated in the pre- and post-mitigation condition in accordance with Section XI rules. While broad, these performance criteria appear to be comprehensive. An assessment of each performance criterion is contained in Section 5.0 of Fredette and Scott (2009). Although the assessment was performed for welds mitigated by MSIP, this assessment of the Appendix I performance criteria supports the appropriateness of each criterion and does not suggest the need for supplementary criteria.

The examination requirements of Table 1, the notes to Table 1, and Appendix I provide a set of comprehensive inspection requirements that parallel existing Section IWB Class 1 requirements and are similar to or as conservative as the requirements in the ASME Code for Class 1 butt welds that are not susceptible to PWSCC. The Code Class 1 butt weld examination requirements of Section XI were based on a defense-in-depth philosophy for monitoring welds to ensure that the welds were not experiencing an active degradation mechanism. For consistency with this approach, the NRC imposed a number of additional conditions it believed were necessary to appropriately design and install the WOLs and to monitor and assess these welds over their design life. These conditions are discussed in Appendix B.2.

\section{B.2 Assessment of NRC Implementing Requirements}

This section discusses the WOL-related conditions in the rule that imposed Code Case N-770-1 (76 FR 36232). These conditions are (F)(1), (2), (4), (6), (8), (9)and (10). 
Condition $\S 50.55 \mathrm{a}(\mathrm{g})(6)(\mathrm{ii})(\mathrm{F})(1)$ of the rule requires licensees of existing operating PWRs as of July 21, 2011, to implement the requirements of ASME Code Case N-770-1, subject to the conditions specified in paragraphs $(\mathrm{g})(6)(\mathrm{ii})(\mathrm{F})(2)$ through $(\mathrm{g})(6)(\mathrm{ii})(\mathrm{F})(10)$ by the first refueling outage after August 22, 2011. This is the basic implementing requirement imposing Code Case N-770-1 with conditions.

Condition $\S 50.55 \mathrm{a}(\mathrm{g})(6)(\mathrm{ii})(\mathrm{F})(2)$ of the rule allows existing FSWOLs authorized by the NRC staff to be categorized as Inspection Items $\mathrm{C}$ or $\mathrm{F}$, as appropriate. At the time the rule was issued, only one plant had authorization to install OWOLs. The OWOLs at this plant could not be categorized as Code Case N-770-1 Inspection Item D or E without specific authorization by the NRC. Categorization of future FSWOLs as Code Case Inspection Items C or F and future OWOLs as Code Case N-770-1 Inspection Items D or E has to be specifically authorized by the NRC, generally, as part of NRC's authorization to install the WOLs. Plant-specific authorization from the NRC to install FSWOLs or OWOLs and categorize the WOLs as Inspection Items C, D, E, and F, as appropriate, will not be needed after ASME Code Cases N-740 and N-754, or a suitable revision of these Code Cases, are endorsed in Regulatory Guide 1.147 with conditions, if applicable, and incorporated in $\$ 50.55 \mathrm{a}$. This condition is intended to ensure that WOL mitigations are designed, installed, and examined in a manner that will ensure an acceptable level of quality and safety before credit can be taken for the inspection frequencies of Inspection Items C, D, E, and F, as appropriate.

Code Case N-770-1, paragraph -2500(c) states that, "For axial and circumferential flaws, examination shall be performed to the maximum extent practical using qualified personnel and procedures. If essentially $100 \%$ coverage for circumferential flaws (100\% of the susceptible material volume) can be achieved, the examination for axial flaws shall be completed to achieve the maximum coverage practical." The NRC disagreed with this provision. Axial flaws can lead to through-wall cracks and leakage of reactor coolant, which is a safety concern. Condition $\$ 50.55 \mathrm{a}(\mathrm{g})(6)(\mathrm{ii})(\mathrm{F})(4)$ requires that the axial (flaw) examination coverage requirements of -2500 (c) may not be considered to be satisfied unless essentially 100 percent coverage is achieved. This condition was added for the NRC to ensure that, through NRC review of an authorization of alternative inspection coverage, appropriate actions are being taken to address potential inspection limitations for axial flaws. The industry guidelines of MRP-139 (EPRI 2005c) allow less than essentially 100\% coverage in some cases. This condition of the rule applies to the examination of all inspection items, including $\mathrm{C}$ and F (for FSWOLs) and D and $\mathrm{E}$ (for OWOLs).

Condition $\S 50.55 \mathrm{a}(\mathrm{g})(6)(\mathrm{ii})(\mathrm{F})(6)$ is an inservice inspection reporting requirement for mitigated welds if growth of existing flaws is found that exceeds the previous IWB-3600 flaw evaluations or if new flaws are detected. In such cases, licensees are required to provide a report to the NRC, prior to entering Mode 4, that summarizes licensee's flaw evaluation with inputs, methodologies, assumptions, and cause of the new flaw or flaw growth. This condition applies to FSWOLs and OWOLs as well as welds mitigated by other techniques. If volumetric examination detects new flaws or growth of existing flaws in the required examination volume, the mitigation will not be performing as designed and the NRC will need to evaluate the licensee's actions to address the problem. Therefore, this condition was added to verify the acceptability of the weld prior to being placed back in service.

Condition $\S 50.55 \mathrm{a}(\mathrm{g})(6)(\mathrm{ii})(\mathrm{F})(8)$ states that welds mitigated by OWOLs in Inspection Items D and E are not permitted to be placed into a population to be examined on a sample basis, as permitted by the Code Case, and must be examined once each inspection interval. If significant cracking were to occur in the Alloy 82/182 weld material, the more crack-resistant Alloy 52/152 optimized weld overlay material 
would substantially diminish or inhibit crack growth when the crack encounters the overlay. The postulation of a long flaw that is completely through the original weld is beyond the design basis, but it has been shown that OWOLs maintain structural integrity under design-basis loading, although the structural factors may be somewhat less than required by the ASME Code. The NRC staff was concerned that an OWOL with a weld cracked to this degree could prevent the weld from leaking and could potentially rupture without prior evidence of leakage under design-basis conditions. The NRC considered Condition $(\mathrm{F})(8)$ to be necessary to ensure that all optimized weld overlays are periodically inspected for potential degradation.

Condition $\S 50.55 \mathrm{a}(\mathrm{g})(6)(\mathrm{ii})(\mathrm{F})(9)$ pertains to scheduling and deferral of initial examinations and is discussed in Appendix B.1 in connection with Table 1, Note (11).

Condition $\S 50.55 \mathrm{a}(\mathrm{g})(6)(\mathrm{ii})(\mathrm{F})(10)$ pertains to the alternative examination volume for OWOLs discussed in Note (b) of Figure 5(a) of the Code Case. This condition states that this alternative examination volume may not be applied unless NRC approval is authorized under $\S 50.55 a(a)$ (3)(i) or (ii). This condition was applied because the alternative examination volume of Note (b) of Figure 5(a) was not provided in the proposed rule (75 FR 24324) and therefore was not available for public comment.

Based on the preceding discussion, it can be concluded that these conditions were developed by the NRC to ensure that the level of quality and safety provided by the requirements for WOLs is consistent with that provided by existing ASME Code and NRC requirements for butt welds that are not susceptible to PWSCC. 
Appendix C

\section{Dissimilar Metal Weld Inspection Limitations of a Typical Westinghouse Plant}





\section{Appendix C}

\section{Dissimilar Metal Weld Inspection Limitations of a Typical Westinghouse Plant}

\section{C.1 Introduction}

The information contained in this appendix was obtained during a workshop held with LMT, Inc., an inspection vendor for the commercial nuclear power industry. This vendor uses ultrasonic testing (UT) inspection methods qualified under ASME Code, Section XI, Appendix VIII, including phased-array (PA) techniques and conventional UT techniques in encoded and non-encoded delivery modes, as specified by the utility. This workshop was held to discuss the characteristics of UT data of indications attributed to stress corrosion cracking (SCC). This data was from encoded examinations of piping welds acquired from scans of the outside diameter (OD) surface. This workshop was also held to discuss limitations to achieving Code-required volume (CRV) coverage on Alloy 82/182 butt welds in a typical Westinghouse plant and a typical Combustion Engineering (CE) plant. This appendix provides information on limitations to obtaining the CRV coverage that may be encountered during examinations of Alloy 82/182 butt welds in the reactor coolant system in a Westinghouse plant.

Table C. 1 provides a listing of the Alloy 82/182 butt welds that are typically found in a Westinghouse plant. The location of these welds is depicted in Figure C.1. The CRV coverage for the Alloy 82/182 in butt welds in the piping systems in Table C.1 is dependent on site-specific configurations and allowable scan access thereof. Site-specific designs vary in regards to material and component configuration(s). Therefore, the coverage depicted is applicable only to the site-specific design used to prepare this document. Standard $45^{\circ}$ and $60^{\circ}$ angles were utilized for CRV coverage assessments unless specified otherwise in the illustrations. The Alloy 82/182 butt welds depicted in Sections A.2-A.4 in the sitespecific design used to prepare this document had been mitigated by weld overlays.

Table C.1. Alloy 82/182 Butt Welds and Dimensions in Typical Westinghouse

\begin{tabular}{lccc}
\hline \multicolumn{1}{c}{ Description } & Quantity & Circumference(Weld C/L) & Thickness (Weld C/L) \\
\hline PZR Surge Nozzle & 1 & $47.5^{\prime \prime}$ & $1.60^{\prime \prime}$ \\
PZR Spray Nozzle & 1 & $18.7^{\prime \prime}$ & $0.87^{\prime \prime}$ \\
PZR Safety \& Relief Nozzle & 4 & $25^{\prime \prime}$ & $1.37^{\prime \prime}$ \\
RPV Hot Leg Nozzle & $3 / 4$ & $113^{\prime \prime}$ & $2.50^{\prime \prime}$ \\
SG Hot Leg Nozzle & $3 / 4$ & $132.3^{\prime \prime}$ & $4.90^{\prime \prime}$ \\
SG Cold Leg Nozzle & $3 / 4$ & $132.3^{\prime \prime}$ & $4.90^{\prime \prime}$ \\
RPV Cold Leg Nozzle & $3 / 4$ & $113^{\prime \prime}$ & $2.50^{\prime \prime}$ \\
\hline
\end{tabular}

PZR - pressurizer; RPV - reactor pressure vessel; SG - steam generator; $3 / 4-3$ or 4 loops 


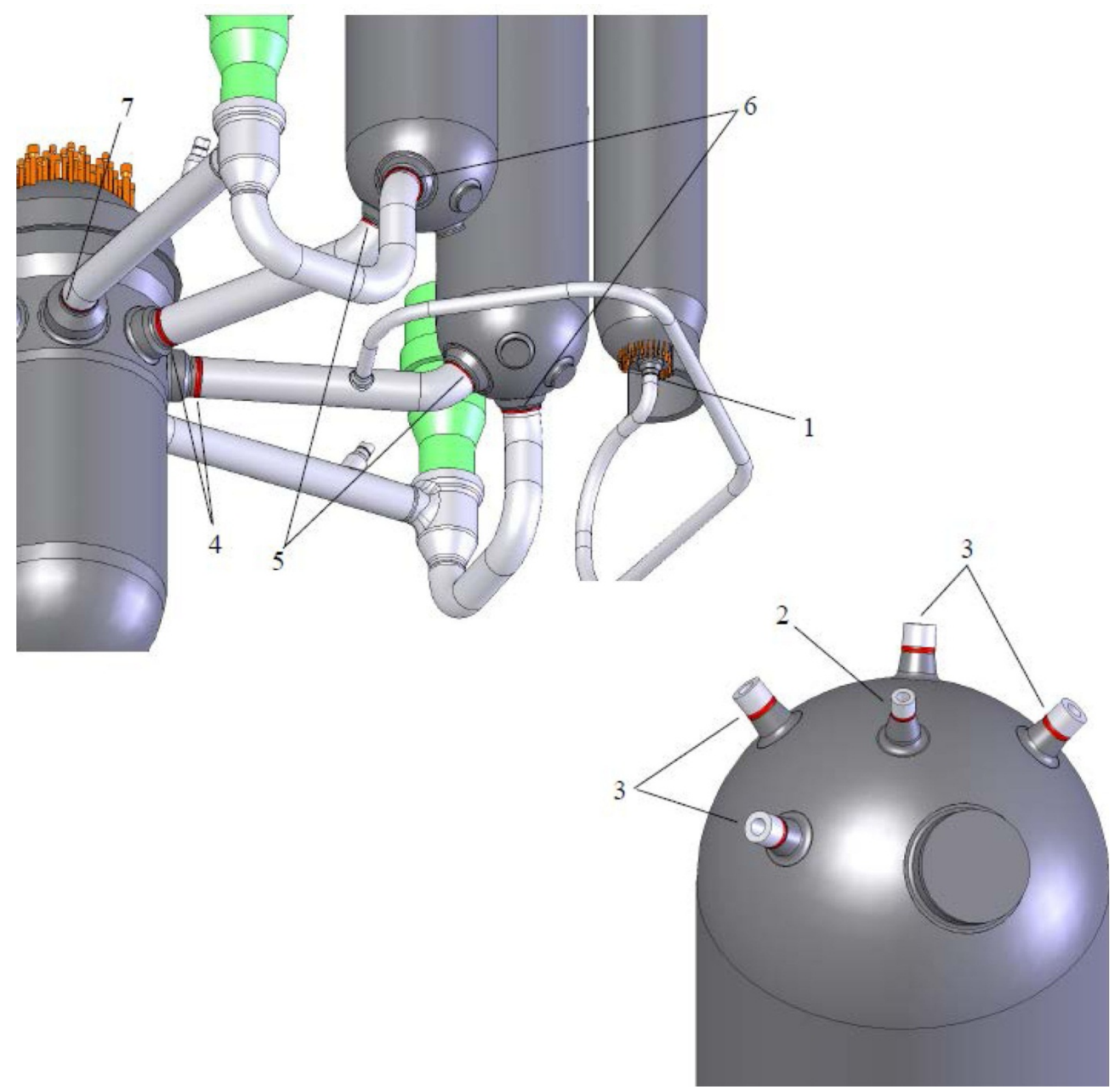

Figure C.1. Typical Locations of Alloy 82/182 Butt Welds in Westinghouse Design Plants 


\section{C.2 PZR Surge Nozzle}

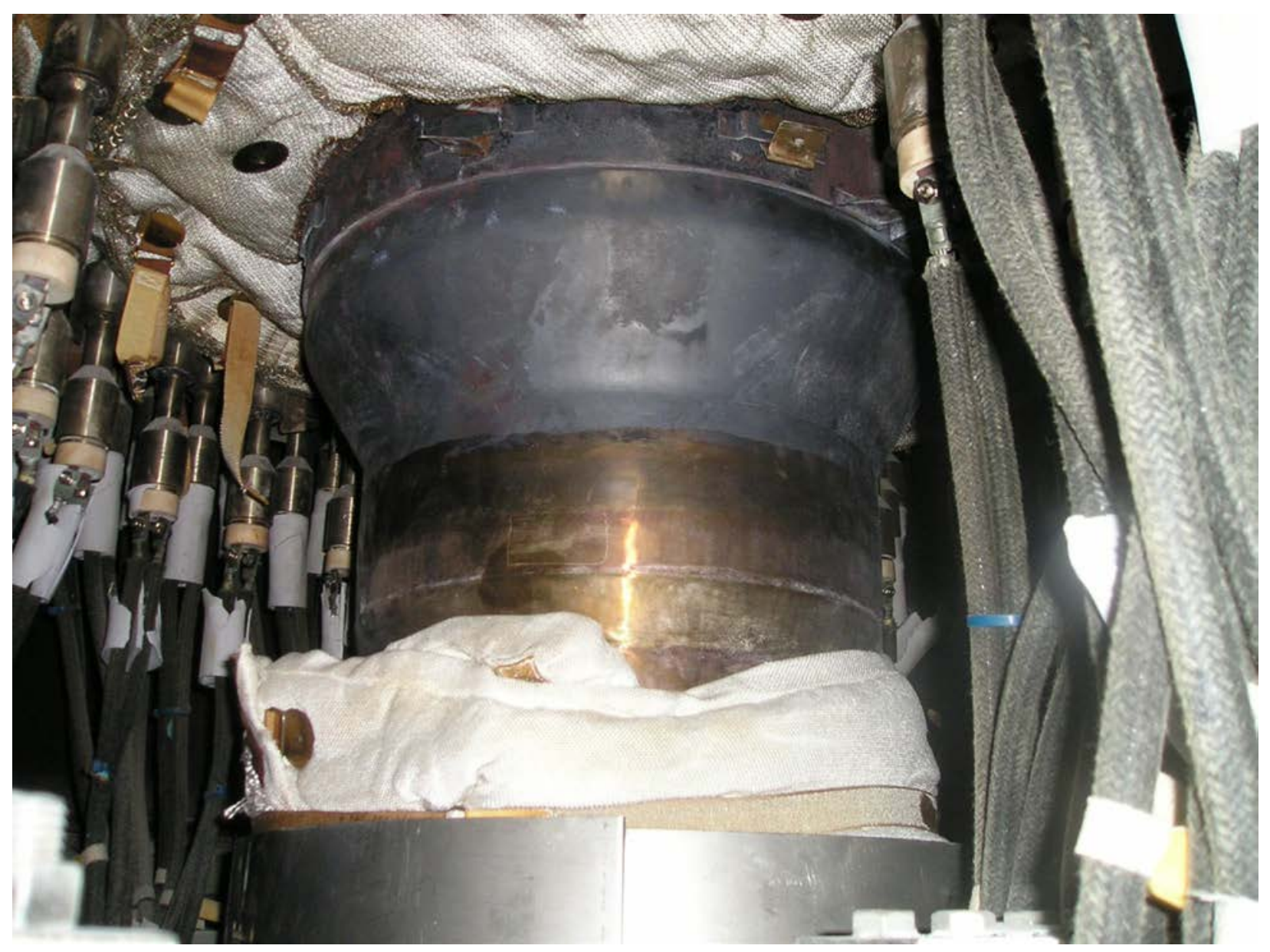

Figure C.2. Photograph of PZR Surge Nozzle, Nozzle Weld, and Safe End

The examination limitations for the PZR surge nozzle Alloy 82/182 butt weld were minimal scanning surface and the OD examination surface contour and condition.

The cross-sectional examination coverage in the axial scan direction for circumferential flaws is depicted in Figure C.3. The axial scan direction CRV coverage achievable was $80 \%$. The cross-sectional examination coverage in the circumferential scan direction for axial flaws is depicted in Figure C.4. The circumferential scan direction CRV coverage achievable was $100 \%$. 


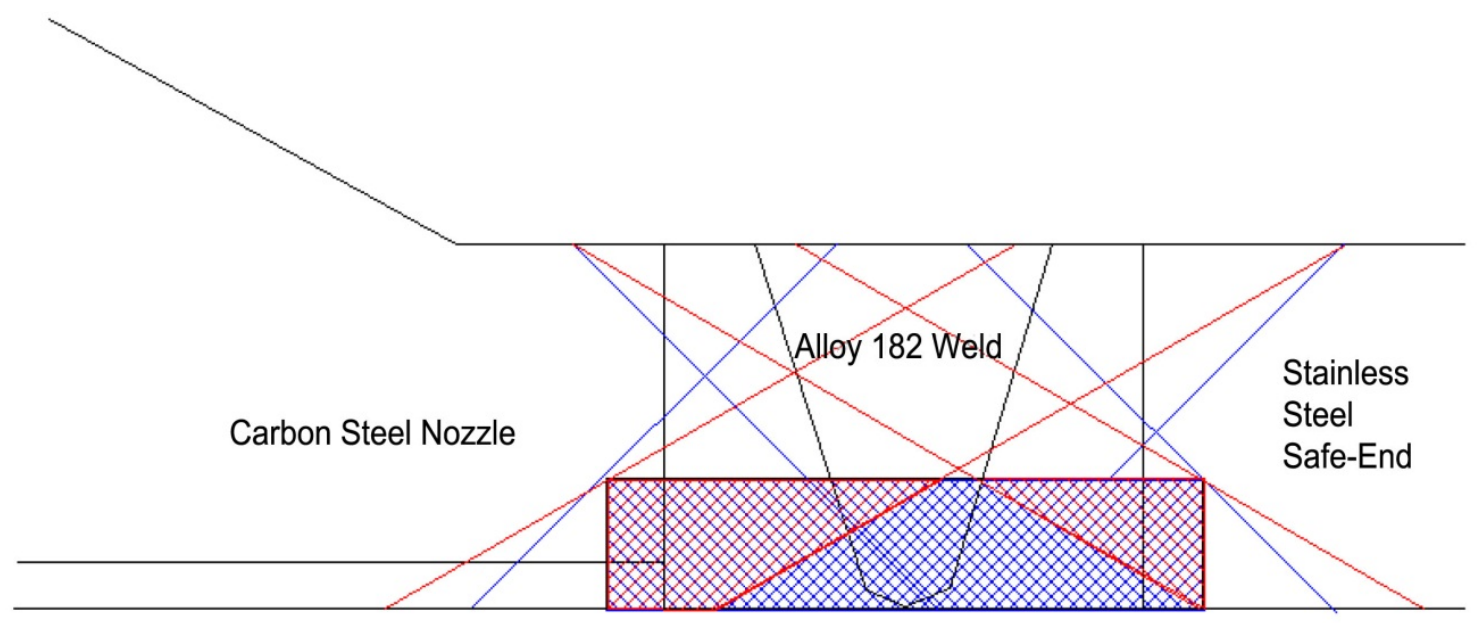

Figure C.3. PZR Surge Nozzle Weld Axial Scan CRV Coverage Assessment

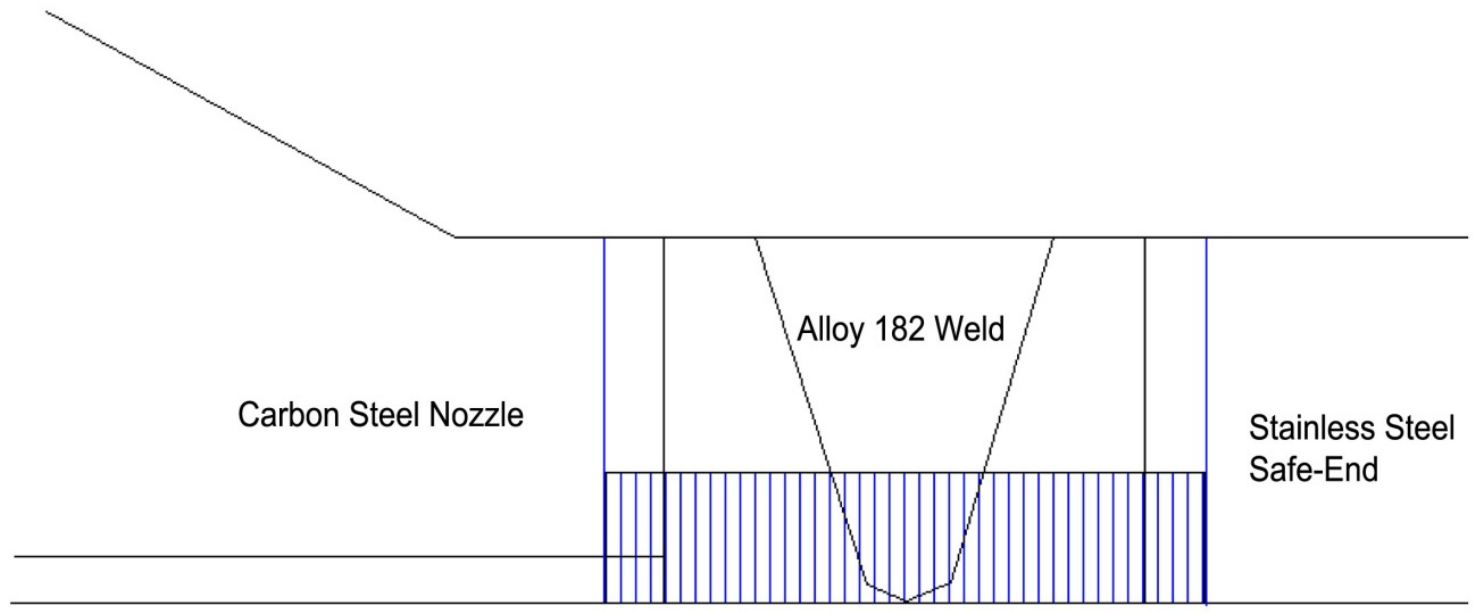

Figure C.4. PZR Surge Nozzle Weld Circumferential Scan CRV Coverage Assessment 


\section{C.3 PZR Spray Nozzle}

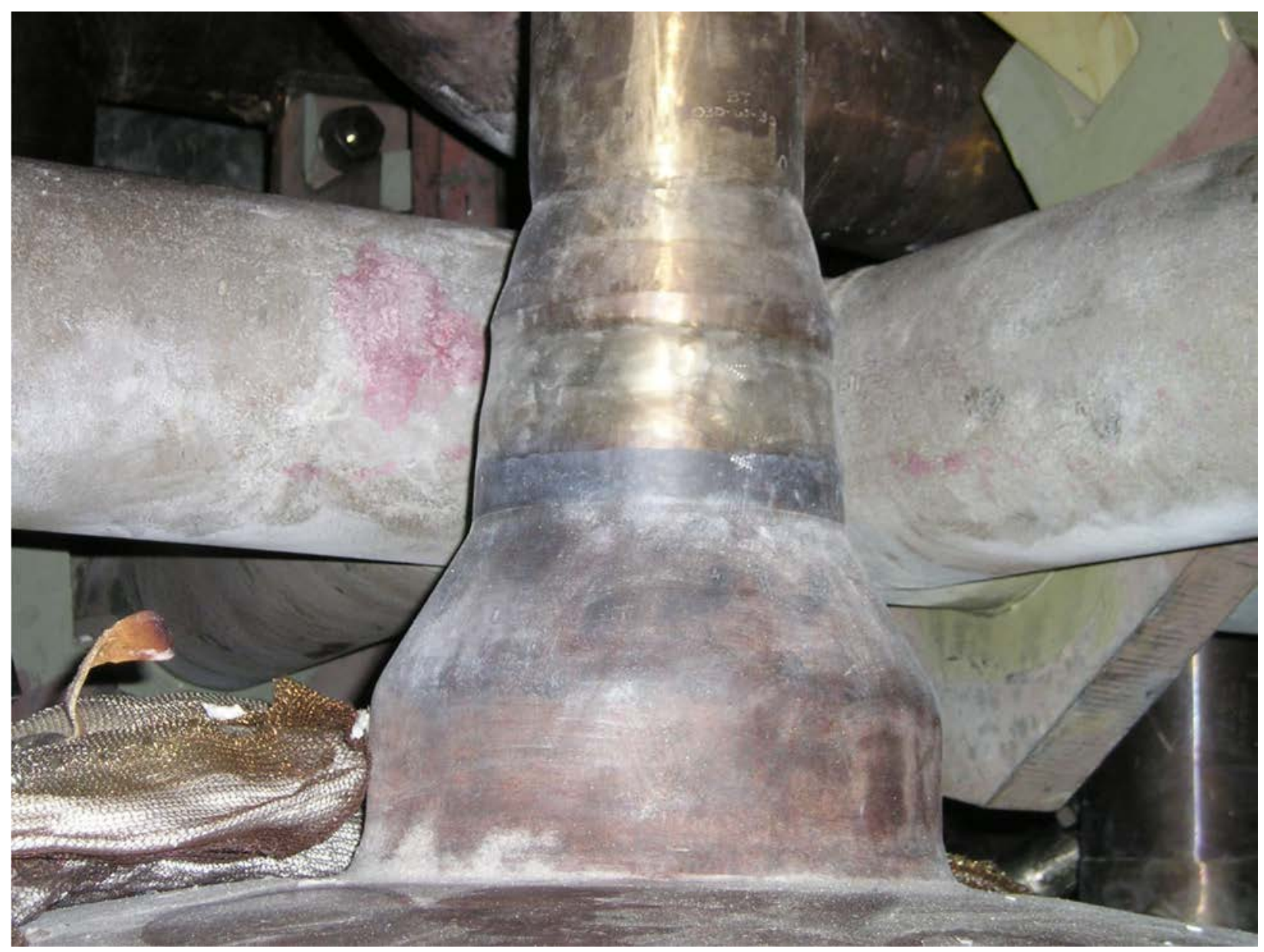

Figure C.5. Photograph of PZR Spray Nozzle, Nozzle Weld, and Safe End

The examination limitations for the PZR spray nozzle Alloy 82/182 butt weld were minimal scanning surface and the OD examination surface contour and condition.

The cross-sectional examination coverage in the axial scan direction for circumferential flaws is depicted in Figure C.6. The axial scan direction CRV coverage achievable was $40 \%$. The cross-sectional examination coverage in the circumferential scan direction for axial flaws is depicted in Figure C.7. The circumferential scan direction CRV coverage achievable was $34 \%$. 


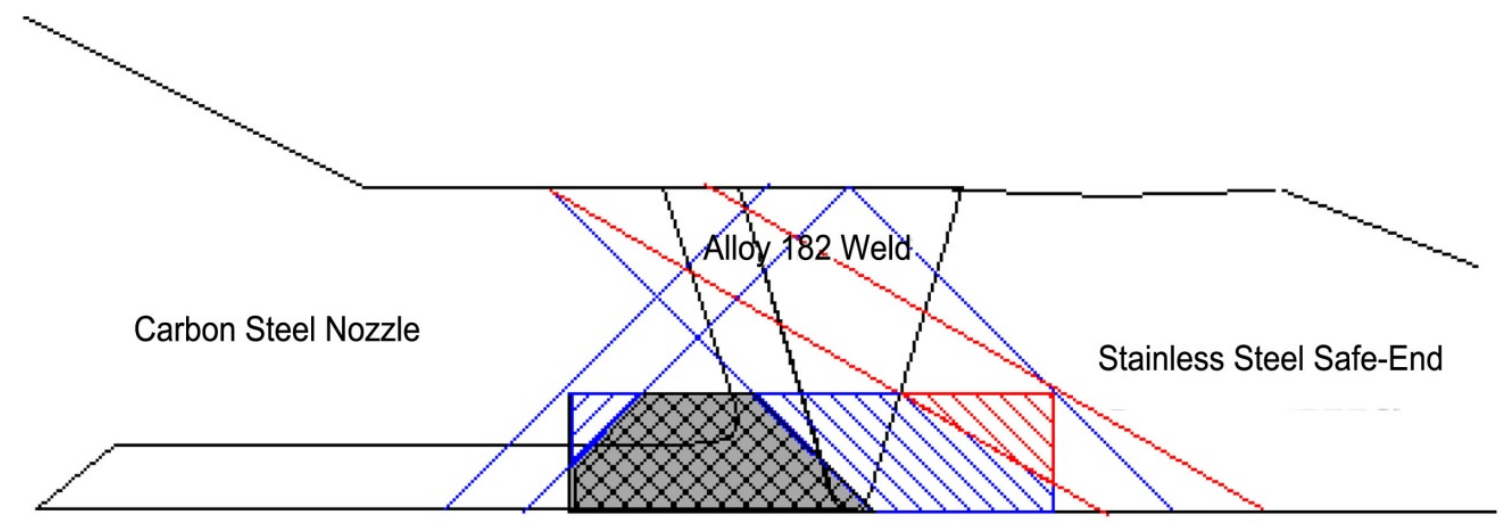

Figure C.6. PZR Spray Nozzle Weld Axial Scan CRV Coverage Assessment

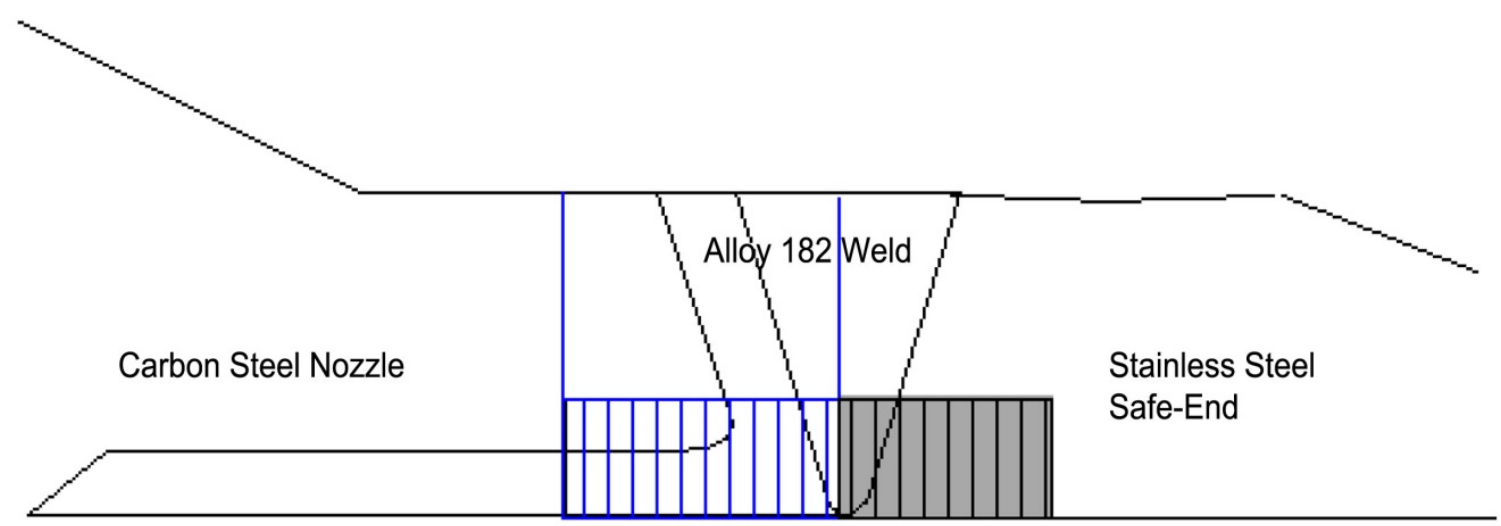

Figure C.7. PZR Spray Nozzle Weld Circumferential Scan CRV Coverage Assessment 


\section{C.4 PZR Safety and Relief Nozzle}

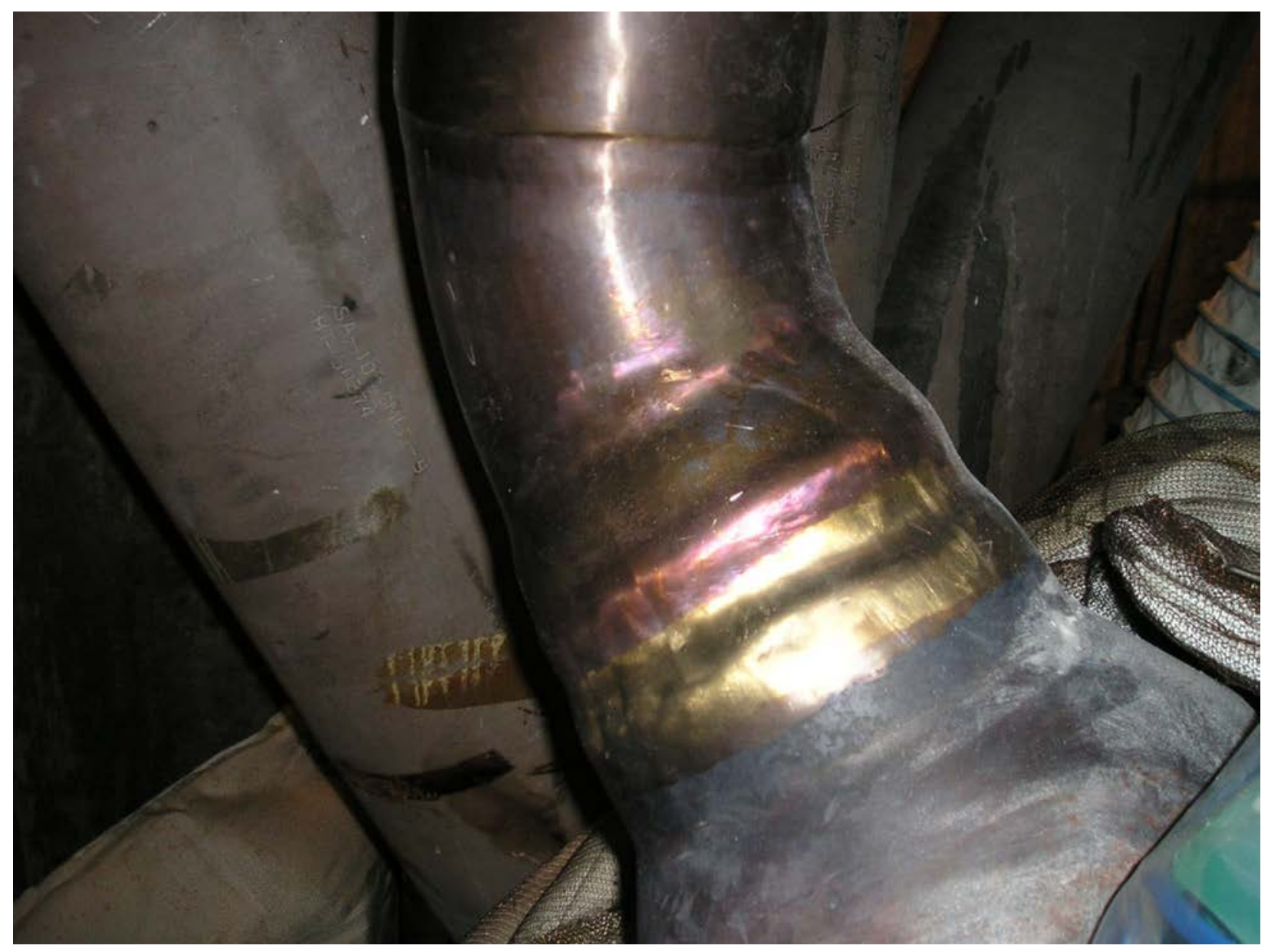

Figure C.8. Photograph of PZR Safety and Relief Nozzle, Nozzle Weld, and Safe End

The examination limitations for the PZR safety and relief nozzle Alloy 82/182 butt weld were minimal scanning surface and the OD examination surface contour and condition.

The cross-sectional examination coverage in both the axial scan direction for circumferential flaws and in the circumferential direction for axial flaws was $0 \%$. This configuration does not allow a meaningful examination for either circumferential or axial flaws. The cross-sectional examination coverage for both scan directions is depicted in the assessment diagram in Figure C.9. 


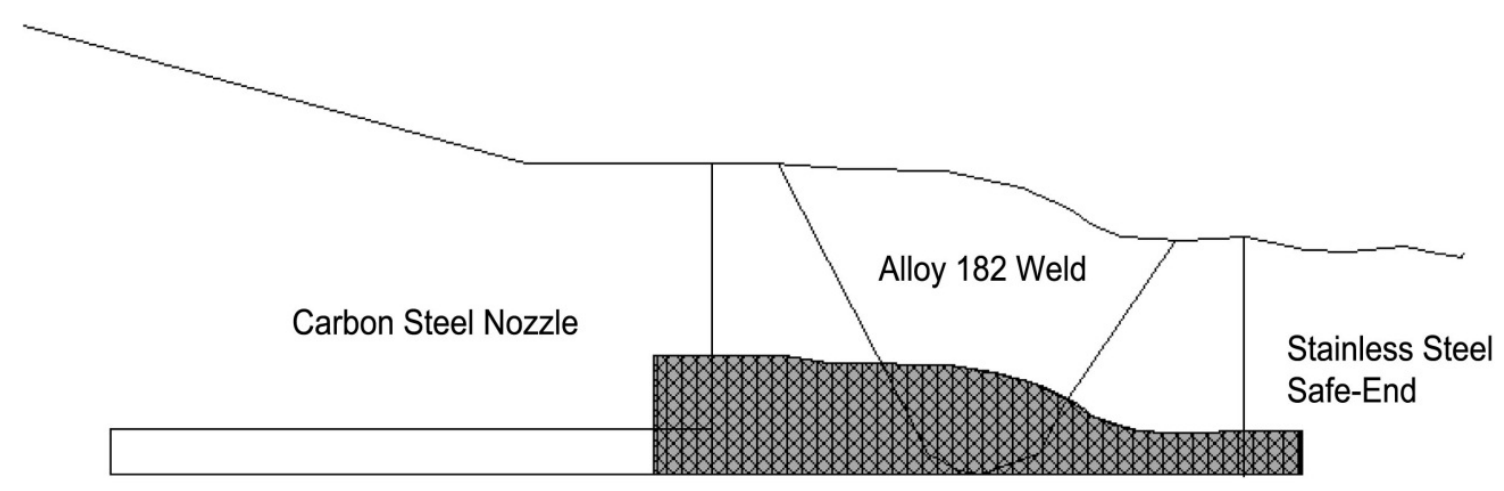

Figure C.9. PZR Safety and Relief Nozzle Weld Axial Scan CRV Coverage Assessment

\section{C.5 Reactor Pressure Vessel Hot Leg Nozzle}

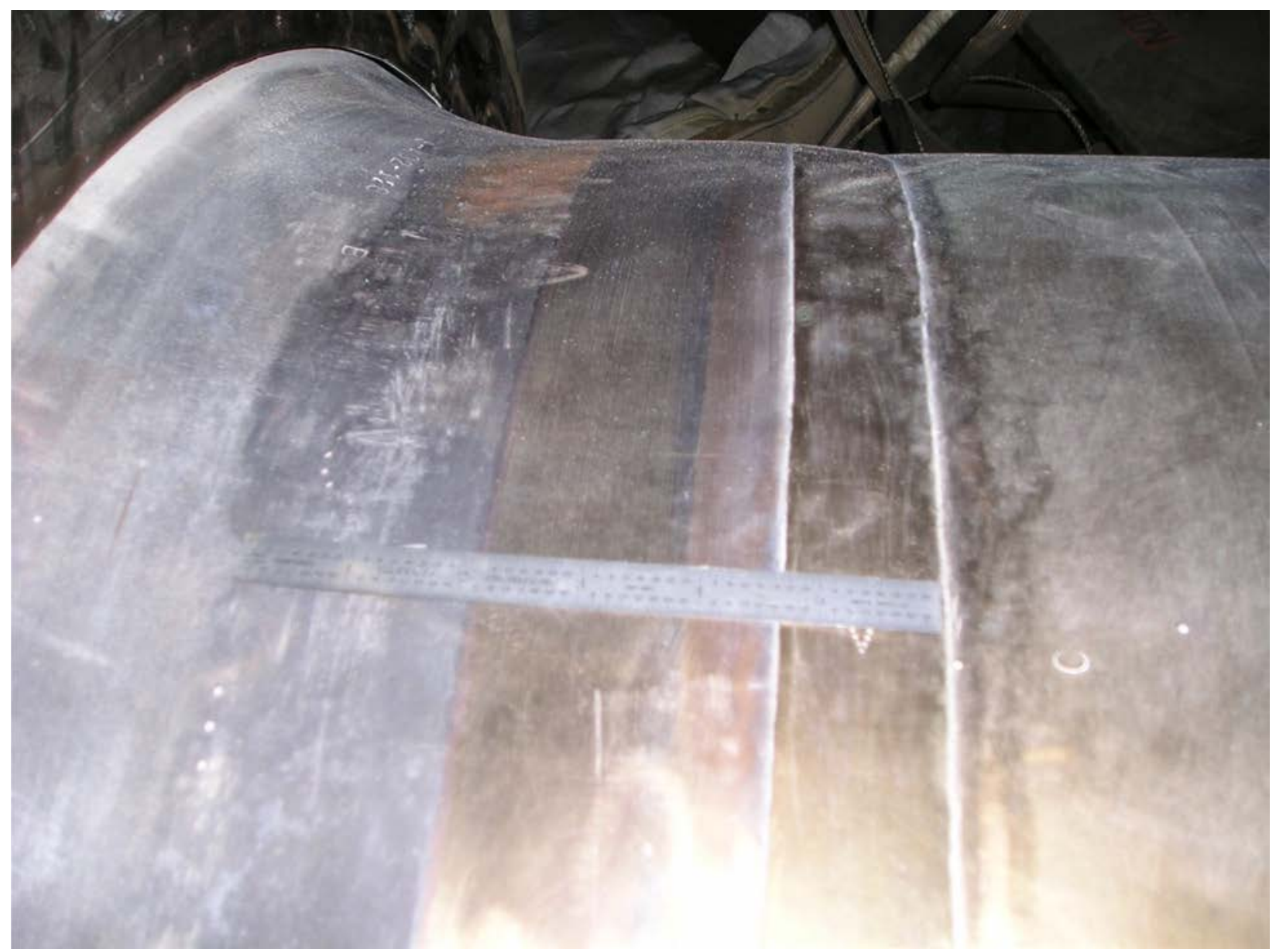

Figure C.10. RPV Hot Leg Nozzle, Nozzle Weld, and Safe End 
The examination limitations for the RPV hot leg nozzle Alloy 82/182 butt weld were minimal scanning surface and OD examination surface contour and condition.

The cross-sectional examination coverage in the axial scan direction for circumferential flaws is depicted in Figure C.11. The axial scan direction CRV coverage achievable was $28.8 \%$. The crosssectional examination coverage in the circumferential scan direction for axial flaws is depicted in Figure C.12. The circumferential scan direction CRV coverage achievable was $100 \%$.

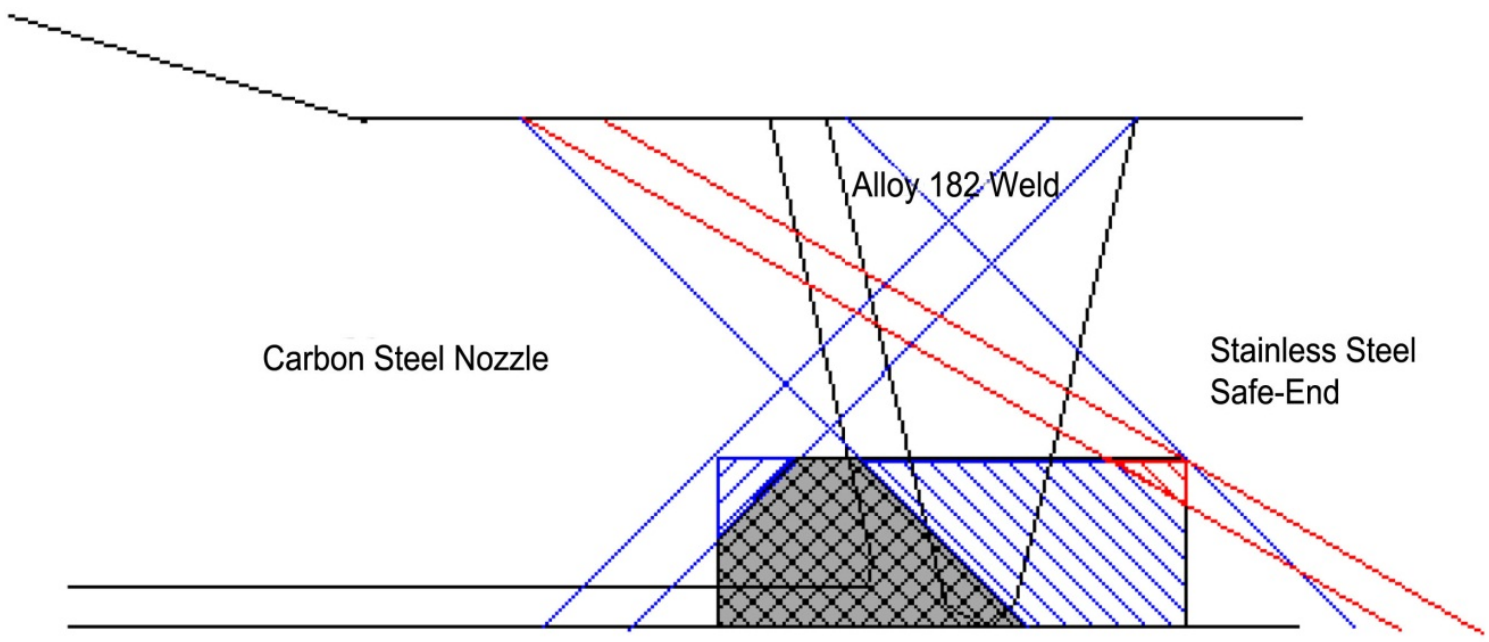

Figure C.11. RPV Hot Leg Nozzle Weld Axial Scan CRV Coverage Assessment

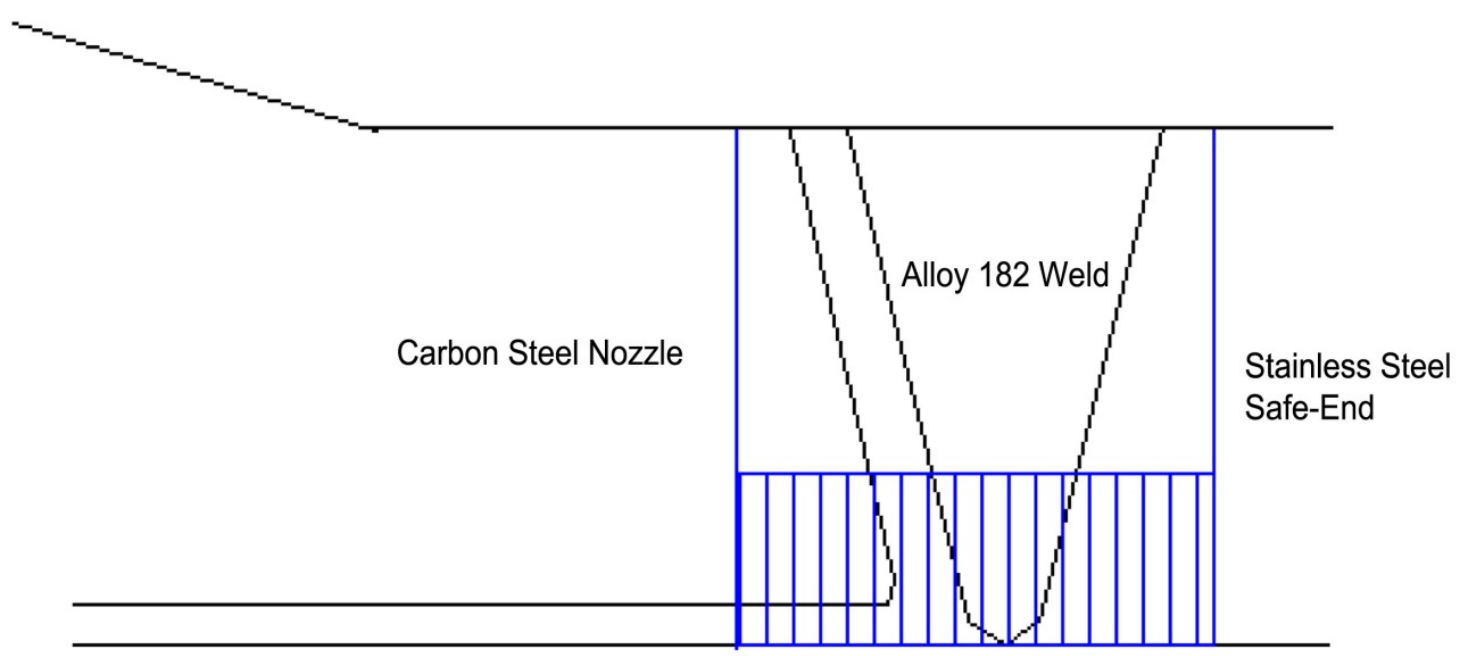

Figure C.12. RPV Hot Leg Nozzle Weld Circumferential Scan CRV Coverage Assessment 


\section{C.6 Steam Generator Hot Leg Nozzle}

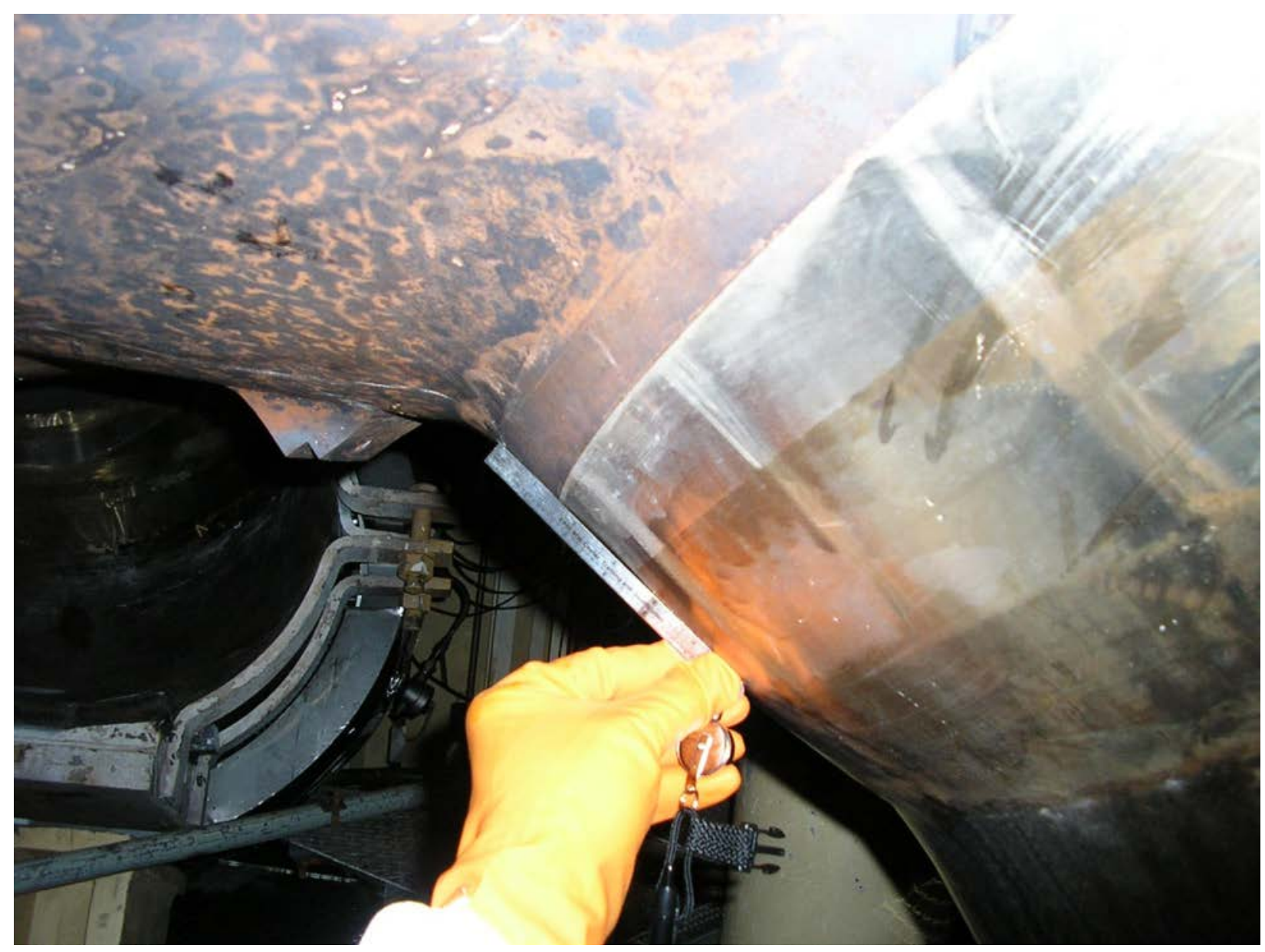

Figure C.13. Photograph of Steam Generator Hot Leg Nozzle, Nozzle Weld, and Safe End

The examination limitations for the RPV hot leg nozzle Alloy 82/182 butt weld were minimal scanning surface and OD examination surface contour and condition.

The cross-sectional examination coverage in the axial scan direction for circumferential flaws is depicted in Figure C.14. The axial scan direction CRV coverage achievable was 95.4\%. This examination consisted, in part, of a PAUT technical justification of performance demonstration per sitespecific mock-up criteria. The cross-sectional examination coverage in the circumferential scan direction for axial flaws is depicted in Figure C.15. The axial scan direction CRV coverage achievable was 100\%. 


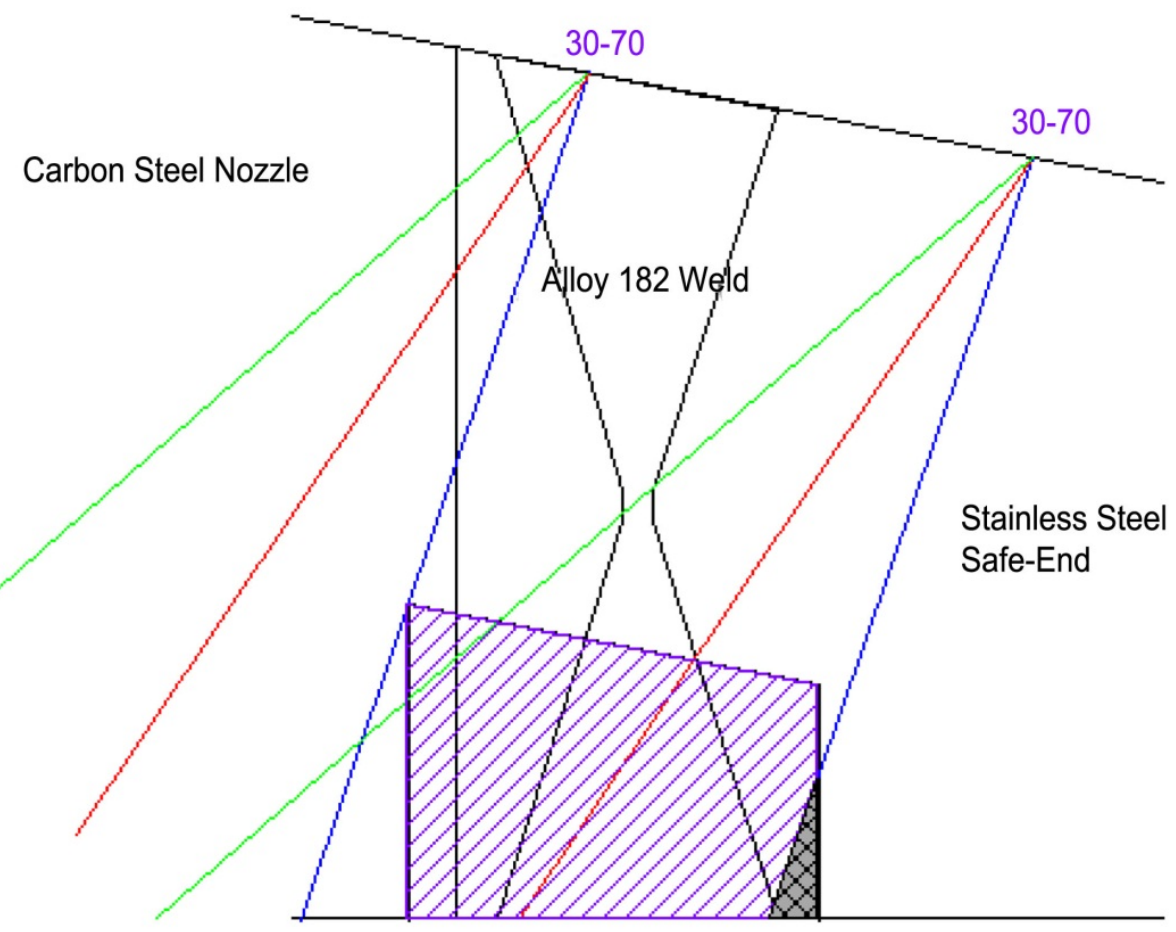

Figure C.14. Steam Generator Hot Leg Nozzle Weld Axial Scan CRV Coverage Assessment

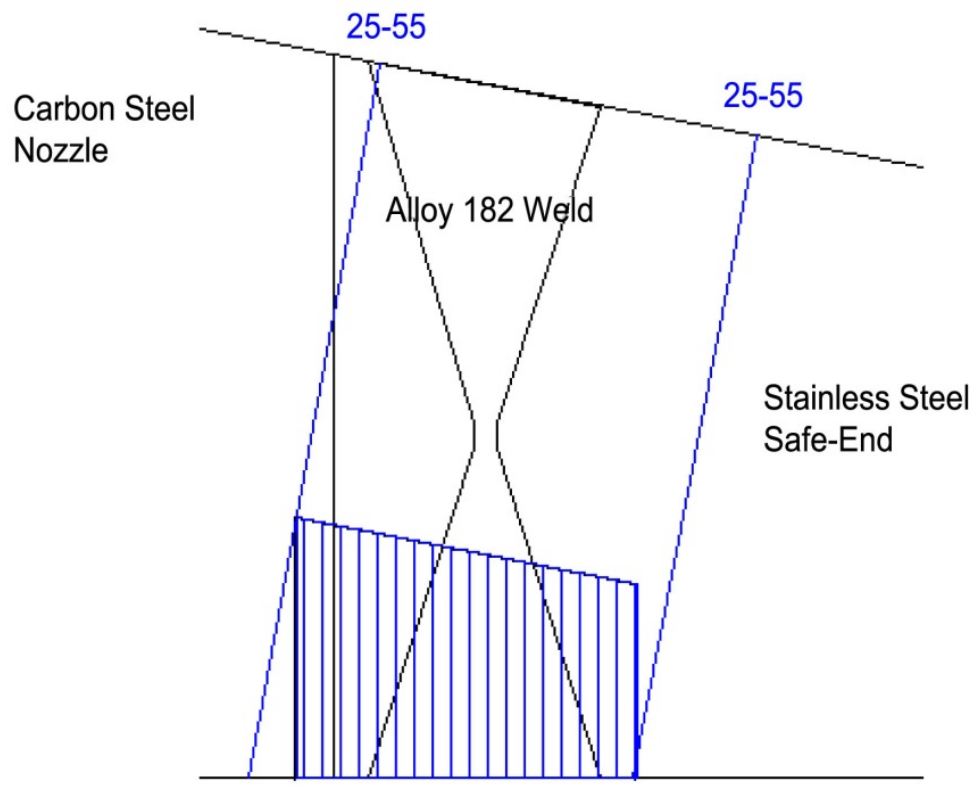

Figure C.15. Steam Generator Hot Leg Nozzle Weld Circumferential Scan CRV Coverage Assessment 


\section{C.7 Steam Generator Cold Leg Nozzle}

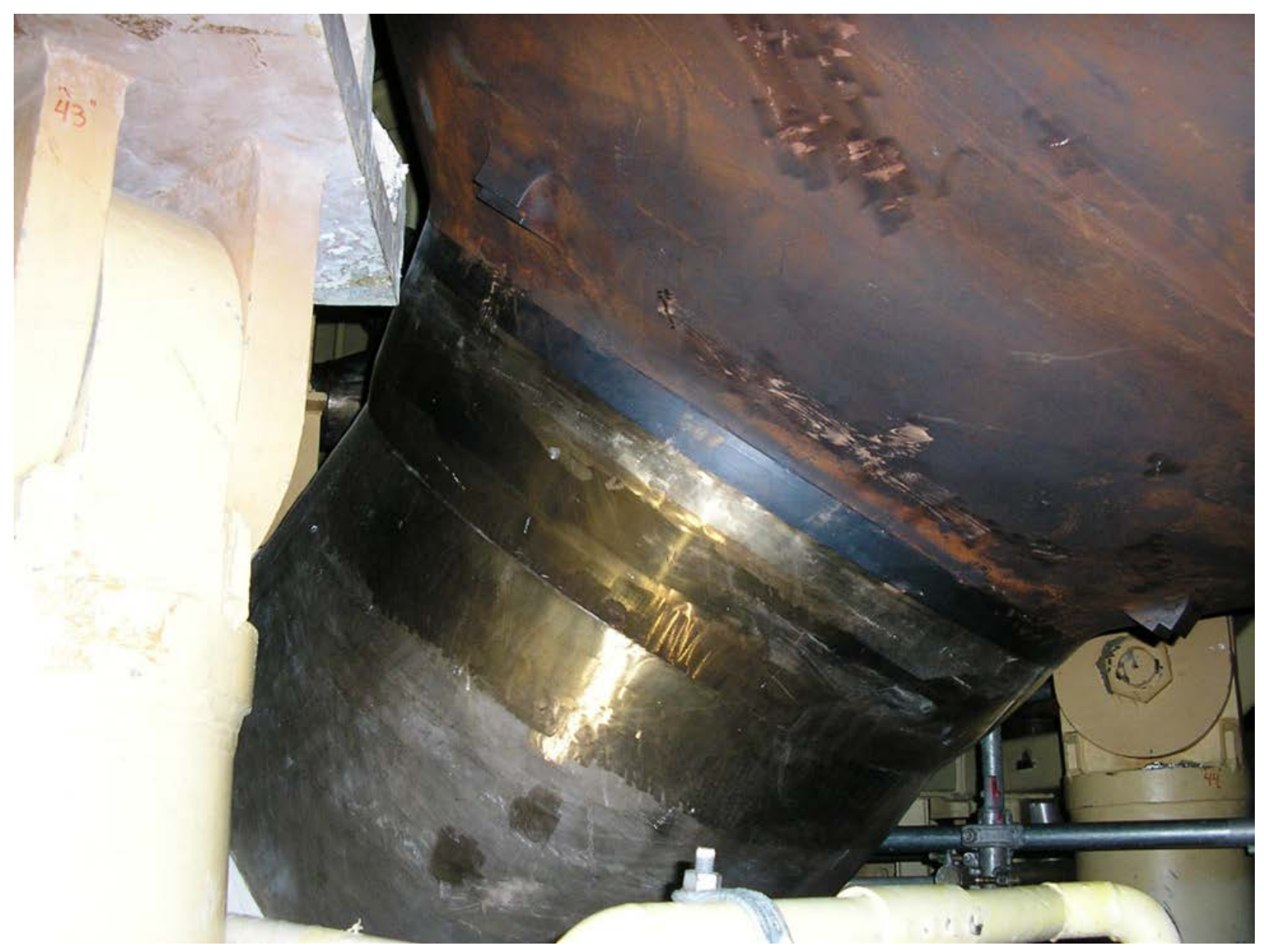

Figure C.16. Photograph of Steam Generator Cold Leg Nozzle, Nozzle Weld, and Safe End

The examination limitations for the steam generator cold leg nozzle Alloy 82/182 butt weld were minimal scanning surface and OD examination surface contour and condition.

The cross-sectional examination coverage in the axial scan direction for circumferential flaws is depicted in Figure C.17. The axial scan direction CRV coverage achievable was 95.4\%. This examination consisted, in part, of a PAUT technical justification of performance demonstration per sitespecific mock-up criteria. The cross-sectional examination coverage in the circumferential scan direction for axial flaws is depicted in Figure C.18. The axial scan direction CRV coverage achievable was 100\%. 


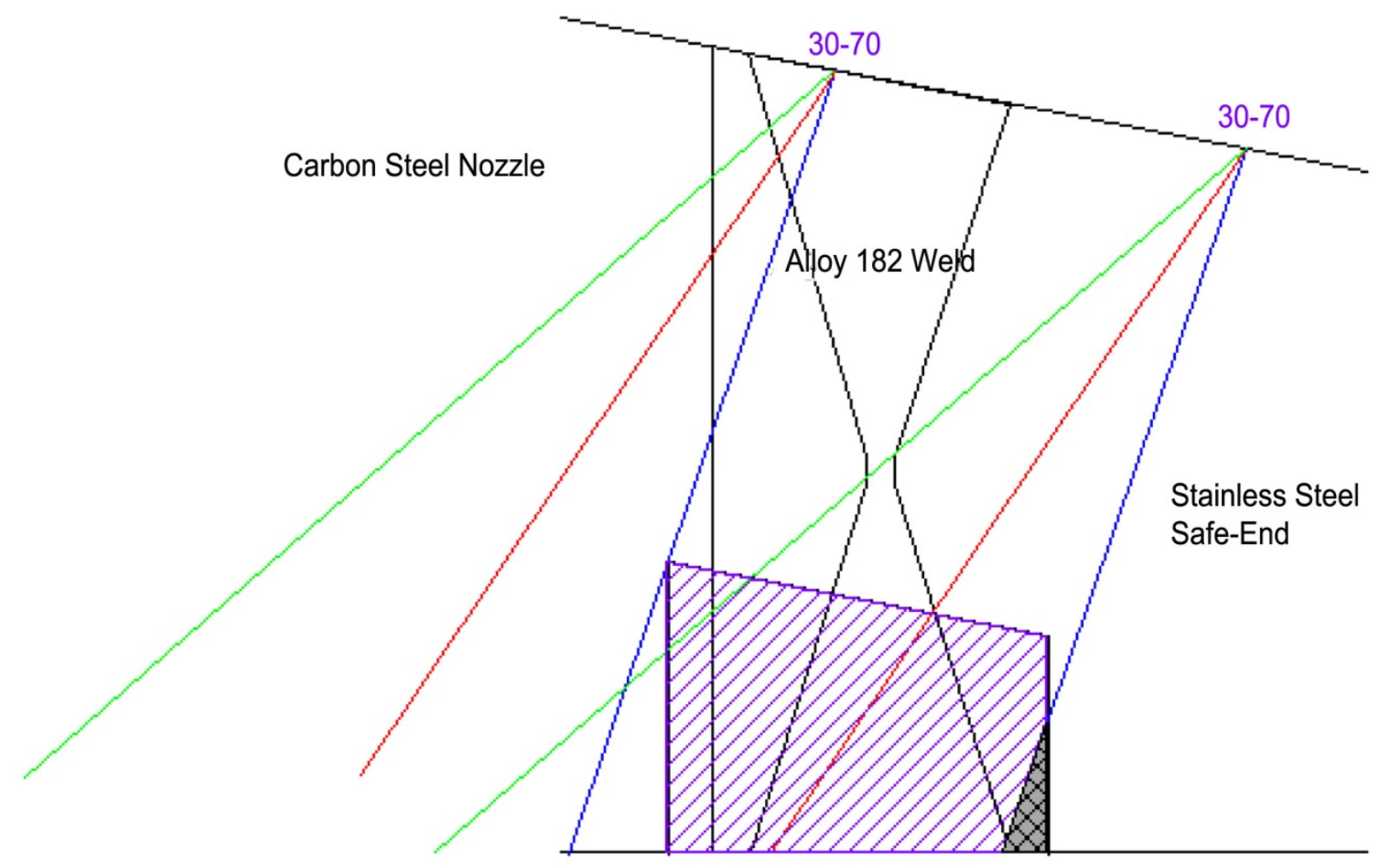

Figure C.17. Steam Generator Cold Leg Nozzle Weld Axial Scan CRV Coverage Assessment

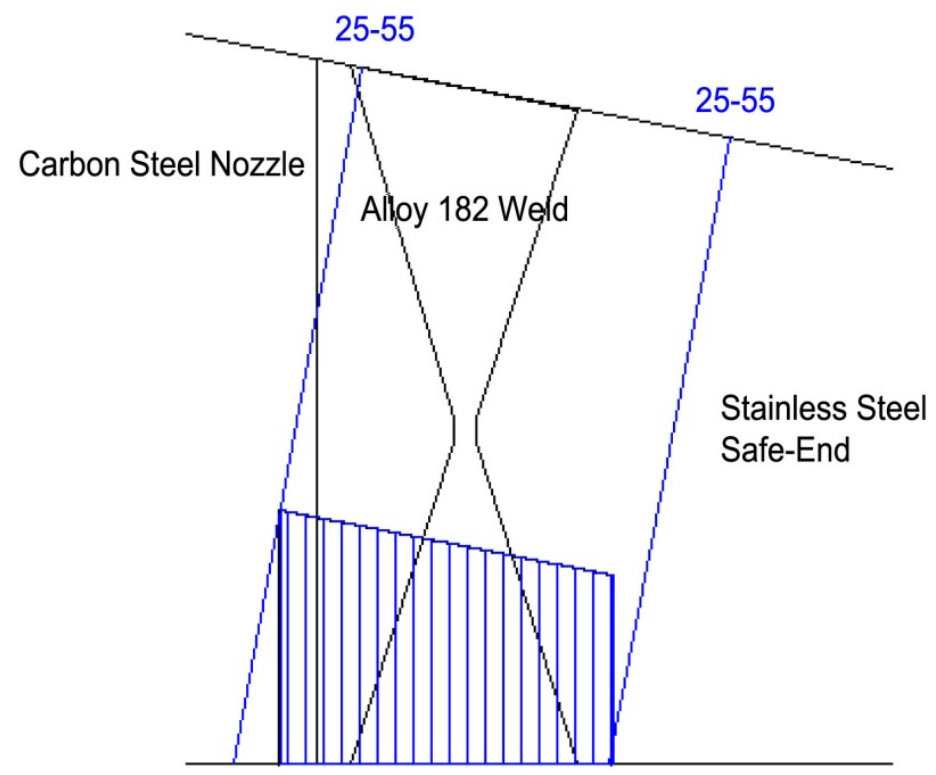

Figure C.18. Steam Generator Cold Leg Nozzle Weld Circumferential Scan CRV Coverage Assessment 


\section{C.8 RPV Cold Leg Nozzle}

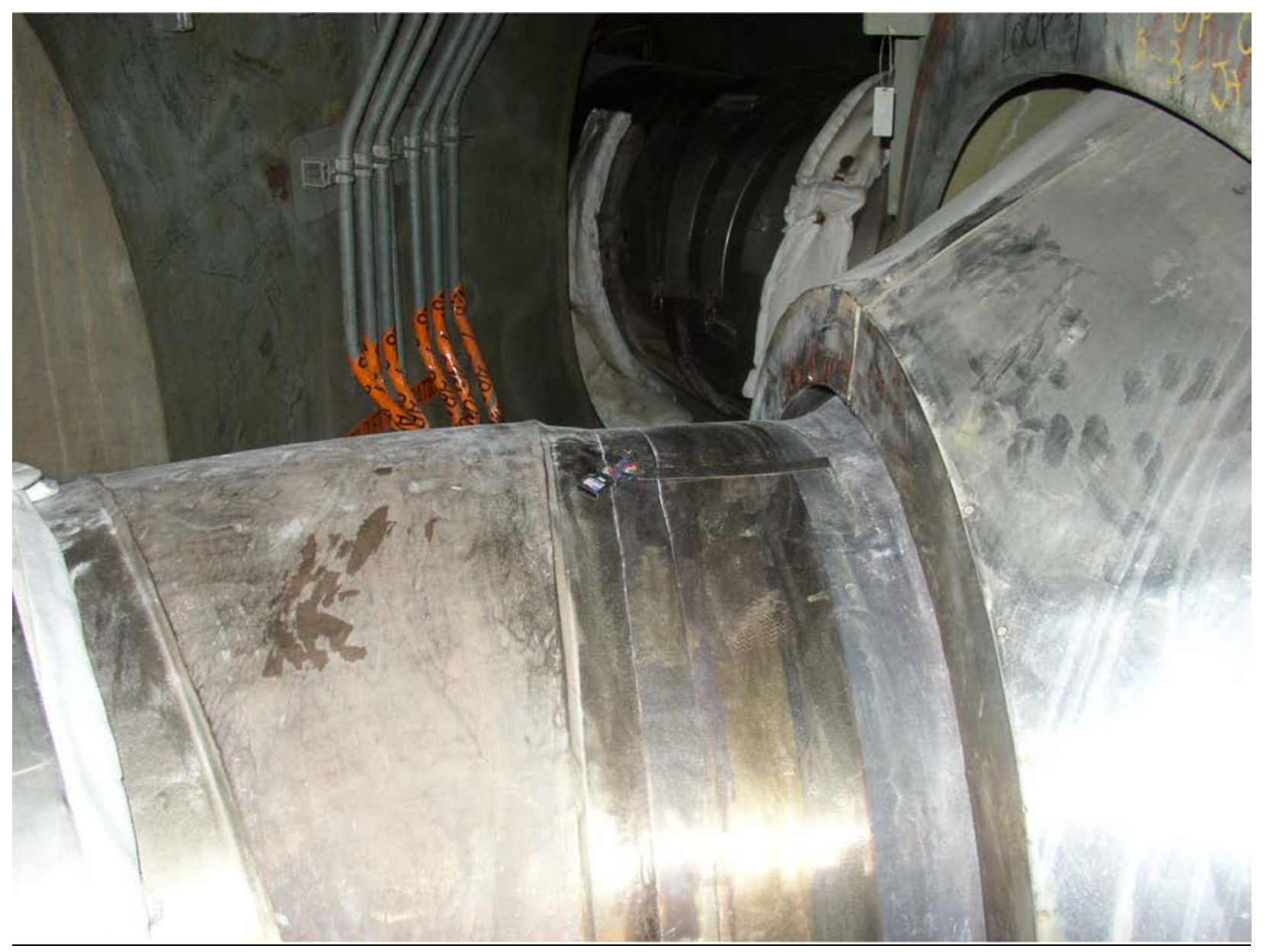

Figure C.19. Photograph of RPV Cold Leg Nozzle

The examination limitations for the steam generator cold leg nozzle Alloy 82/182 butt weld were minimal scanning surface and OD examination surface contour and condition.

The cross-sectional examination coverage in the axial scan direction for circumferential flaws is depicted in Figure C.20. The axial scan direction CRV coverage achievable was $100 \%$. This examination consisted, in part, of a PAUT technical justification of performance demonstration per sitespecific mock-up criteria. The cross-sectional examination coverage in the circumferential scan direction for axial flaws is depicted in Figure C.21. The axial scan direction CRV coverage achievable was 100\%. 


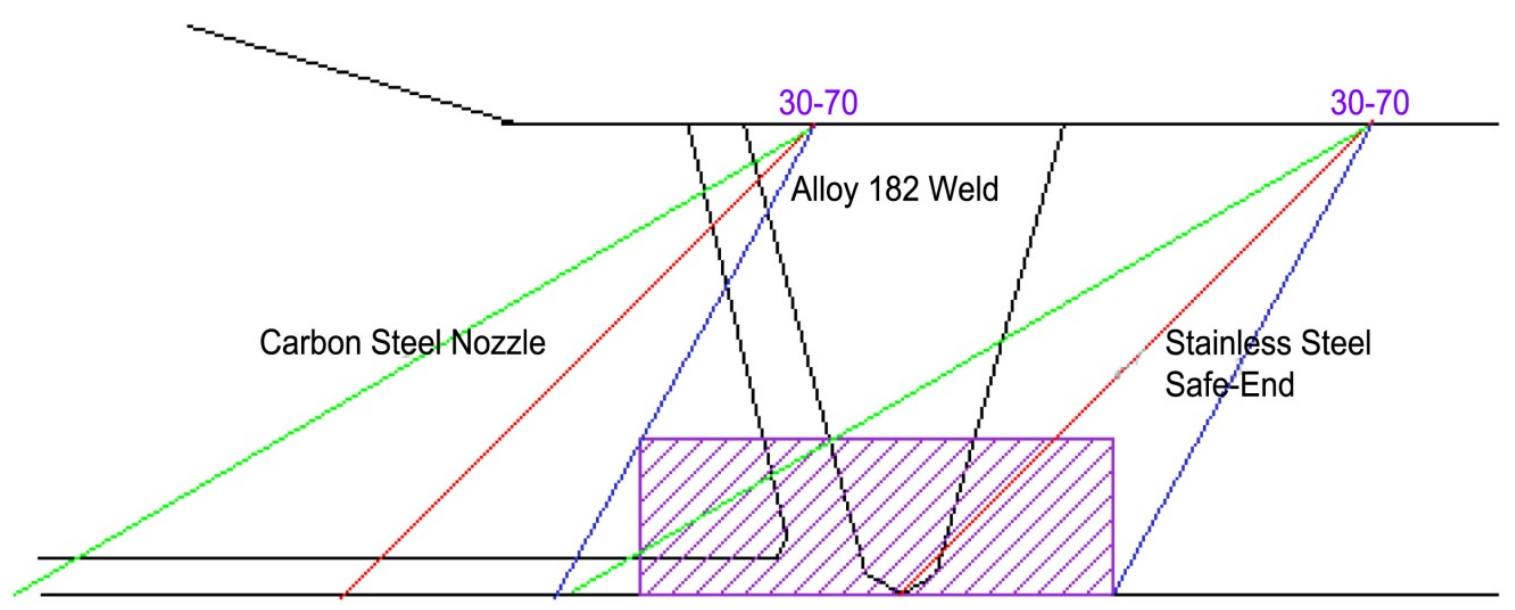

Figure C.20. RPV Cold Leg Nozzle Weld Axial Scan CRV Coverage

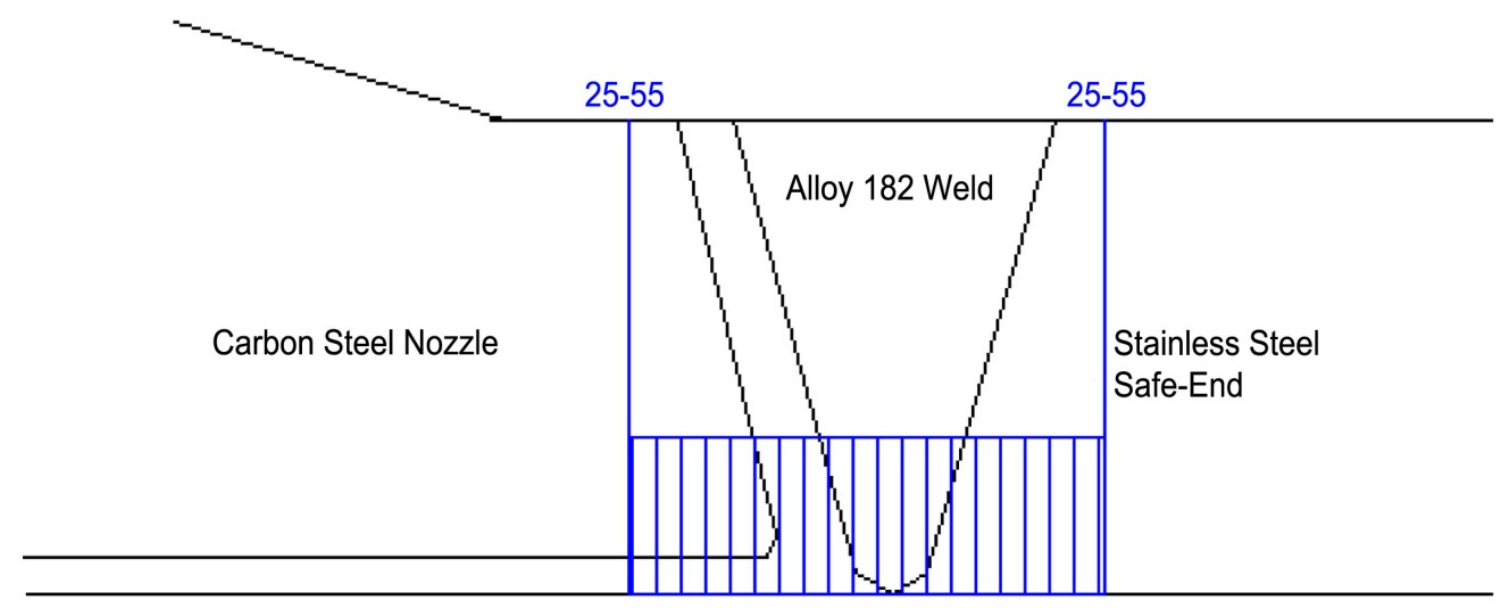

Figure C.21. RPV Cold Leg Nozzle Weld Circumferential Scan CRV Coverage 



\section{Appendix D}

\section{Dissimilar Metal Weld Inspection Limitations of a Typical Combustion Engineering (CE) Plant}





\section{Appendix D}

\section{Dissimilar Metal Weld Inspection Limitations of a Typical Combustion Engineering (CE) Plant}

\section{D.1 Introduction}

The information contained in this appendix was obtained during a workshop held with LMT, Inc., an inspection vendor for the commercial nuclear power industry. This vendor uses ultrasonic testing (UT) inspection methods qualified under ASME Code, Section XI, Appendix VIII, including phased-array (PA) techniques and conventional UT techniques in encoded and non-encoded delivery modes, as specified by the utility. This workshop was held to discuss the characteristics of UT data of indications attributed to stress corrosion cracking (SCC). This data was from encoded examinations of piping welds acquired from scans of the outside diameter (OD) surface. This workshop was also held to discuss limitations to achieving Code-required volume (CRV) coverage on Alloy 82/182 butt welds in a typical Westinghouse plant and a typical Combustion Engineering (CE) plant. This appendix provides information on limitations to obtaining the CRV coverage that may be encountered during examinations of Alloy 82/182 butt welds in the reactor coolant system in a CE plant.

Table D.1 provides a listing of the Alloy $82 / 182$ butt welds that are typically found in a CE plant. The location of these welds is depicted in Figure D.1. The CRV coverage for the Alloy 82/182 butt welds in the piping systems in in Table D.1 is dependent on site-specific configurations and allowable scan access thereof. Site-specific designs vary in regards to material and component configuration(s). Therefore, the coverage depicted is applicable only to the site-specific design used to prepare this document. Standard $45^{\circ}$ and $60^{\circ}$ angles were utilized for CRV coverage assessments unless specified otherwise in the illustrations. The Alloy 82/182 butt welds depicted in Sections D.2-D.13 in the sitespecific design used to prepare this document had been mitigated by weld overlays. 
Table D.1. Alloy $82 / 182$ Butt Welds and Dimensions in Typical CE Plant

\begin{tabular}{lccc}
\hline \multicolumn{1}{c}{ Description } & Quantity & Circumference (Weld C/L) & Thickness (Weld C/L) \\
\hline RCP Suction to RC Pipe & 4 & $36.60^{\prime \prime}$ & $3.45^{\prime \prime}$ \\
RCP Discharge to RC Pipe & 4 & $36.60^{\prime \prime}$ & $3.35^{\prime \prime}$ \\
RC Loop Surge Nozzle & 1 & $42.00^{\prime \prime}$ & $1.57^{\prime \prime}$ \\
Letdown and Drain Nozzle & 4 & $3.90^{\prime \prime}$ & $0.90^{\prime \prime}$ \\
Hot Leg Drain Nozzle & 1 & $3.90^{\prime \prime}$ & $0.90^{\prime \prime}$ \\
Charging Inlet Nozzle & 2 & $18.00^{\prime \prime}$ & $1.20^{\prime \prime}$ \\
Safety Injection Nozzle & 4 & $42.00^{\prime \prime}$ & $1.55^{\prime \prime}$ \\
Shutdown Cooling Nozzle & 1 & $50.25^{\prime \prime}$ & $1.57^{\prime \prime}$ \\
Spray Nozzle & 2 & $16.00^{\prime \prime}$ & $0.93^{\prime \prime}$ \\
PZR Surge Nozzle & 1 & $41.00^{\prime \prime}$ & $1.59^{\prime \prime}$ \\
PZR Spray Nozzle & 1 & $5.20^{\prime \prime}$ & $0.83^{\prime \prime}$ \\
PZR Safety Nozzle & 3 & $7.95^{\prime \prime}$ & $1.40^{\prime \prime}$ \\
\hline RCP - reactor coolant pump; RC - reactor coolant; PZR - pressurizer & \\
\hline
\end{tabular}




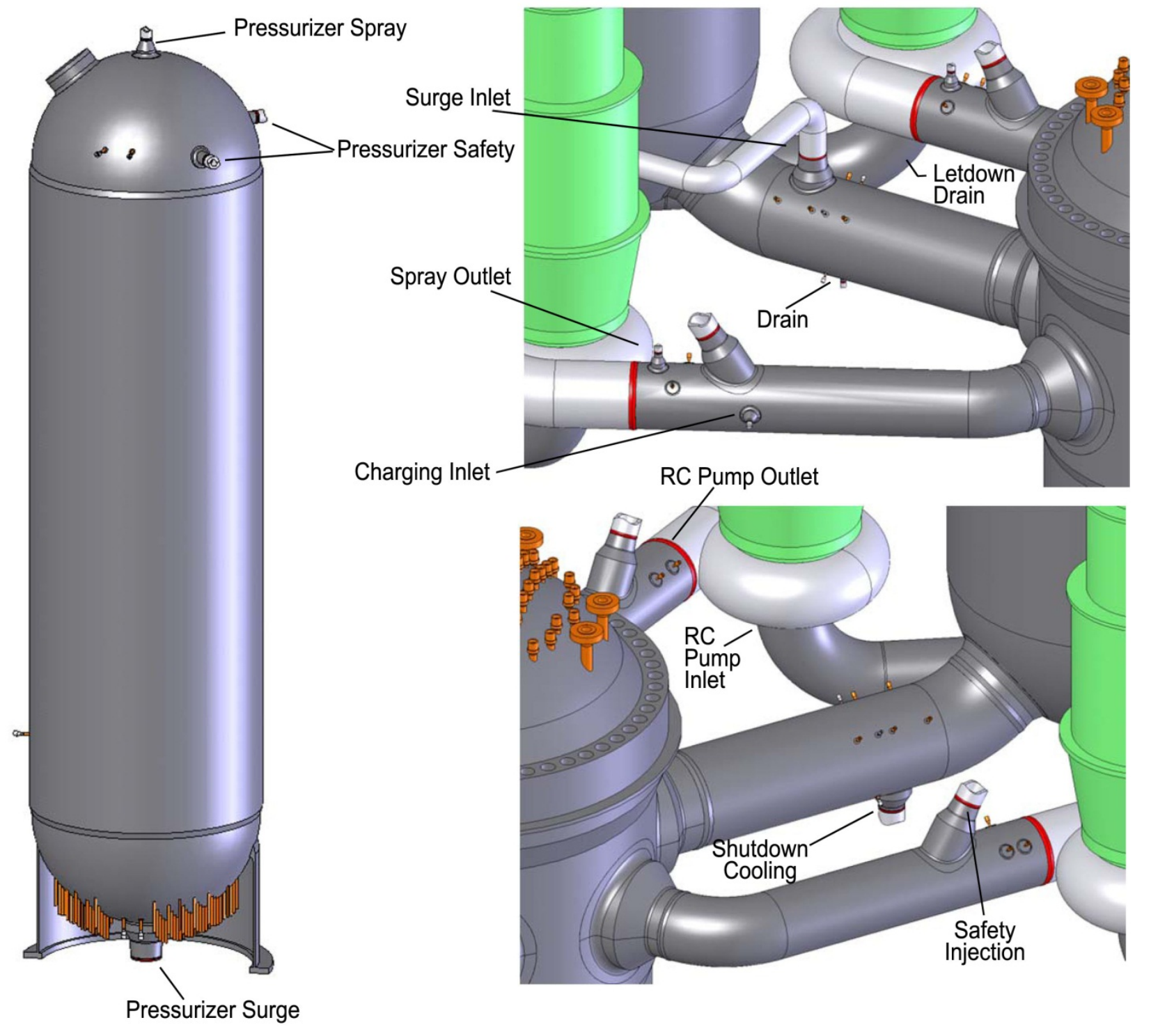

Figure D.1. Typical Locations of Alloy 82/182 Butt Welds in CE Design Plants 


\section{D.2 Reactor Coolant Pump (RCP) Suction}

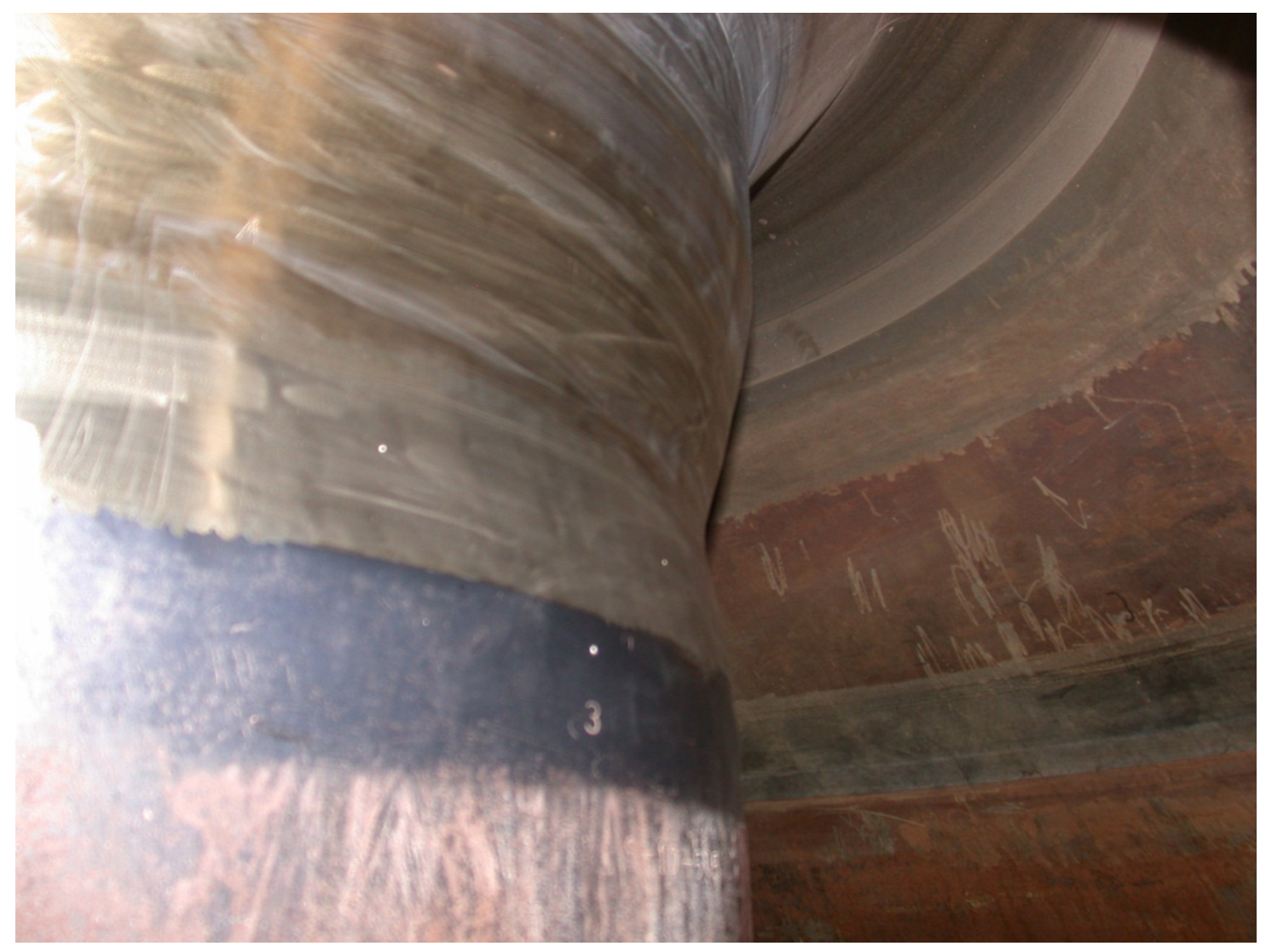

Figure D.2. Photograph of RCP Suction Nozzle, Nozzle Weld, and Safe End

The examination limitations for the RCP suction nozzle Alloy 82/182 butt weld were the CASS pump nozzle material on the downstream side of the Alloy 82/182 weld and the examination surface (OD) contour /condition.

The cross-sectional examination coverage in the axial scan direction for circumferential flaws is depicted in Figure D.3. The axial scan direction CRV coverage achievable was $100 \%$. The crosssectional examination coverage in the circumferential scan direction for axial flaws is depicted in Figure D.4. The circumferential scan direction CRV coverage achievable was $44.3 \%$. 


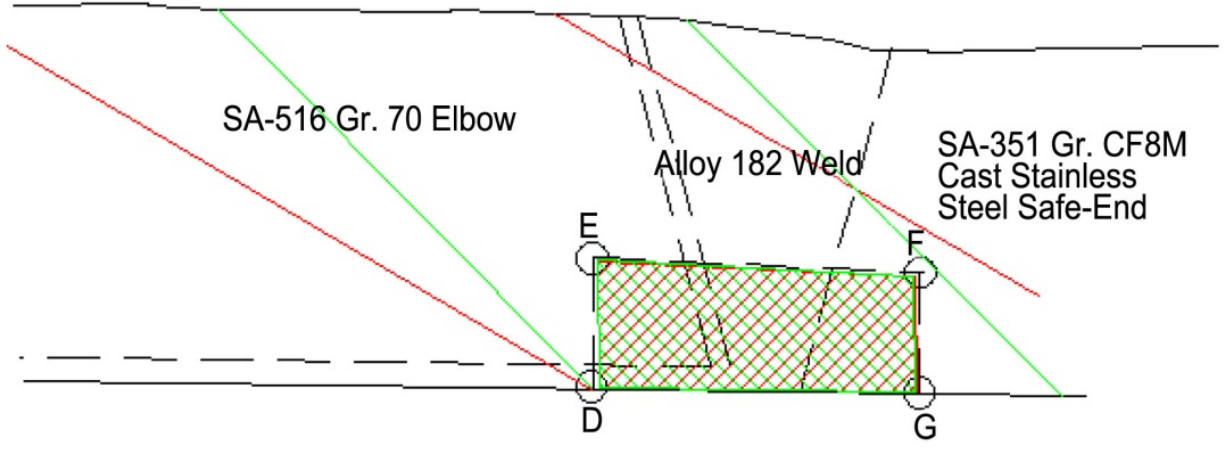

Figure D.3. RCP Suction Nozzle Weld Axial Scan Coverage Assessment

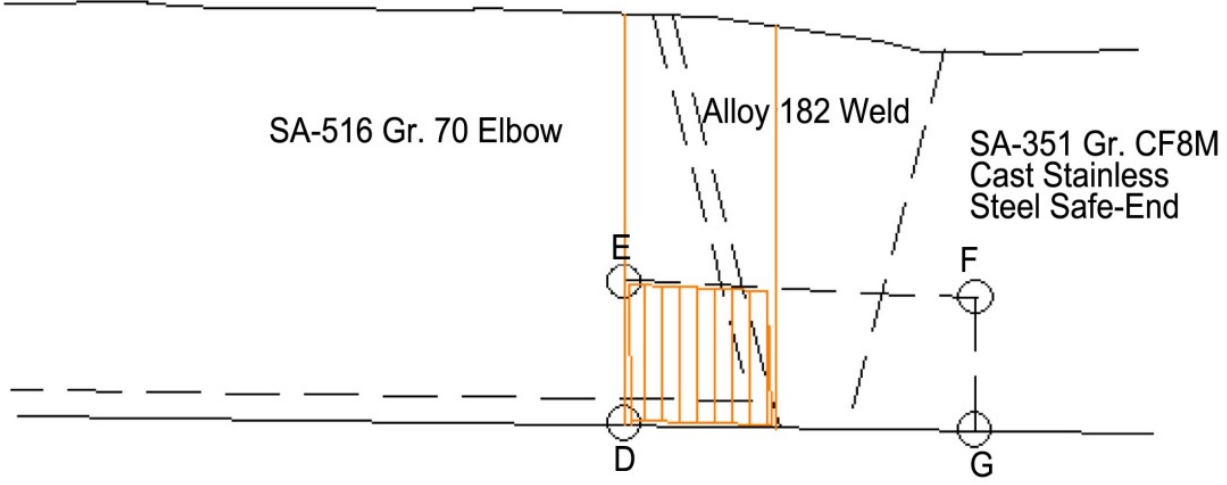

Figure D.4. RCP Suction Nozzle Weld Circumferential Scan Coverage Assessment 


\section{D.3 Reactor Coolant Pump Discharge}

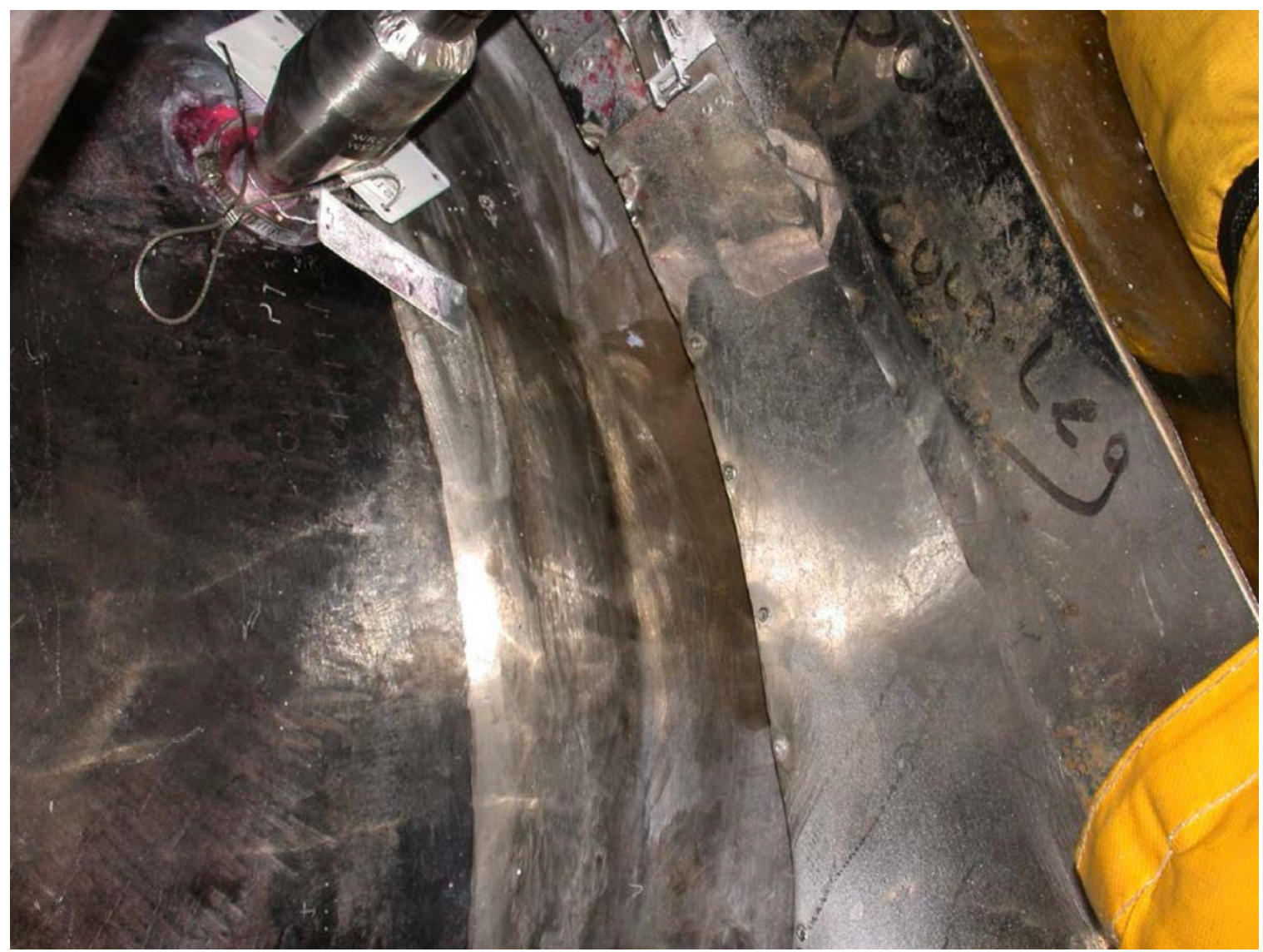

Figure D.5. Photograph of RCP Discharge Nozzle, Nozzle Weld, and Safe End

The examination limitations for the RCP discharge nozzle Alloy 82/182 butt weld were the CASS pump nozzle material on the upstream side of the Alloy 82/182 weld, the examination surface (OD) contour/condition, and instrumentation, safety injection, charging and spray nozzle connections. No coverage was obtainable in the locations where nozzle connections interfere with probe travel.

The cross-sectional examination coverage in the axial scan direction for circumferential flaws is depicted in Figure D.6. The axial scan direction CRV coverage achievable was $77 \%$. The cross-sectional examination coverage in the circumferential scan direction for axial flaws is depicted in Figure D.7. The circumferential scan direction CRV coverage achievable was $34 \%$. 


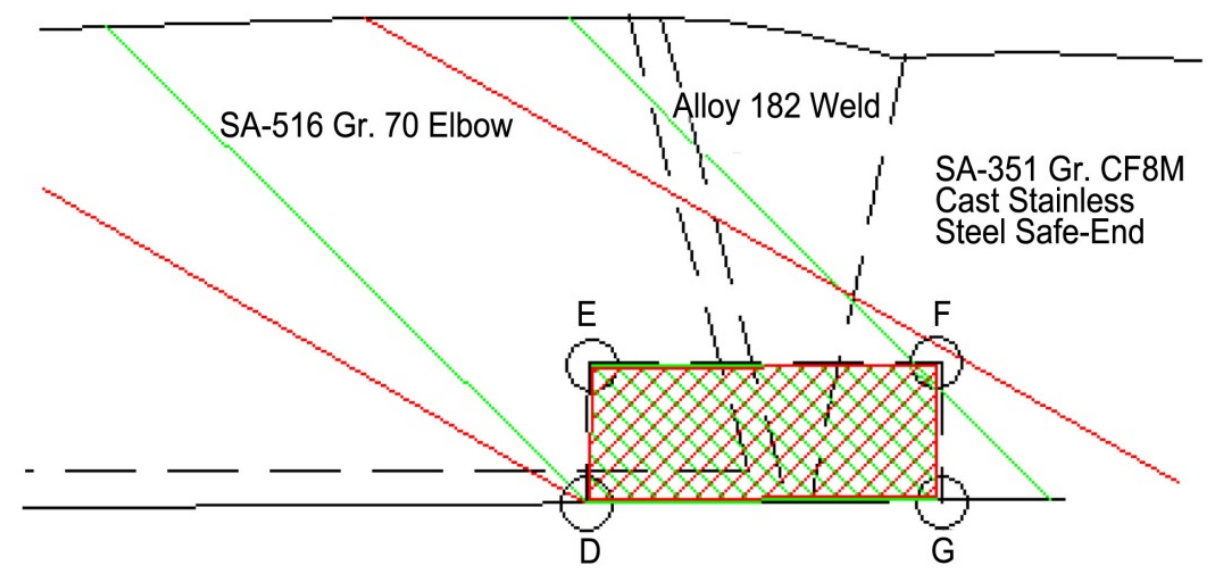

Figure D.6. RCP Discharge Nozzle Weld Axial Scan CRV Coverage Assessment

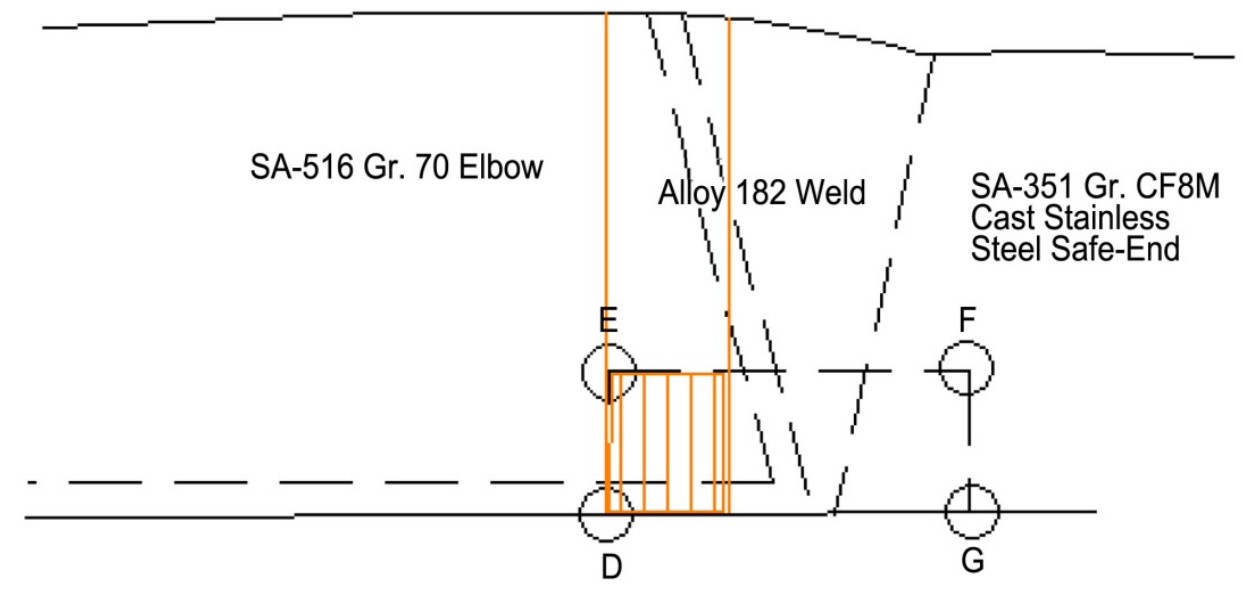

Figure D.7. RCP Discharge Nozzle Weld Circumferential Scan CRV Coverage Assessment 


\section{D.4 Reactor Coolant (RC) Loop Surge}

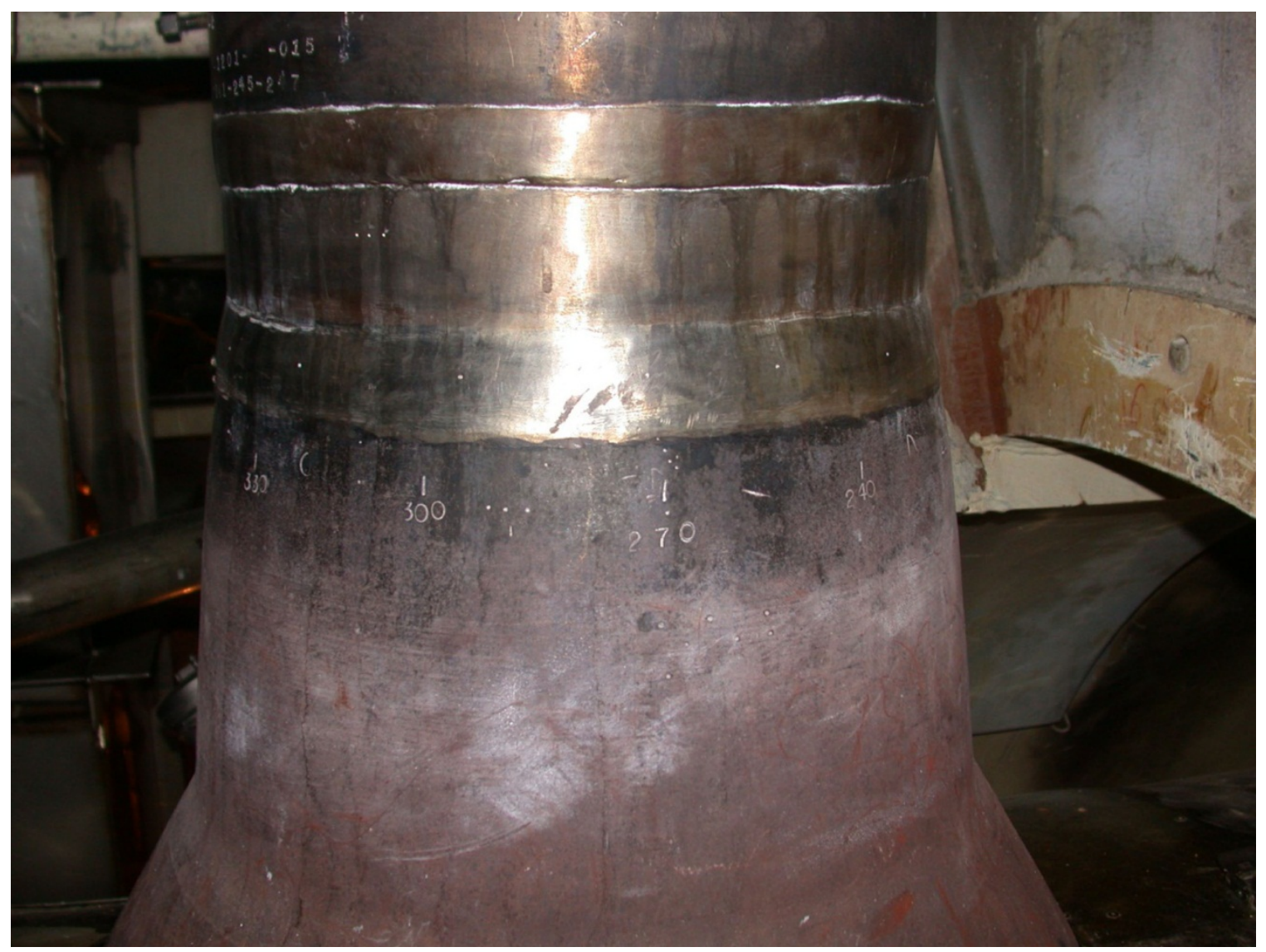

Figure D.8. Photograph of Surge Nozzle, Nozzle Weld, and Safe End

The examination limitations for the surge nozzle Alloy 82/182 butt weld were the CASS safe-end material on downstream side of the Alloy 82/182 weld and the examination surface (OD) contour/ condition.

The cross-sectional examination coverage in the axial scan direction for circumferential flaws is depicted in Figure D.9. The axial scan direction CRV coverage achievable was $82.4 \%$. The crosssectional examination coverage in the circumferential scan direction for axial flaws is depicted in Figure D.10. The circumferential scan direction CRV coverage achievable was $31.3 \%$. 


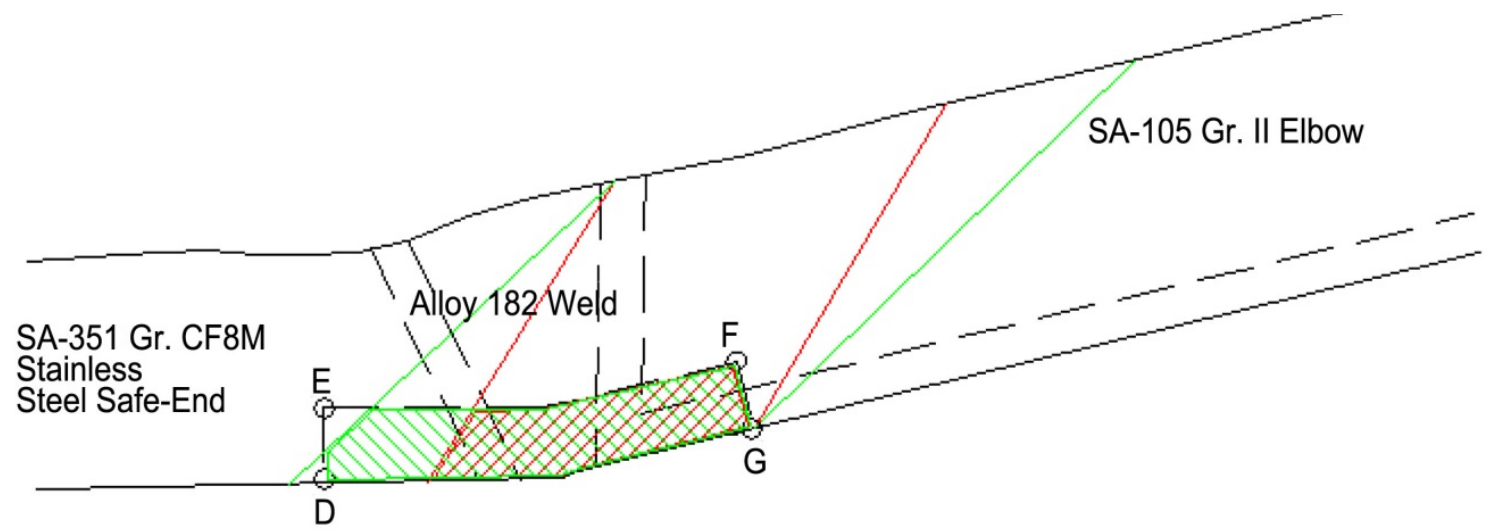

Figure D.9. Surge Nozzle Weld Axial Scan CRV Coverage Assessment

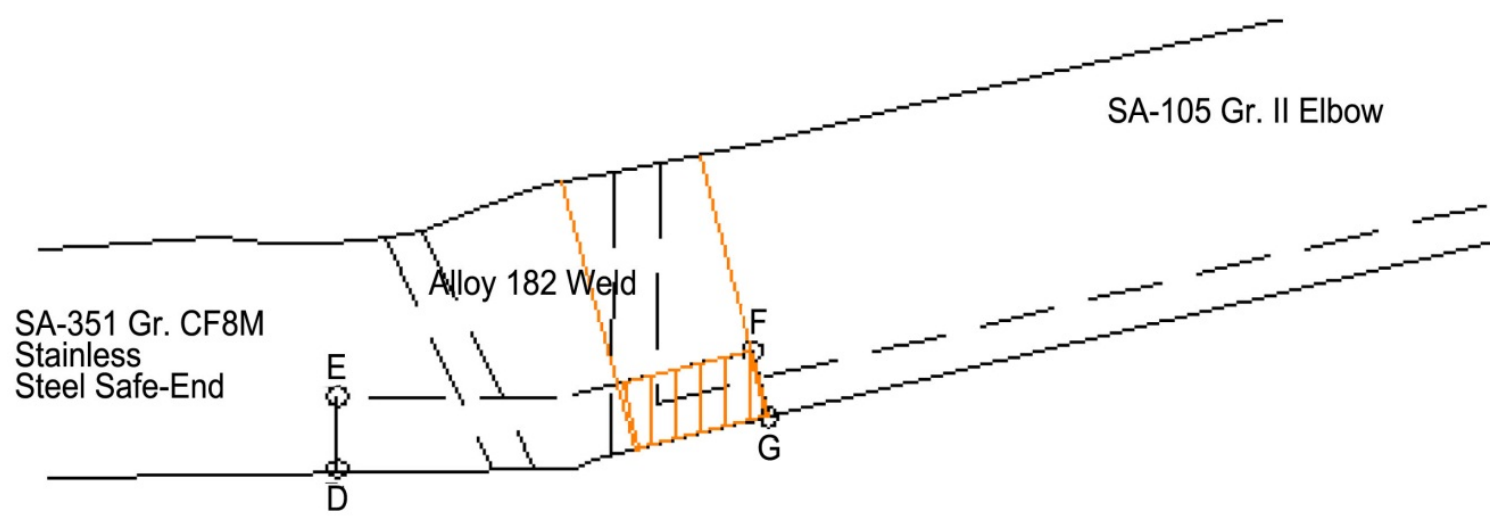

Figure D.10. Surge Nozzle Weld Circumferential Axial Scan CRV Coverage Assessment 


\section{D.5 Letdown and Drain}

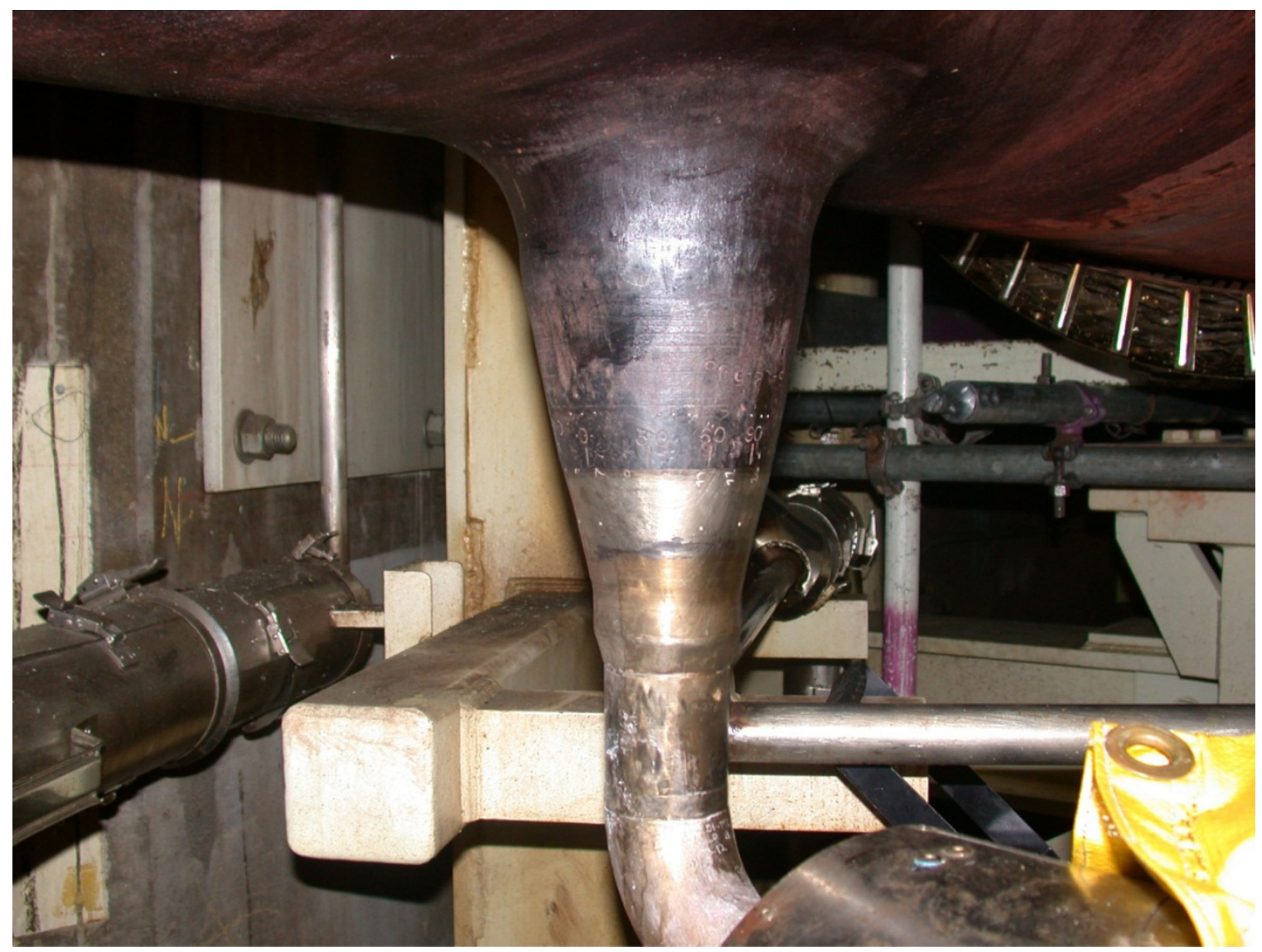

Figure D.11. Photograph of Letdown and Drain Nozzle, Nozzle Weld, and Safe End

There were no examination limitations for the letdown and drain nozzle Alloy 82/182 butt weld.

The cross-sectional examination coverage in the axial scan direction for circumferential flaws is depicted in Figure D.12. The axial scan direction CRV coverage achievable was 100\%. The crosssectional examination coverage in the circumferential scan direction for axial flaws is depicted in Figure D.13. The circumferential scan direction CRV coverage achievable was $100 \%$. 

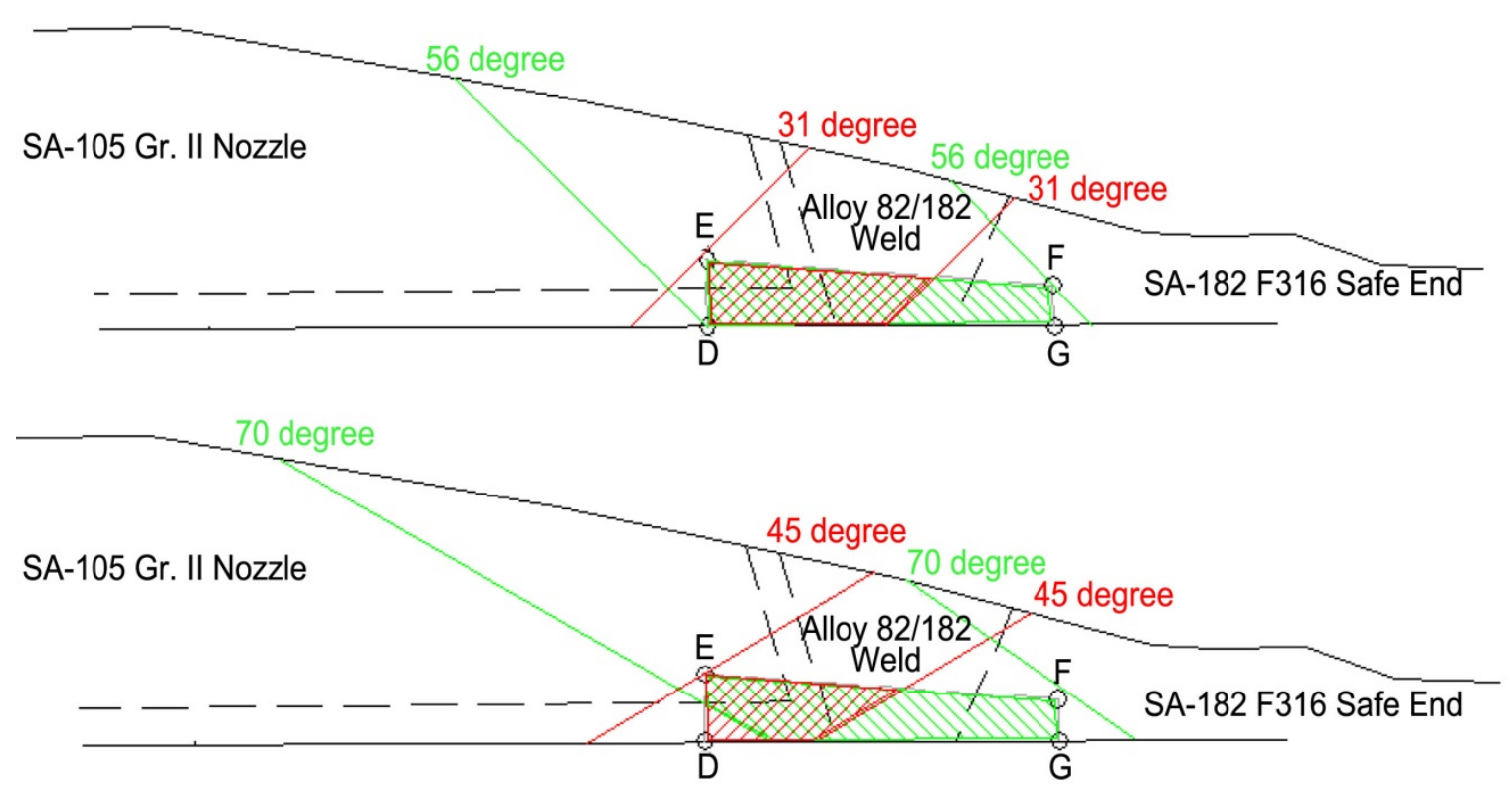

Figure D.12. Letdown and Drain Nozzle Weld Axial Scan CRV Coverage Assessment

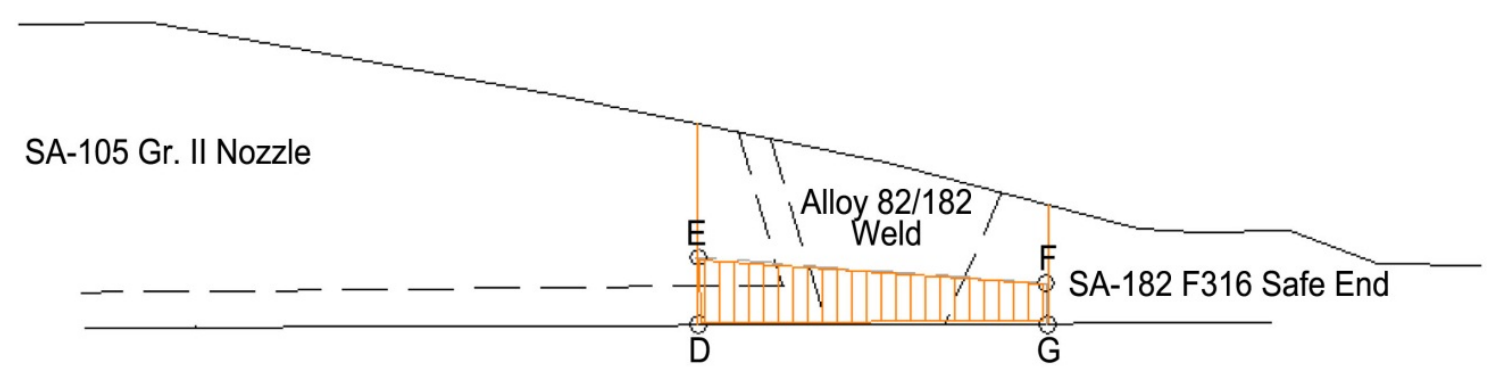

Figure D.13. Letdown and Drain Nozzle Weld Circumferential Scan CRV Coverage Assessment 


\section{D.6 Hot Leg Drain}

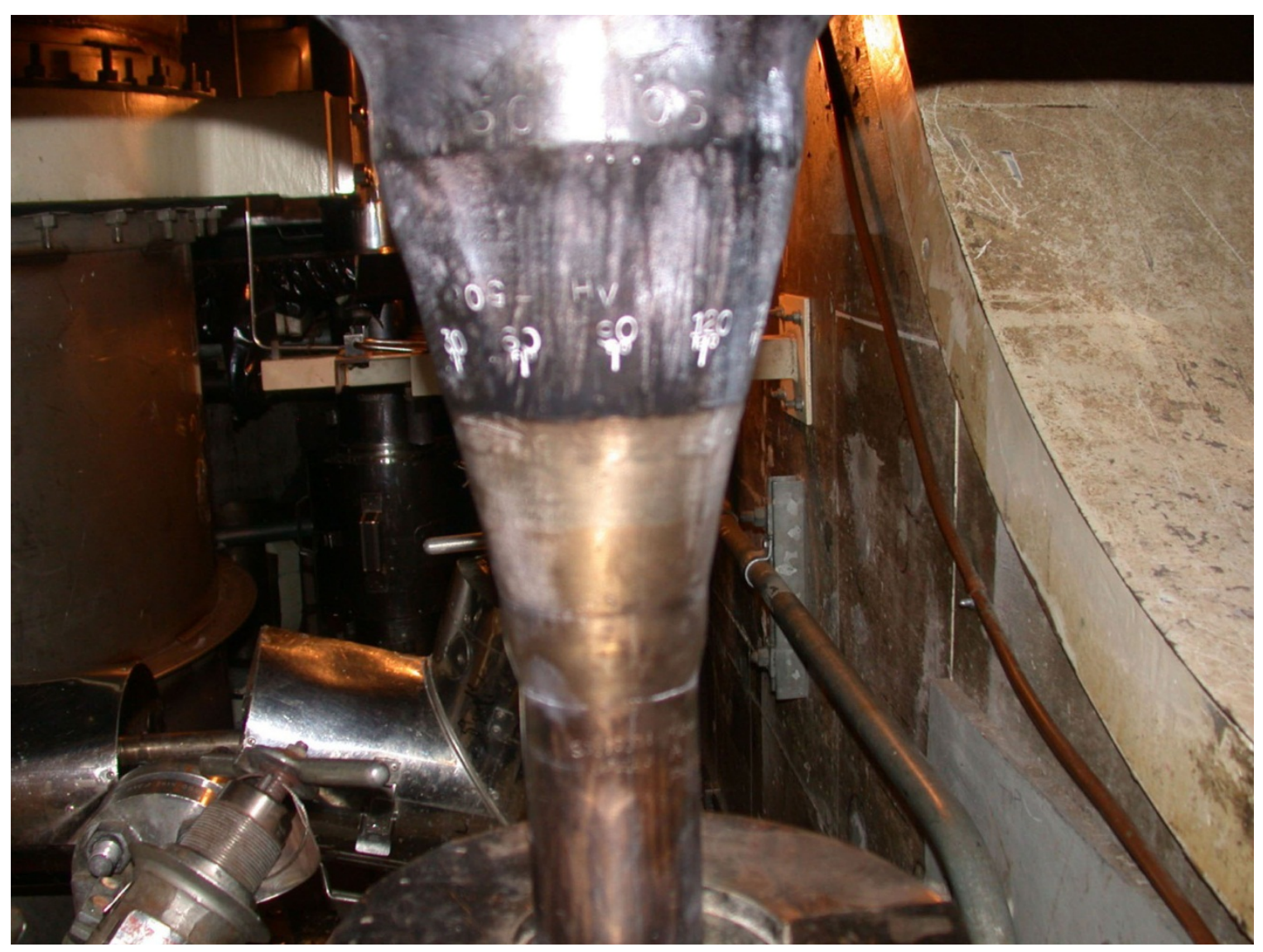

Figure D.14. Photograph of Hot Leg Drain Nozzle, Nozzle Weld, and Safe End

There were no examination limitations for the hot leg drain nozzle Alloy 82/182 butt weld.

The cross-sectional examination coverage in the axial scan direction for circumferential flaws is depicted in Figure D.15. The axial scan direction CRV coverage achievable was $100 \%$. The crosssectional examination coverage in the circumferential scan direction for axial flaws is depicted in Figure D.16. The circumferential scan direction CRV coverage achievable was $100 \%$. 

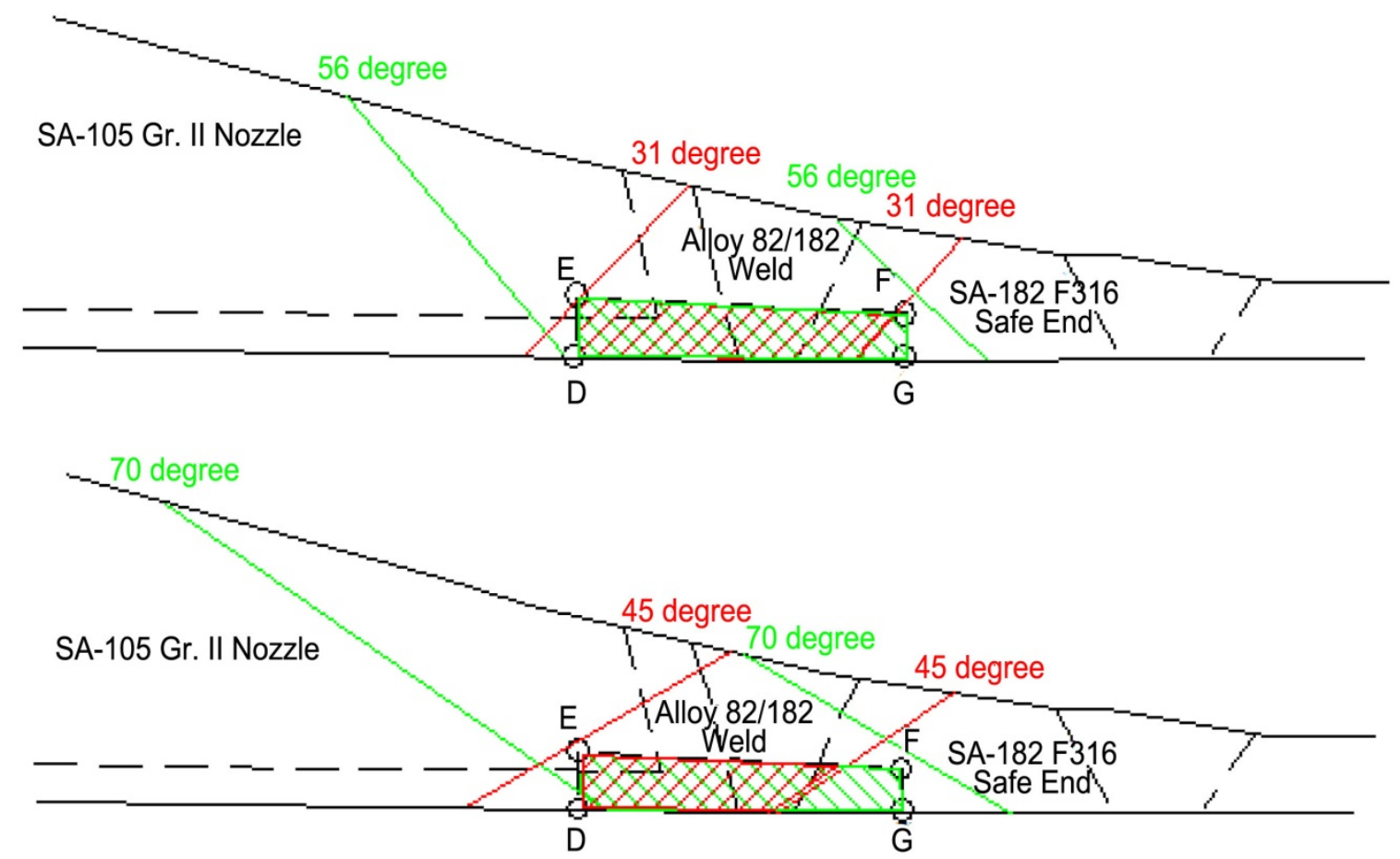

Figure D.15. Hot Leg Drain Nozzle Weld Axial Scan CRV Coverage Assessment

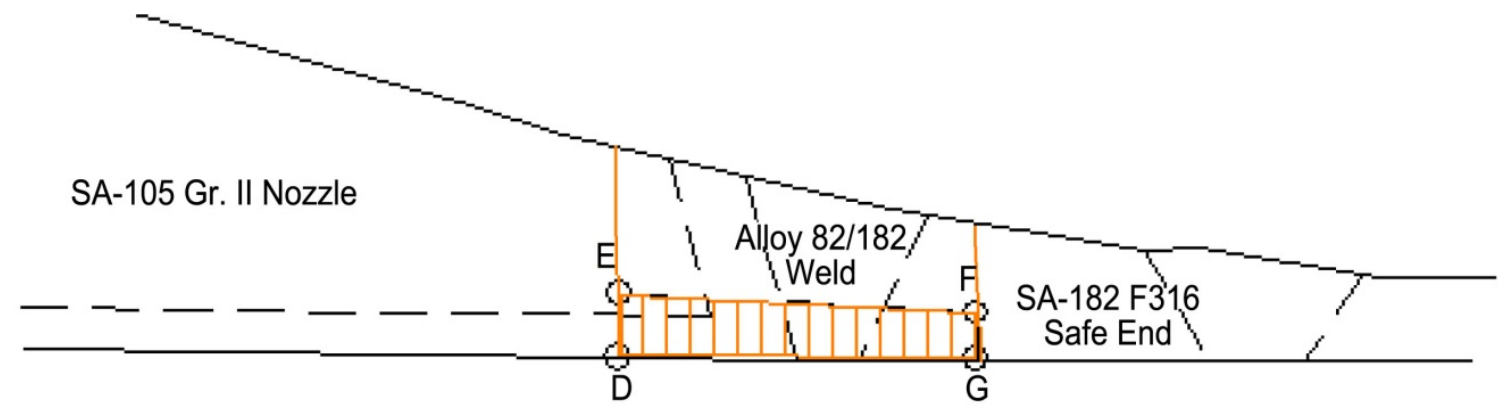

Figure D.16. Hot Leg Drain Nozzle Weld Circumferential Scan CRV Coverage Assessment 


\section{D.7 Charging Inlet}

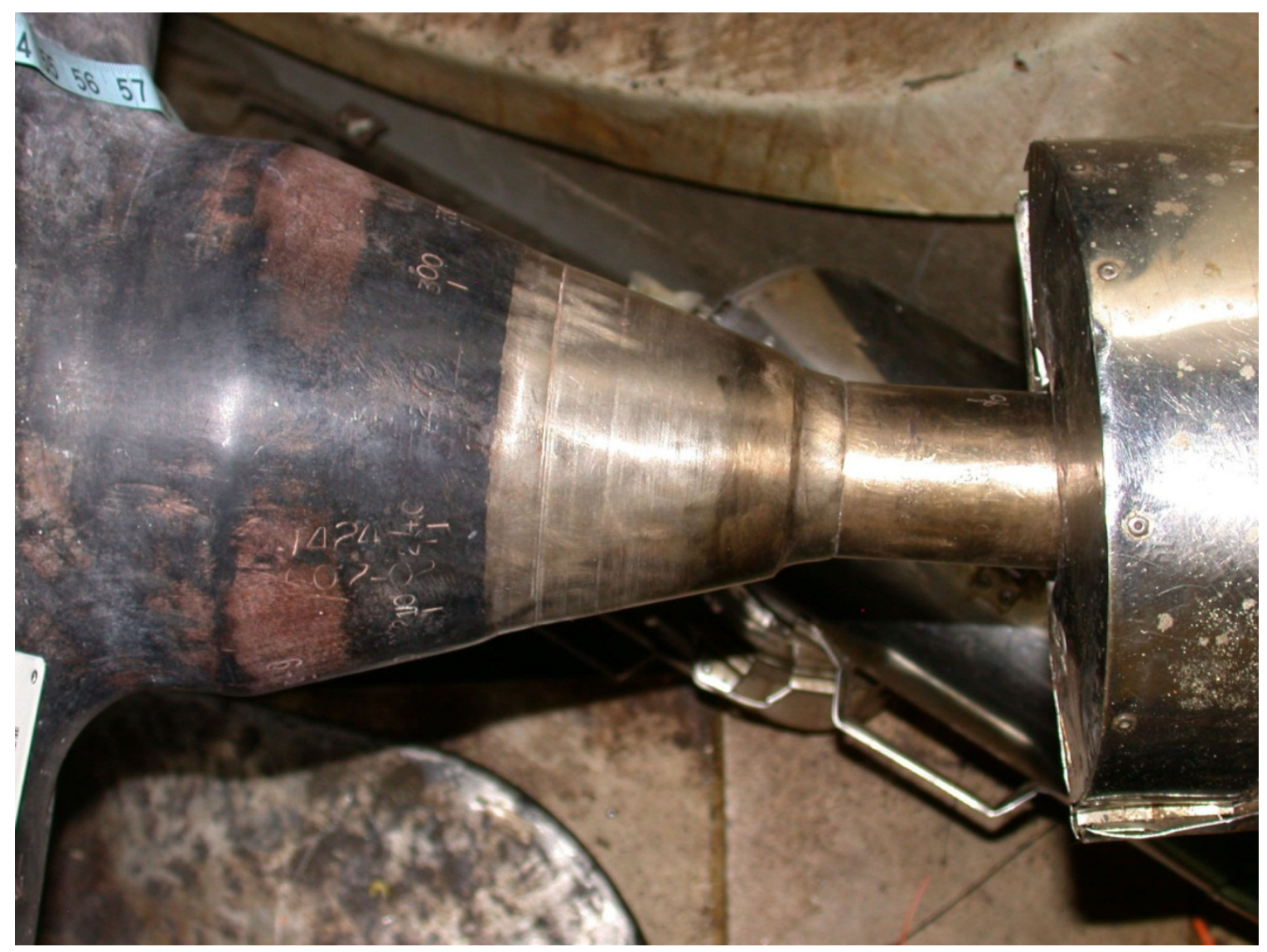

Figure D.17. Photograph of Charging Inlet Nozzle, Nozzle Weld, and Safe End

There were no examination limitations for the charging inlet nozzle Alloy 82/182 butt weld.

The cross-sectional examination coverage in the axial scan direction for circumferential flaws is depicted in Figure D.18. The axial scan direction CRV coverage achievable was $100 \%$. The crosssectional examination coverage in the circumferential scan direction for axial flaws is depicted in Figure D.19. The circumferential scan direction CRV coverage achievable was 100\%. 

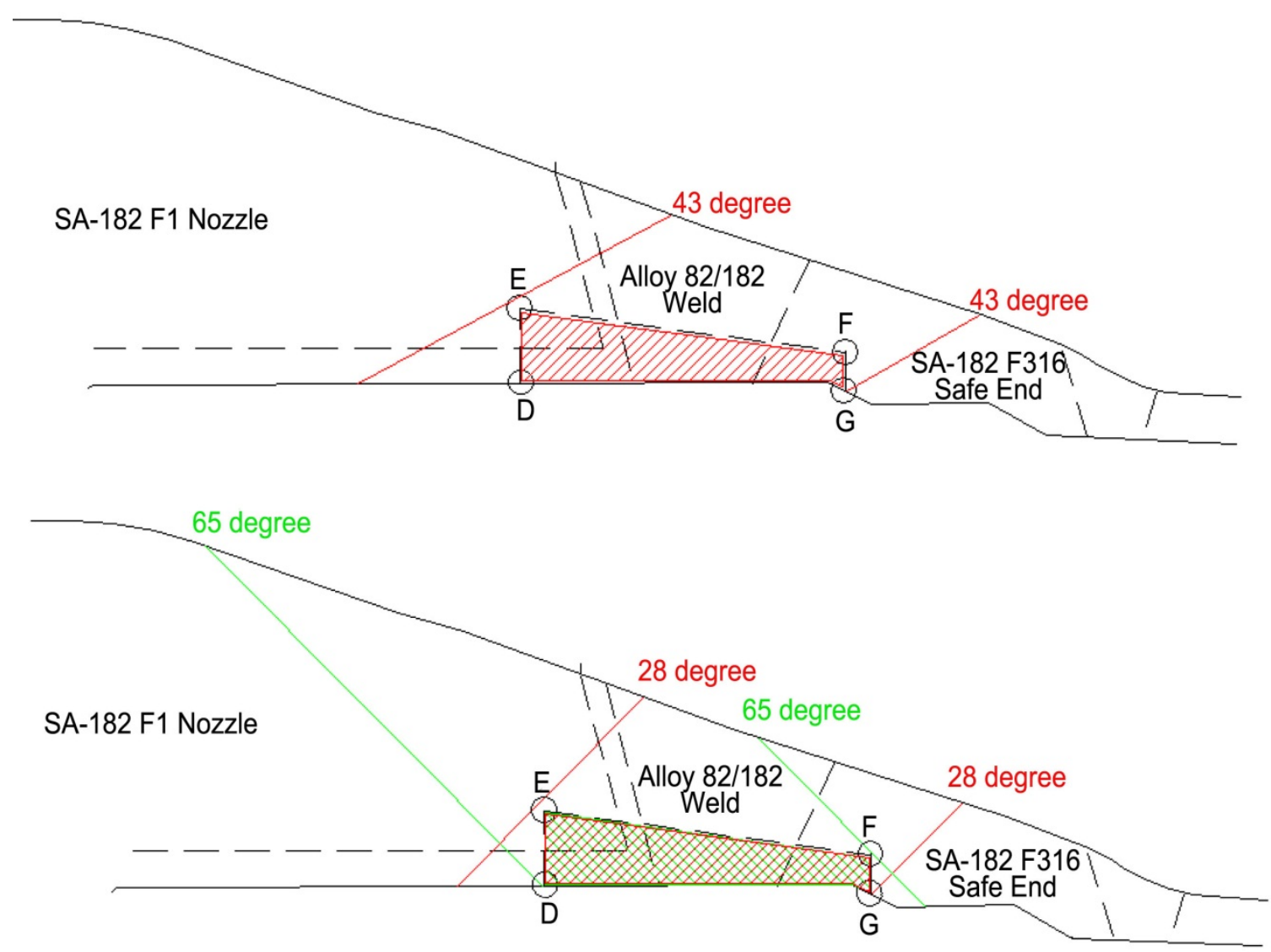

Figure D.18. Charging Inlet Nozzle Weld Axial Scan CRV Coverage Assessment

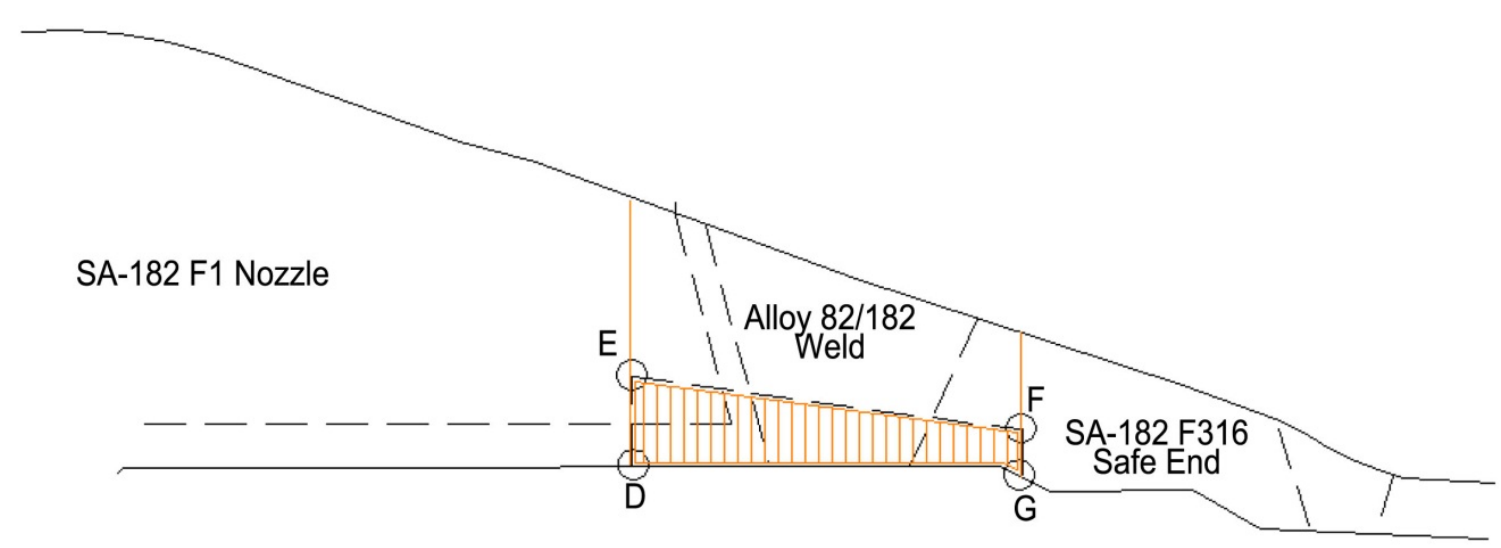

Figure D.19. Charging Inlet Nozzle Weld Circumferential Scan CRV Coverage Assessment 


\section{D.8 Safety Injection}

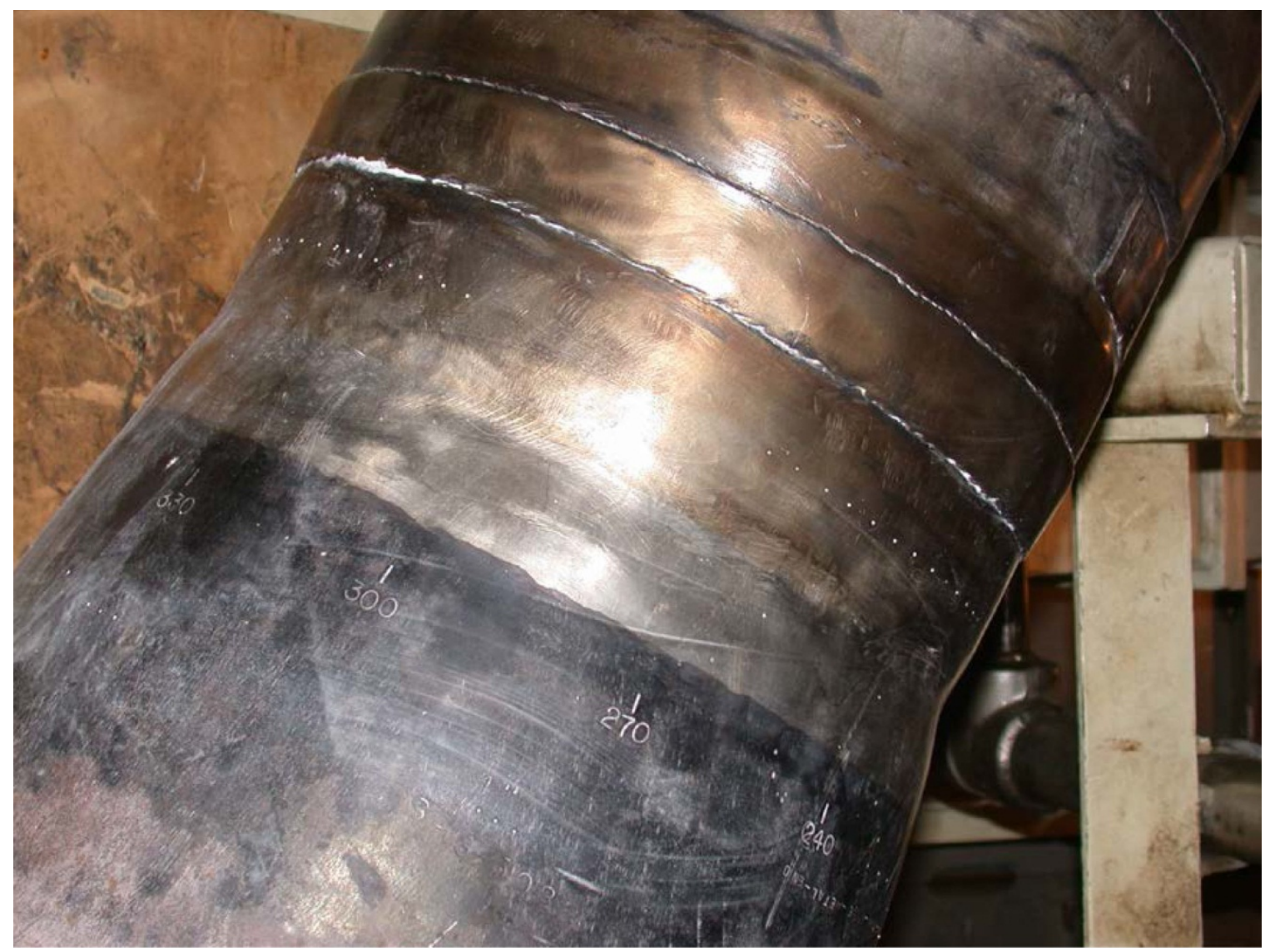

Figure D.20. Photograph of Safety Injection Nozzle, Nozzle Weld, and Safe End

The examination limitations for the safety injection nozzle Alloy 82/182 butt weld were the CASS safe-end material on upstream side of the Alloy 82/182 weld and the examination surface (OD) contour/ condition.

The cross-sectional examination coverage in the axial scan direction for circumferential flaws is depicted in Figure D.21. The axial scan direction CRV coverage achievable was $94.3 \%$. The crosssectional examination coverage in the circumferential scan direction for axial flaws is depicted in Figure D.22. The circumferential scan direction CRV coverage achievable was $26.6 \%$. 


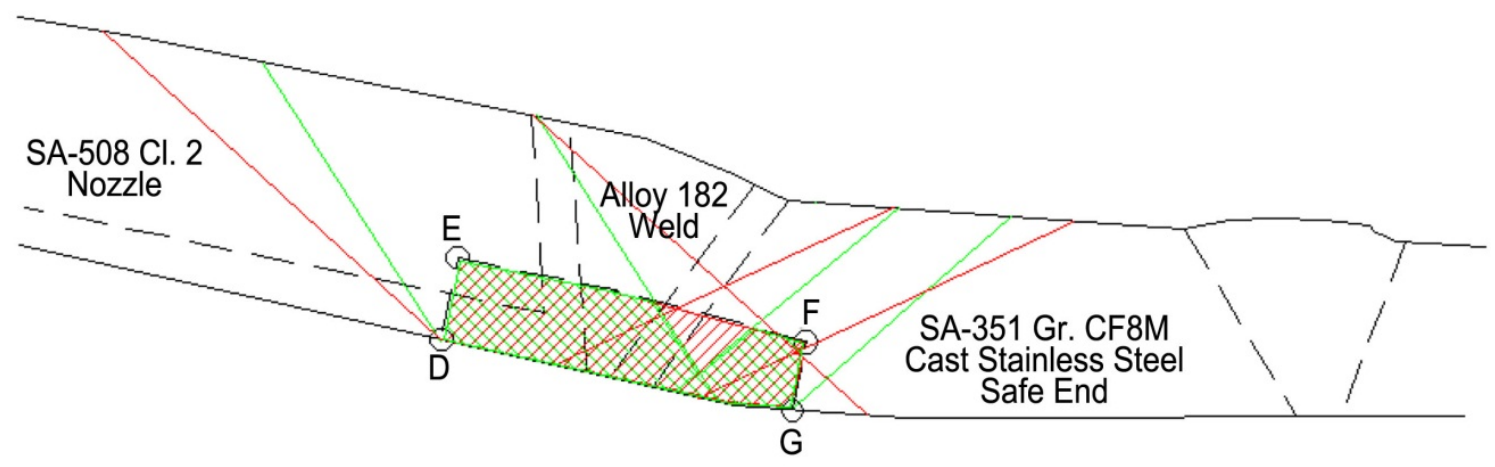

Figure D.21. Safety Injection Nozzle Weld Axial Scan CRV Coverage Assessment

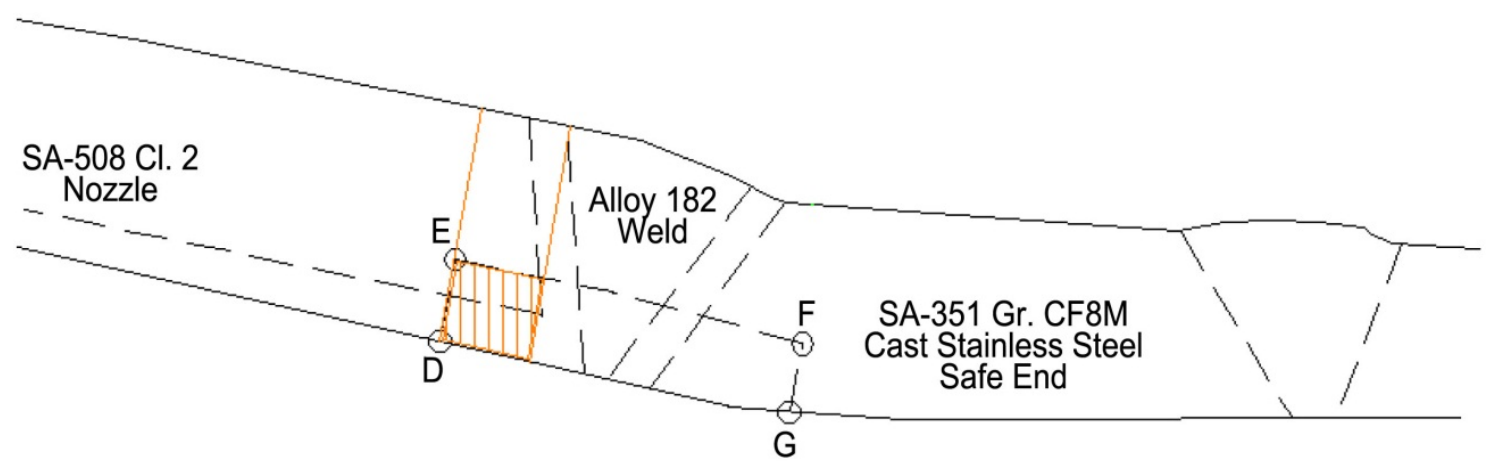

Figure D.22. Safety Injection Nozzle Weld Circumferential Scan CRV Coverage Assessment 


\section{D.9 Shutdown Cooling}

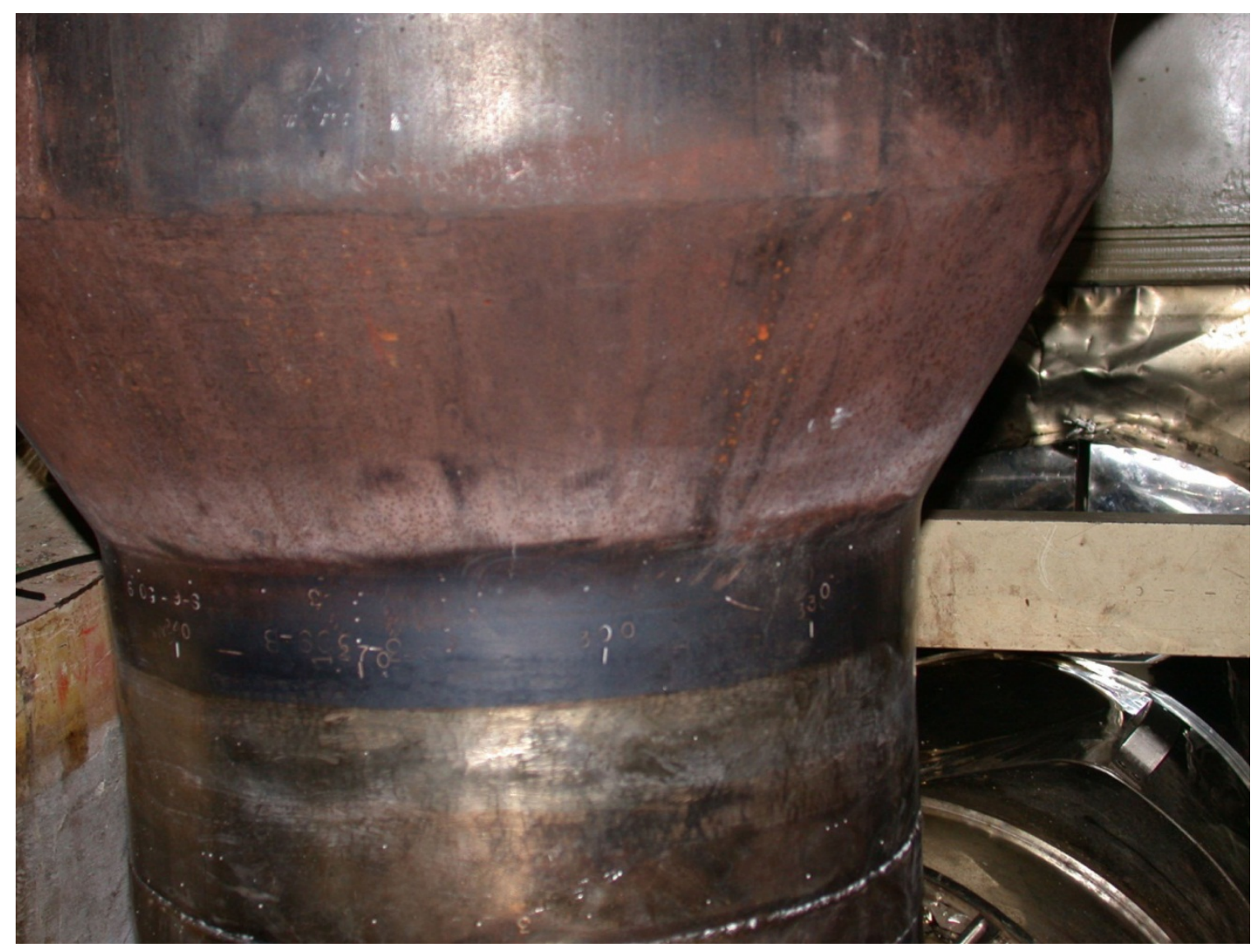

Figure D.23. Photograph of Shutdown Cooling Nozzle, Nozzle Weld, and Safe End

The examination limitations for the shutdown cooling nozzle Alloy 82/182 butt weld were the CASS safe-end material on the downstream side of the Alloy 82/182 weld and the examination surface (OD) contour/condition.

The cross-sectional examination coverage in the axial scan direction for circumferential flaws is depicted in Figure D.24. The axial scan direction CRV coverage achievable was 98\%. The crosssectional examination coverage in the circumferential scan direction for axial flaws is depicted in Figure D.25. The circumferential scan direction CRV coverage achievable was $100 \%$. 


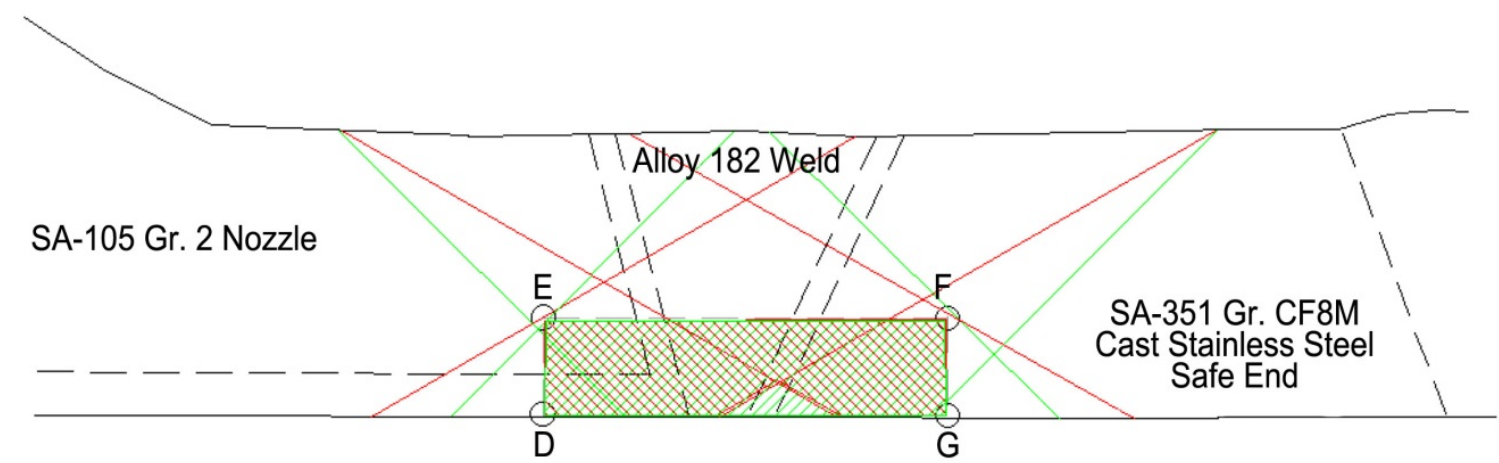

Figure D.24. Shutdown Cooling Nozzle Weld Axial Scan CRV Coverage Assessment

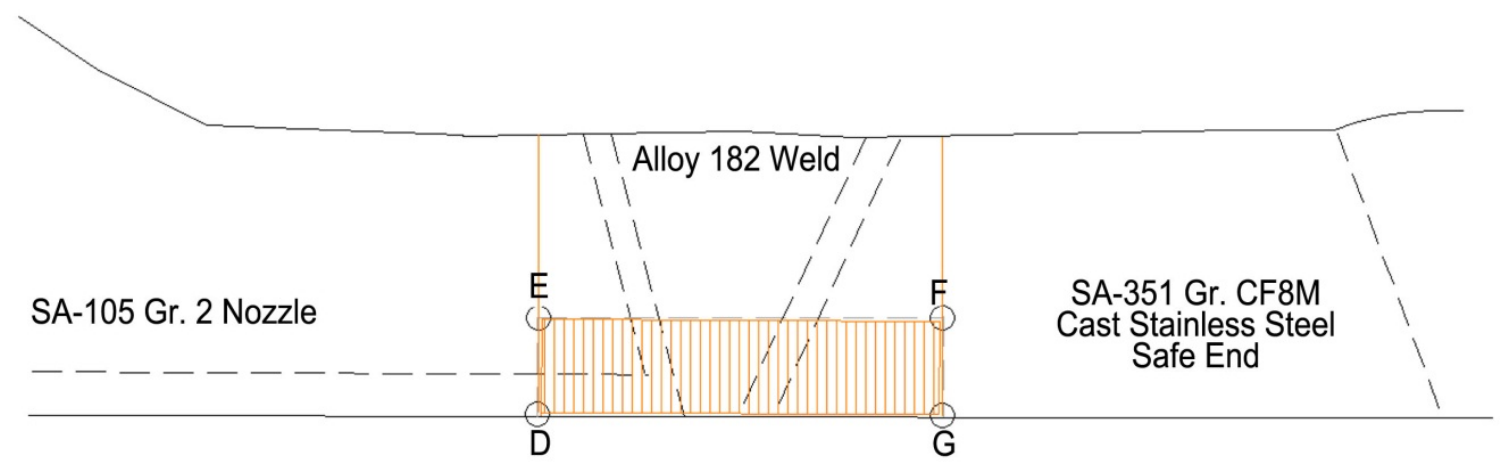

Figure D.25. Shutdown Cooling Nozzle Weld Circumferential Scan CRV Coverage Assessment 


\section{D.10 Spray}

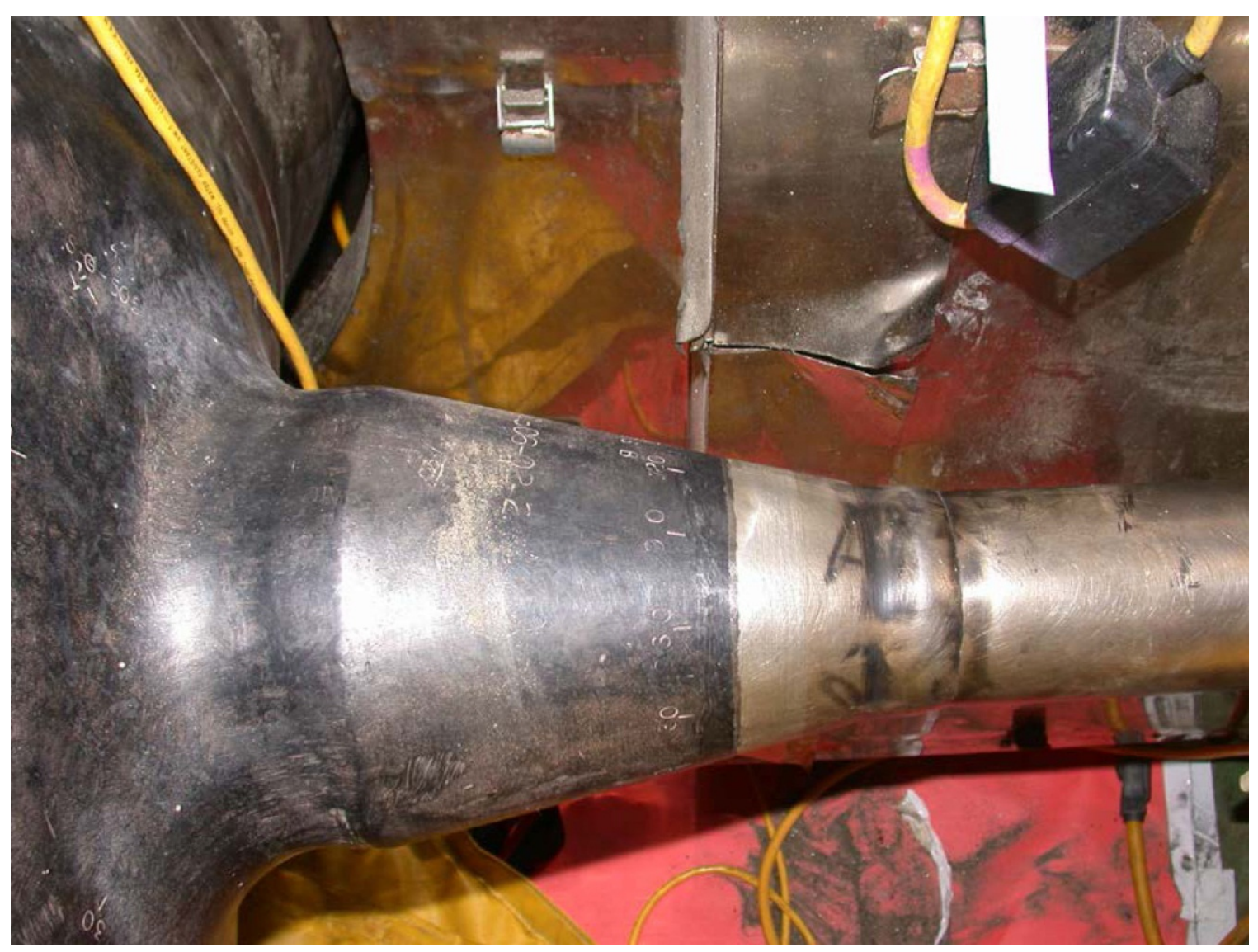

Figure D.26. Photograph of Spray Nozzle, Nozzle Weld, and Safe End

There were no examination limitations for the spray nozzle Alloy 82/182 butt.

The cross-sectional examination coverage in the axial scan direction for circumferential flaws is depicted in Figure D.27. The axial scan direction CRV coverage achievable was 100\%. The crosssectional examination coverage in the circumferential scan direction for axial flaws is depicted in Figure D.28. The circumferential scan direction CRV coverage achievable was 100\%. 


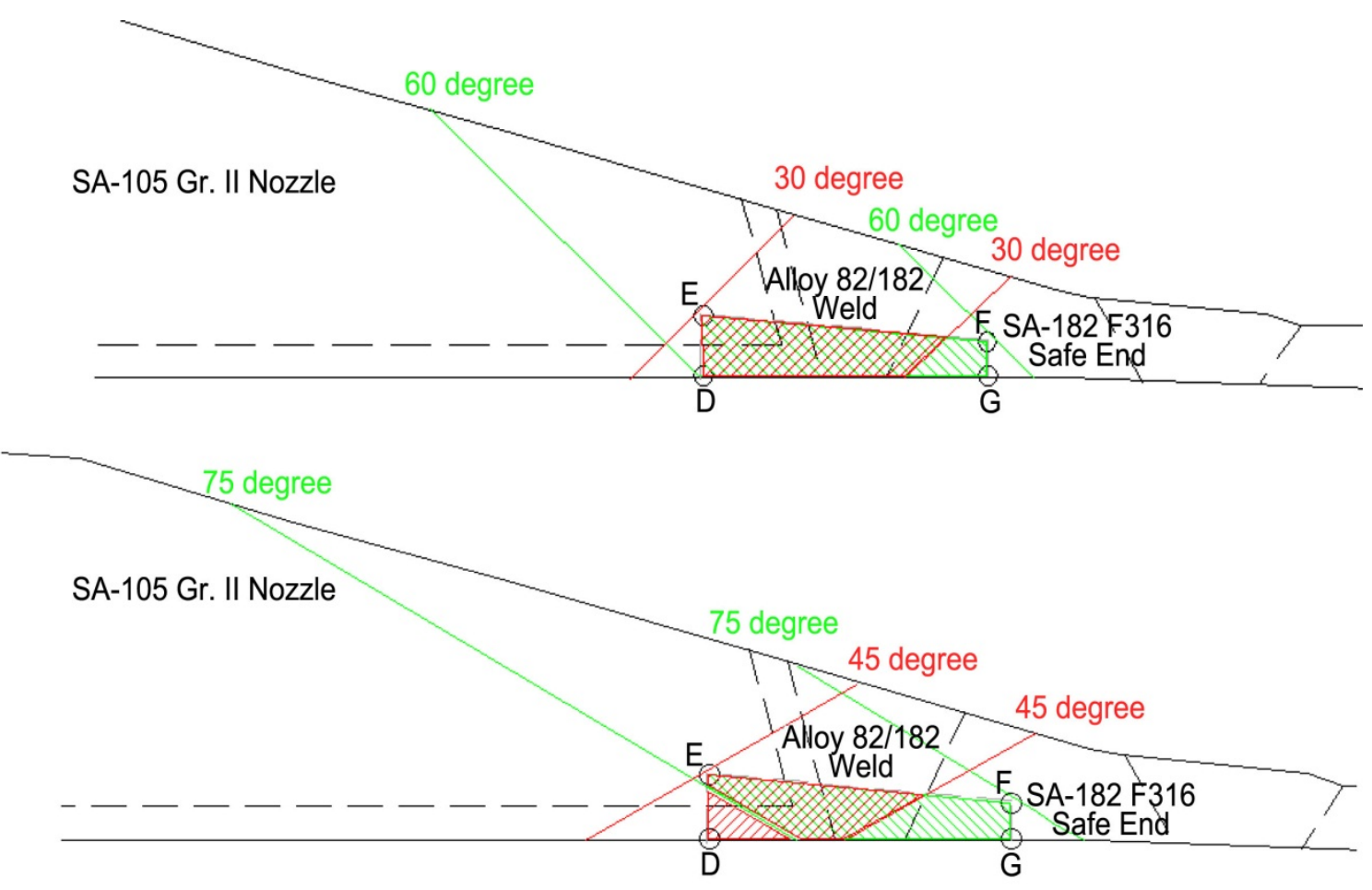

Figure D.27. Spray Nozzle Weld Axial Scan CRV Coverage Assessment

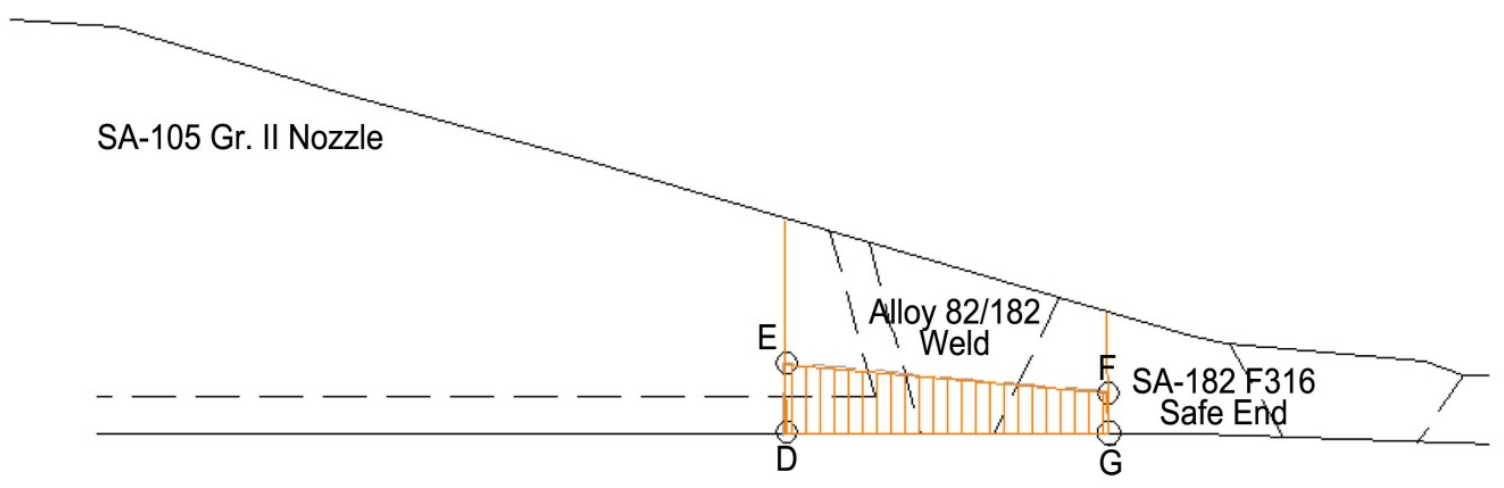

Figure D.28. Spray Nozzle Weld Circumferential Scan CRV Coverage Assessment 


\section{D.11 PZR Surge}

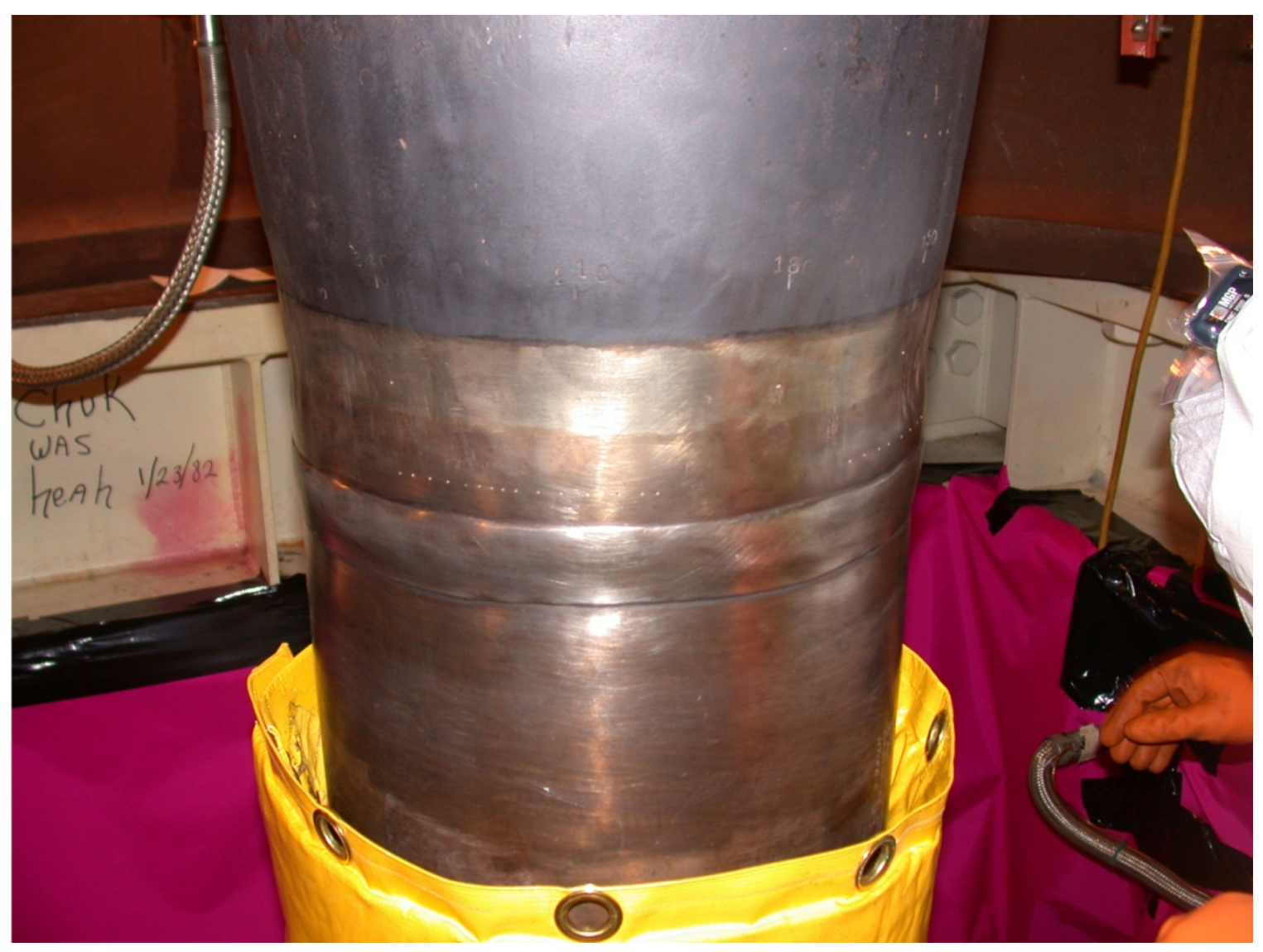

Figure D.29. Photograph of PZR Surge Nozzle, Nozzle Weld, and Safe End

There were no examination limitations for the PZR surge nozzle Alloy 82/182 butt weld.

The cross-sectional examination coverage in the axial scan direction for circumferential flaws is depicted in Figure D.30. The axial scan direction CRV coverage achievable was $100 \%$. The crosssectional examination coverage in the circumferential scan direction for axial flaws is depicted in Figure D.31. The circumferential scan direction CRV coverage achievable was $100 \%$. 


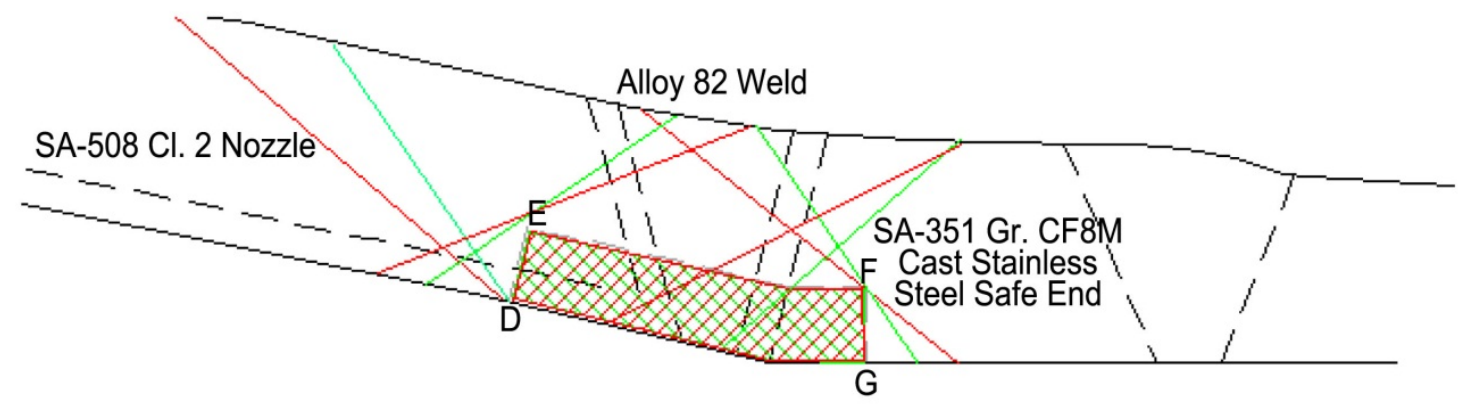

Figure D.30. PZR Surge Nozzle Weld Axial Scan CRV Coverage Assessment

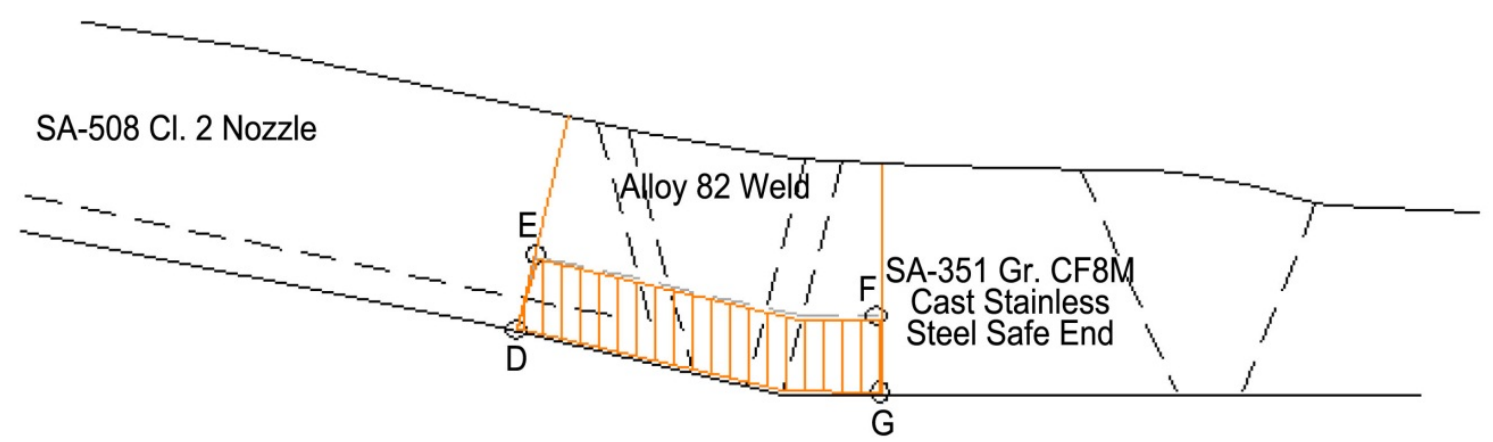

Figure D.31. PZR Surge Nozzle Weld Circumferential Scan CRV Coverage Assessment 


\section{D.12 PZR Spray}

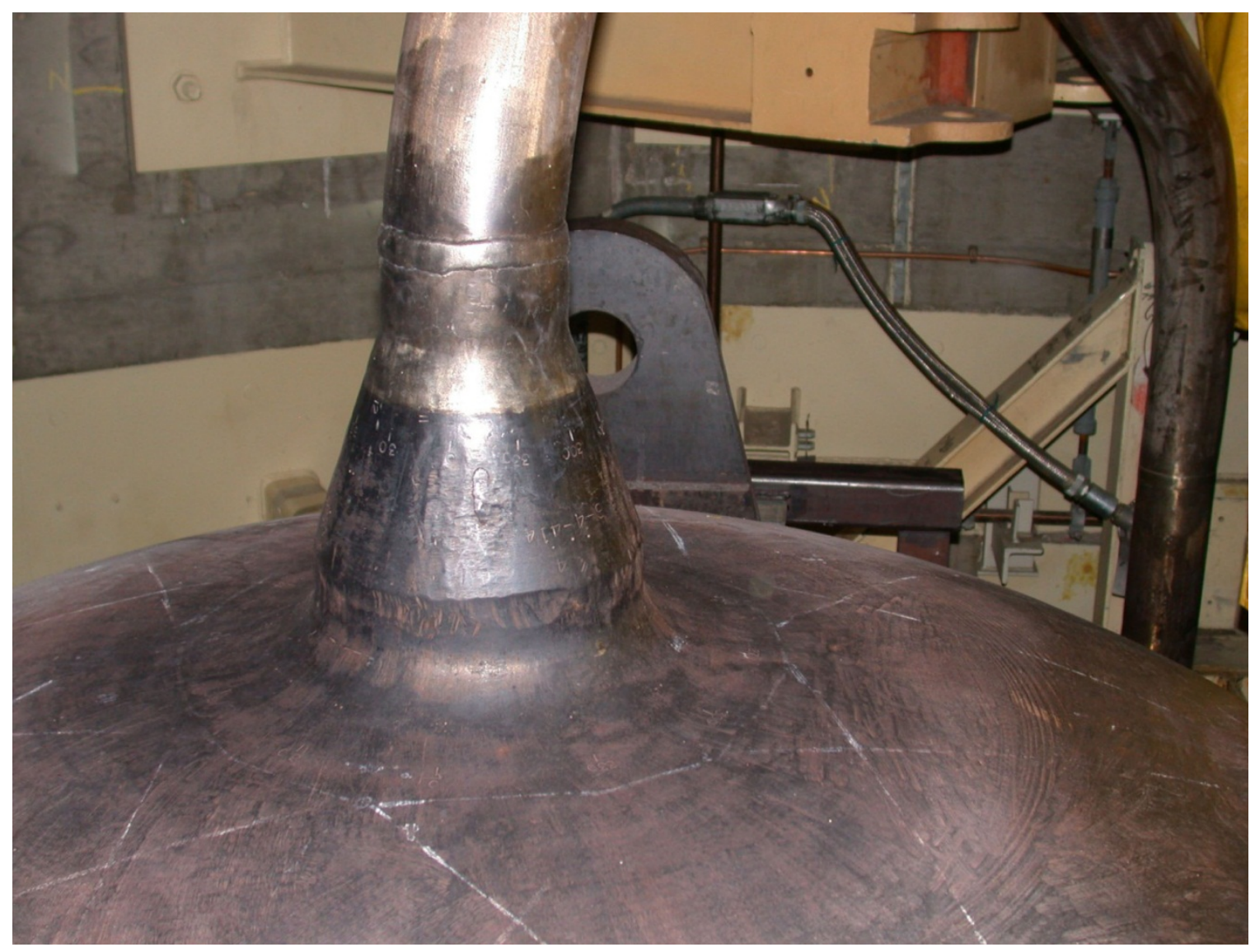

Figure D.32. Photograph of PZR Spray Nozzle, Nozzle Weld, and Safe End

The examination limitation for the PZR spray nozzle Alloy 82/182 butt weld was the examination surface (OD) contour / condition.

The cross-sectional examination coverage in the axial scan direction for circumferential flaws is depicted in Figure D.33. The axial scan direction CRV coverage achievable was $100 \%$. The crosssectional examination coverage in the circumferential scan direction for axial flaws is depicted in Figure D.34. The circumferential scan direction CRV coverage achievable was $68.9 \%$. 


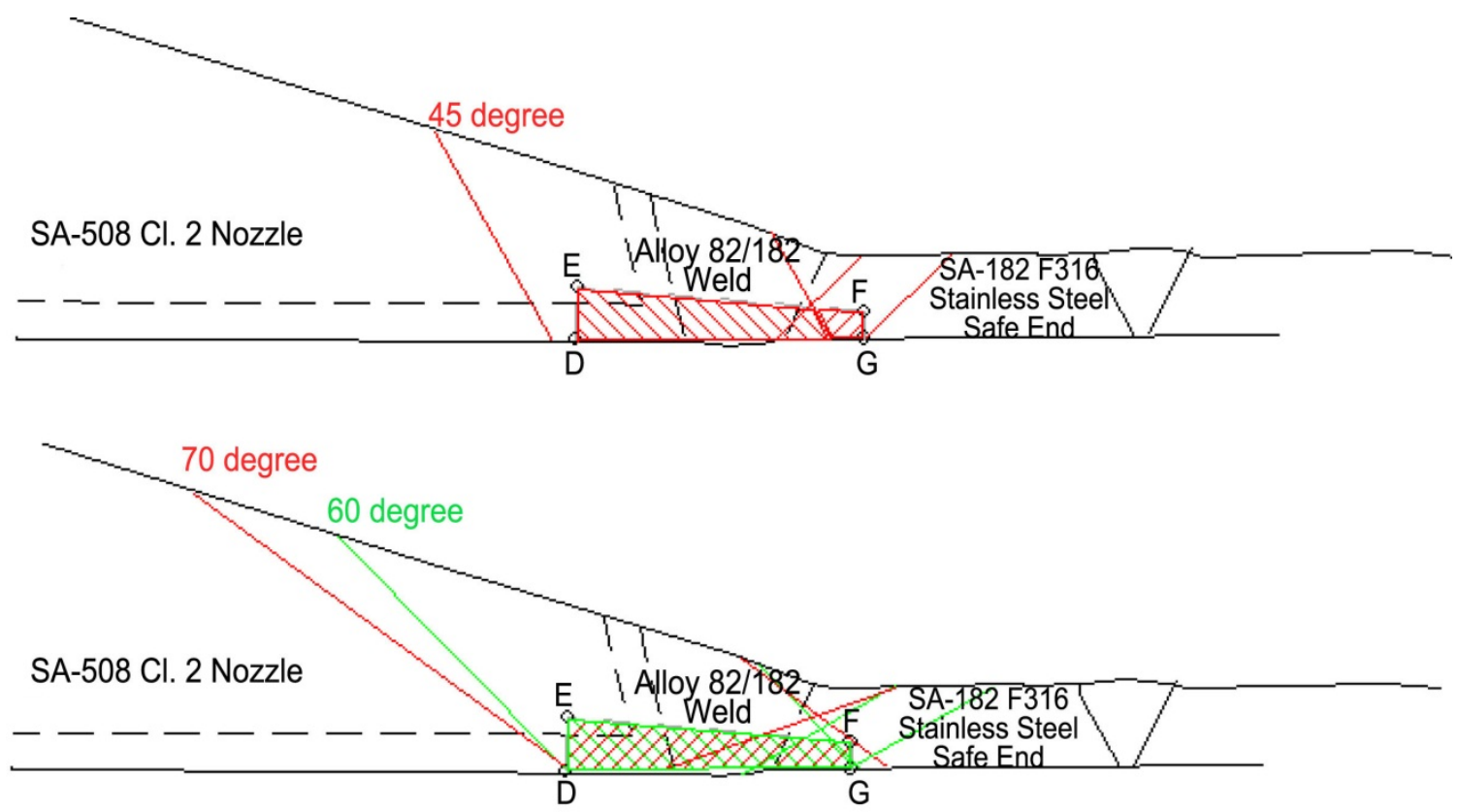

Figure D.33. PZR Spray Nozzle Weld Axial Scan CRV Coverage Assessment

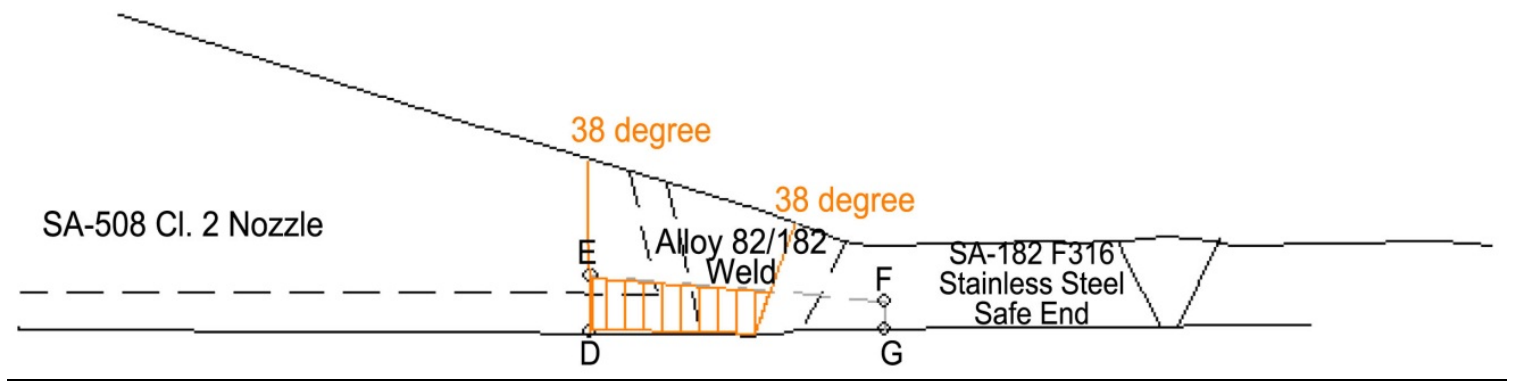

Figure D.34. PZR Spray Nozzle Weld Circumferential Scan CRV Coverage Assessment 


\section{D.13 PZR Safety \& Relief}

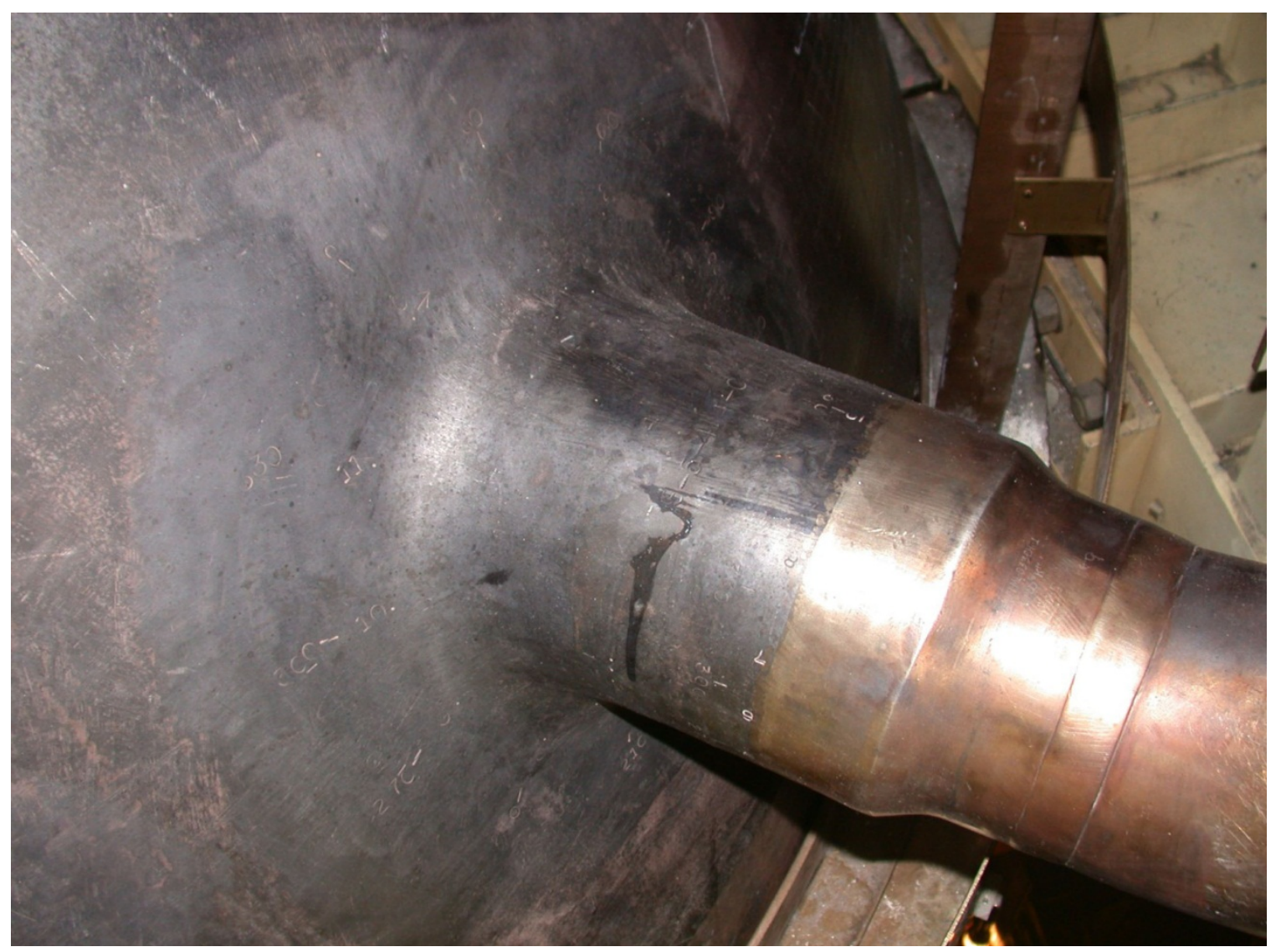

Figure D.35. Photograph of PZR Safety \& Relief Nozzle, Nozzle Weld, and Safe End

There were no examination limitations for the PZR safety and relief nozzle Alloy 82/182 butt weld.

The cross-sectional examination coverage in the axial scan direction for circumferential flaws is depicted in Figure D.36. The axial scan direction CRV coverage achievable was $100 \%$. The crosssectional examination coverage in the circumferential scan direction for axial flaws is depicted in Figure D.37. The circumferential scan direction CRV coverage achievable was $100 \%$. 


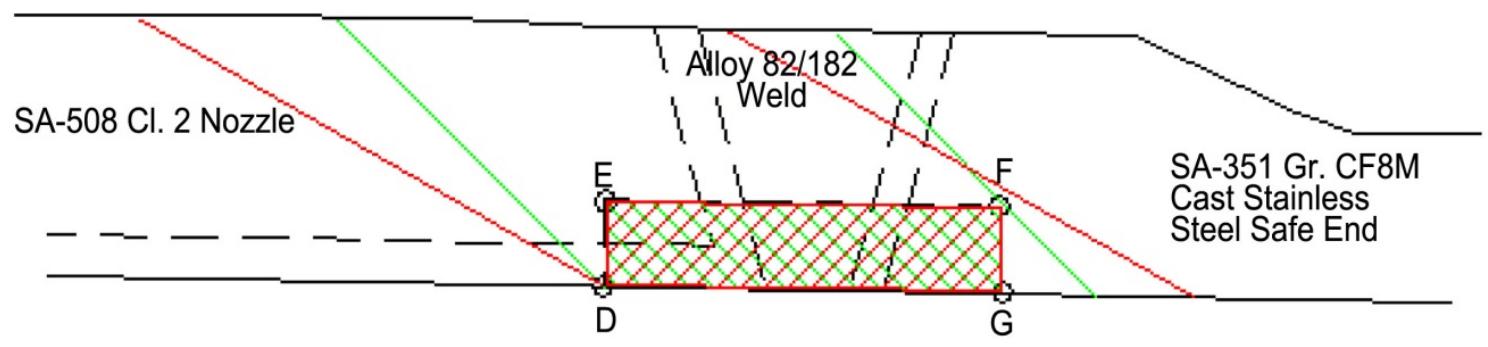

Figure D.36. PZR Safety and Relief Nozzle Weld Axial Scan CRV Coverage Assessment

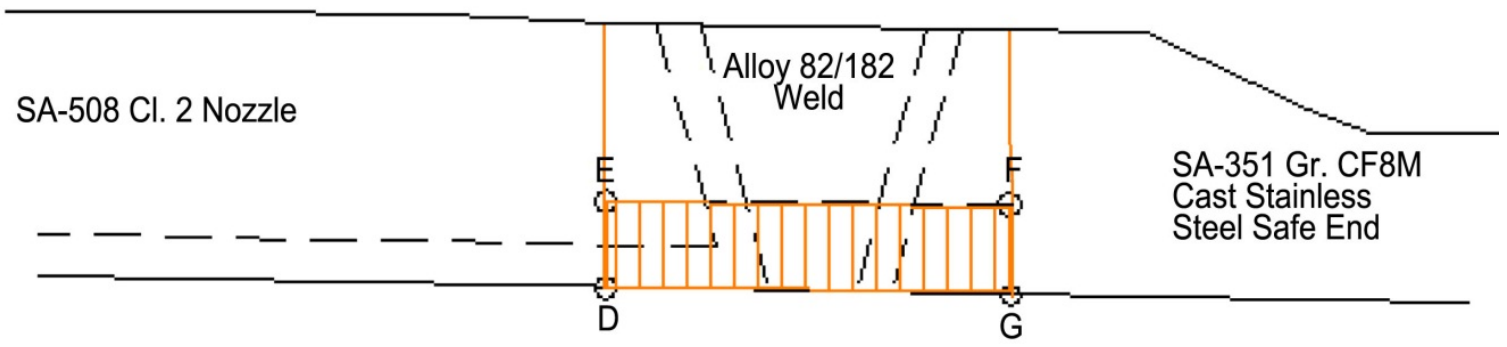

Figure D.37. PZR Safety and Relief Nozzle Weld Circumferential Scan CRV Coverage Assessment 




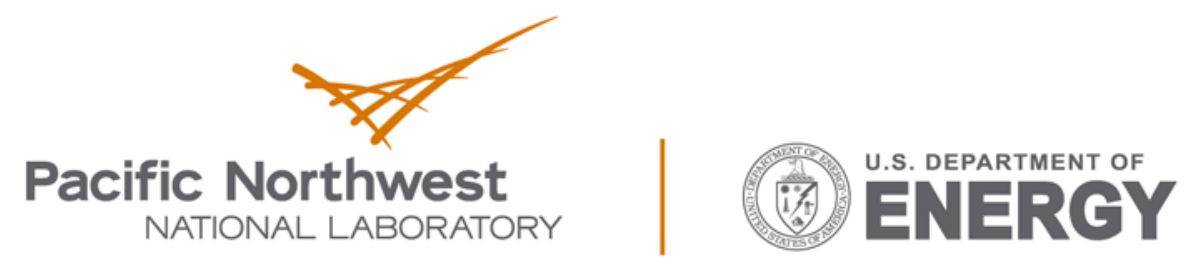

Proudly Operated by Battelle Since 1965

902 Battelle Boulevard

P.O. Box 999

Richland, WA 99352

1-888-375-PNNL (7665)

www.pnnl.gov 